Review Article

\title{
1,4-Dihydropyridine Derivatives: Dihydronicotinamide Analogues-Model Compounds Targeting Oxidative Stress
}

\author{
Astrida Velena, ${ }^{1}$ Neven Zarkovic, ${ }^{2}$ Koraljka Gall Troselj, ${ }^{2}$ Egils Bisenieks, ${ }^{1}$ Aivars Krauze, \\ Janis Poikans, ${ }^{1}$ and Gunars Duburs ${ }^{1}$ \\ ${ }^{1}$ Laboratory of Membrane Active Compounds and Beta-Diketones, Latvian Institute of Organic Synthesis, Riga LV-1006, Latvia \\ ${ }^{2}$ Ruđer Bošković Institute, Bijenička cesta 54, 10000 Zagreb, Croatia \\ Correspondence should be addressed to Astrida Velena; astrida@osi.lv and Neven Zarkovic; zarkovic@irb.hr
}

Received 14 August 2015; Accepted 7 October 2015

Academic Editor: Luciano Saso

Copyright (C) 2016 Astrida Velena et al. This is an open access article distributed under the Creative Commons Attribution License, which permits unrestricted use, distribution, and reproduction in any medium, provided the original work is properly cited.

\begin{abstract}
Many 1,4-dihydropyridines (DHPs) possess redox properties. In this review DHPs are surveyed as protectors against oxidative stress (OS) and related disorders, considering the DHPs as specific group of potential antioxidants with bioprotective capacities. They have several peculiarities related to antioxidant activity (AOA). Several commercially available calcium antagonist, 1,4-DHP drugs, their metabolites, and calcium agonists were shown to express AOA. Synthesis, hydrogen donor properties, AOA, and methods and approaches used to reveal biological activities of various groups of 1,4-DHPs are presented. Examples of DHPs antioxidant activities and protective effects of DHPs against OS induced damage in low density lipoproteins (LDL), mitochondria, microsomes, isolated cells, and cell cultures are highlighted. Comparison of the AOA of different DHPs and other antioxidants is also given. According to the data presented, the DHPs might be considered as bellwether among synthetic compounds targeting OS and potential pharmacological model compounds targeting oxidative stress important for medicinal chemistry.
\end{abstract}

\section{Introduction}

1,4-Dihydropyridines (DHPs) [1], including $\mathrm{Ca}^{2+}$ antagonist (CA) drugs [2], are large group of structurally diverse compounds. Functionally, they are similar to dihydronicotinamide redox-active synthetic compounds with radical scavenging and antioxidant $(\mathrm{AO})$ properties and may be considered as protectors against oxidative stress (OS) and associated disorders [3]

Oxidative stress is extremely important for molecular pathogenesis, especially influencing the redox regulation of cellular signaling pathways [4-7]. Oxidative stress closely relates to presence of oxygen and nitrogen free radicals, known as reactive oxygen species and reactive nitrogen species (ROS and RNS, resp.). They cumulatively increase upon cellular exposure to various endogenous and/or exogenous insults. ROS and RNS have the "two-faced" character and play a dual role as both deleterious and beneficial species $[8,9]$. Although explored in many diseases, various phenomena related to OS have been probably best studied in cancer cells in which, depending on various factors, OS may have anticancer-like effects. Its protumorigenic effects are primarily related to induction of oxidative DNA lesions (8-OH-G) and consequential increase of DNA mutations that may, if not repaired, lead to genome instability and an increased rate of cellular proliferation [10]. On the other hand, antitumorigenic actions of OS have been closely linked to cellular processes of senescence and apoptosis, two major molecular mechanisms that counteract tumor development. Which of these two actions will dominate depends on many factors including the metabolic status of the cell, as recently reviewed by Kujundžić et al., 2014 [11].

Antioxidants (AOs) are defined as substances that, even when present in low concentrations compared to those of an oxidizable substrate, prevent or significantly delay the oxidation process (Halliwell and Gutteridge, 1995 [12]). Their activity depends on complex factors including the nature of the antioxidants, the condition of oxidation, the properties of substrate oxidized, and the level of oxidation (reviewed in Kancheva and Kasaikina, 2013 [13]). Accordingly, an 
antioxidative effect may be direct, resulting from direct ROS scavenging, or indirect from the influence on various signaling pathways related to cellular defense, that is, stress responses. In relation to human physiology, antioxidants are traditionally classified as exogenous (supplied mostly through food) and endogenous and are further subclassified as enzymatic (i.e., superoxide dismutase (SOD) and catalase (CAT)) and nonenzymatic (i.e., glutathione, vitamins $\mathrm{A}, \mathrm{C}$, and $\mathrm{E}$, etc.) [3].

DHPs could be classified as the separate group of synthetic nonenzymatic, however, biomimetic AOs.

\section{Oxidative Stress and Its Prevention: Wavy Scientific Process Development-Pro et Contra}

There are opposite views both towards the role of oxidative stress and about potential applications of exogenous antioxidants in onset of OS [14-16].

Herewith, we need to mention that antioxidants have been studied for decades (starting from 1970s) as the tools for the treatment of various disorders. The role of native and synthetic antioxidants (acting on lipid peroxidation (LP) in biological membranes) in radiation damage and malignant growth was seriously evaluated [17]. The overall conclusions point out antioxidants role in decreasing the damage of cells by reducing oxidants before the occurrence of cellular damage [14]. It was elicited and accented (Burlakova et al. [15]) that

(i) antioxidants, nontoxic inhibitors of free radical processes, exhibit a wide gamut (pleiotropy) of biological activity (as further will be reported, this phenomenon is also characteristic for the DHP antioxidants group);

(ii) the biological effectiveness of AOs correlates with their antioxidant activity (AOA);

(iii) depending on dose, AOs may either increase or decrease the AOA;

(iv) the efficacy of $\mathrm{AO}$ depends on the time of introduction in the course of medical treatment because the development of the disease may be accompanied by stages of changing the AOA.

In relation to dose-effect dependence, Burlakova et al. [15] have found the nonlinear pattern: after addition of an AO, there is an initial increase of AOA, followed by returning to normal and finally decreasing drastically below the normal value. Therefore, antioxidants may produce a specific effect by decreasing (at low doses) or increasing (at high doses) the rate of free radical reactions. Hence, the compound may be efficient $\mathrm{AO}$ only if it is introduced in a low dose at the stage of reduced AOA or in a high dose at the stage of AOA elevation. The widespread opinion of opponents was that the antioxidant function, even that of tocopherol, was a side effect of its activity and important only for in vitro processes and without any role in bioobjects life. This opinion was supported by the fact that the deficiency of natural AO tocopherol (E-avitaminosis) cannot be cured completely by applying synthetic AO. Eventually, it was not certain also that detected lipid peroxides have been generated in vivo in the intact organs and were not artificially formed during the isolation [15]. All these objections and skepticism were rejected in due time.

However, some other research directions were suggested.

Fang et al. [18] reported two different therapeutic strategies for modulating OS in cancer and inflammation, including (1) antioxidant therapy and (2) "oxidation therapy."

For (1), polymeric superoxide dismutase (e.g., pyran copolymer-SOD), xanthine oxidase (XO) inhibitor, developed water-soluble form of 4-amino-6-hydroxypyrazolo[3,4d]pyrimidine (AHPP), heme oxygenase-1 (HO-1) inducers (e.g., hemin and its polymeric form), and other antioxidants or radical scavengers (e.g., phenolic compound canolol, 4vinyl-2,6-dimethoxyphenol) were used.

About (2), besides neurodegenerative diseases, cancer may represent yet another very interesting field for exploring antioxidants and prooxidants as therapeutic substances due to their cytotoxic effects (including overproduction of ROS) that, if achieving proper selectivity, may be used for cancer cells destruction (Fang et al. [18]). To achieve this goal, a unique therapeutic strategy was developed, named as "oxidation therapy," by delivering cytotoxic ROS directly to the solid tumor or alternatively inhibiting the antioxidative enzyme system, such as HO-1 in tumor. This anticancer strategy was examined by use of $\mathrm{O}_{2}{ }^{--}$or $\mathrm{H}_{2} \mathrm{O}_{2}$-generating enzymes (i.e., $\mathrm{XO}$ and d-amino acid oxidase [DAO], resp.) and by discovering the inhibitor of HO-1 (i.e., zinc protoporphyrin $[\mathrm{ZnPP}]$ and its polymeric derivatives).

While deleterious when present at high concentrations, low concentrations of ROS exhibit beneficial properties needed for controlling physiological cellular processes (reviewed in Valko et al., 2007 [19]).

Jimenez-Del-Rio and Velez-Pardo [20] have discussed oxidative stress as an important etiopathogenic factor for occurrence and development of neurodegenerative diseases (notably Alzheimer's disease and Parkinson's disease) and cancer. As an extension, possible preventive and therapeutic values of antioxidants were also discussed. Indeed, if considered within a narrow context of oxidative homeostasis, antioxidants may seem to be ideal weapon in preventing and fighting these diseases. However, the context of human pathology is very broad and, so far, there was little benefit of exogenous antioxidants in human intervention studies or clinical trials. There are numerous reasons for these failures. Maybe, the most important one is the design of the preclinical studies, especially related to concentration of the antioxidant used and time parameters relevant to the clinical setting (Kamat et al., 2008 [21]). The imbalance between uncritical acceptance of antioxidants as powerful "drugs" for various pathological conditions and disappointing results obtained in clinical studies has made a sort of confusion. This issue was addressed by Bast and Haenen [16] through listing ten misconceptions related to commercialized applications of antioxidants: (a) "pros": (1) antioxidants can cure any disease; (2) the more the better; (3) any AO will do (the trick); (4) AO status measures the level of health; (5) natural AOs are superior (over synthesized ones) and (b) "contras": (1) AOs 
increase mortality; (2) when present at high doses, antioxidants become prooxidant; (3) theoretically, antioxidants cannot behave as such; (4) once used, antioxidants are inactive; (5) antioxidant drugs do not work.

The first three "pros" clearly cross the line of realistic way of thinking and cannot be considered seriously. The "pro" \#4 was very informatively discussed by Pompella et al. [22] who comprehensively presented current problems with the methods (ORAC, oxygen radical absorbance capacity; ferricreducing ability of plasma; and TEAC, Trolox equivalent antioxidant capacity) routinely used for measurement of total antioxidant capacity (TAC) in plasma (Pompella et al., 2014 [22]). These include lack of needed specificity, especially relevant for ORAC related measurements. Instead, precise measurement of specific compounds is recommended. Regarding the "pro" \#5, the situation does not seem entirely clear, as some published metastudies related to protective role of vitamin $\mathrm{C}$ in coronary heart disease showed some contradictions (better protection with dietary vitamin $\mathrm{C}$ versus synthetic vitamin C) (Ye and Song [23]; Knekt et al. [24]). In any event, this kind of research is anything but simple, as observed health effects of fruit and vegetable ingestion are certainly related not only to the content of vitamin $\mathrm{C}$ but also to other macro- and micronutrients and phytochemicals, proven to confer additional health benefits (Carr and Vissers [25]). Similar to "pros," stated "contras" seem to be a common misconcept related to the design of the study (this is especially relevant for epidemiological studies), relevance of a specific pathological condition and measurement of its outcomes, and, finally, complexity of a living organism. For all these reasons, there is the realistic need for well-designed epidemiological, clinical, and molecular studies that would offer firm evidence and undoubtful conclusions on the role of antioxidants on human health (see also Sections 3.8 and 3.9).

There are still unanswered questions related to oxidative stress and its mediators in pathogenesis of OS-associated diseases. However, it is clear that overproduction of ROS has harmful cellular effects. For that reason, small synthetic antioxidants, molecular scavengers, have been developed to be used in various pathological conditions. The first one, implemented in the clinic for acute brain infarction, was 3-methyl-1-phenyl-2-pyrazolin-5-one (MCI-186, Edaravone, Radicut, norphenazone), approved until now only in Japan (Tabrizchi, 2000 [26]). So far, its free radical scavenging properties were revealed by various biological effects (antioxidant, attenuation of cytokine production, antiapoptotic, antinecrotic, and some other effects), as recently reviewed (Kikuchi et al. [27]).

\section{1,4-Dihydropyridines: A Separate Group of Bioantioxidants}

1,4-Dihydropyridines could be used as model compounds for studying molecular mechanisms of action modulated by cellular enzymes $\mathrm{NADH}$ and $\mathrm{NAD}(\mathrm{P}) \mathrm{H}$ due to their structural analogy to 1,4-dihydronicotinamide [28]. This structure represents the active part of these reduced coenzymes, which are important modulators of various enzymatic redox reactions and are involved in electron transfer.
Chemically, 1,4-dihydropyridines are synthetic hydrogenated N-heteroaromatic compounds. They may have various substituents at positions 2,6-, 3,5-, and 1,4- (Figures $1-3)$. Their derivatives can be obtained synthetically in the Hantzsch type cyclic condensation reactions.

Bossert and Vater [29] postulated DHPs as a basis for development of new cardiovascular drugs. Today there are many marketed drugs which contain 1,4-DHP ring as basic scaffold [30-32] (Figures 1 and 2).

Grover et al. [33] classified dihydropyridine nucleus (skeleton) as a novel pharmacophore and offered some examples related to DHPs pleiotropy. So far, AOAs have been revealed for several groups of DHP compounds and DHP-based drugs [34-36], contributing to their well-known pleiotropic ways of action (antiaging, neuroprotective, anticancer, antibacterial, [37] and many more). These features are promising for development of novel drugs in the future [32,38].

It is well known that hydrogen donors such as amines, thiols (aminothiols), or phenols (plant phenols and polyphenols as well as synthetic hindered phenols) act as antioxidants, primarily through inhibition of oxidation reactions of various chemical targets/substrates. Similarly, depending on their particular chemical structure, 1,4-dihydropyridines have significant hydrogen donor ability (see further in Section 3.2). This feature allows them to act as direct inhibitors of free radical reactions. It further classifies them as specific group of dihydropyridine type of antioxidants. However, under certain conditions, primarily dependent on individual structure and applied dose, DHPs can act as prooxidants (see further in Section 3.8).

On the other hand, some DHPs may exert synergistic effects when applied together with other types of AOs [39]. They can also be involved in the redox regulation of $\mathrm{Ca}^{2+}$ ion channels [40]. Namely, oxidative stress, characterized by significant increase of ROS, closely relates to cellular imbalance of $\mathrm{Ca}^{2+}$ ions. Such a CA activity of DHPs can also result in the indirect OS modulation as an additional positive side effect. Accordingly, DHPs, acting as CA and as antioxidants, may modify various OS-associated pathological processes by influencing cellular redox signaling potential. Additionally, multiple biological effects of DHPs attenuating OS could be important at drug-drug interactions by combination therapy using DHPs and other CA and/or antioxidants.

It should be mentioned that the studies on the possible AOA of 1,4-DHPs have begun due to the assumption that these substances could be useful for the design for novel antioxidants intended to be used primarily in the food technology, notably as animal chow stabilizers [41-43]. The AOAs of 1,4-dihydropyridine derivatives, 2,6-dimethyl-3,5-diethoxycarbonyl-1,4-dihydropyridine (Hantzsch ester (HEH), diludine) and its close analogues, 4-unsubstituted 1,4-DHPs, were discovered by Latvian scientists that intended to use them for the termination of the lipid peroxidation (LPO) in various chemical lipid substrates/mixtures target (solutions, emulsions, and liposomes) [44, 45]. Afterwards, antioxidant properties of several calcium antagonists DHPs were discovered [31, 46-53]. Interestingly, research on the AOA of DHPs on LPO continues nowadays, including several 
<smiles>CCOC(=O)C1=C(C)NC(C)=C(C(=O)OCC)C1</smiles>

Diludine

(Hantzsch ester, diethone, HEH)<smiles>CC(=O)C1=C(C)NC(C)=C([N+](=O)[O-])C1c1ccccc1C(F)(F)F</smiles>

Bay K 8644<smiles>CC(=O)C1=C(C)NC(C)=C(C(C)=O)C1c1ccccc1[N+](=O)[O-]</smiles>

Nifedipine<smiles>CC(=O)C1=C(C)NC(C)=C(C(=O)OCC(C)C)C1c1ccccc1[N+](=O)[O-]</smiles>

Nisoldipine<smiles>CCOC(=O)C1=C(C)NC(C)=C(C(=O)OCC)C1c1cccc(Cl)c1Cl</smiles>

Felodipine<smiles>CCOC(=O)C1=C(C)NC(COCCN)=C(C(=O)OCC)C1c1ccccc1Cl</smiles>

Amlodipine<smiles>COCCOC(=O)C1=C(C)NC(C)=C(C(=O)OCC=Cc2ccccc2)C1c1cccc([N+](=O)[O-])c1</smiles>

Cilnidipine<smiles>CCOC(=O)C1=C(C)NC(C)=C(C(=O)OCCOC)C1c1cccc([N+](=O)[O-])c1</smiles>

Nimodipine

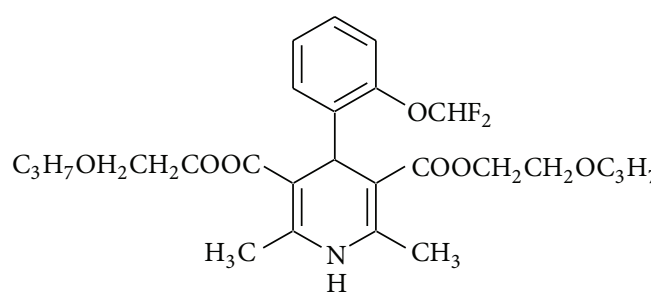

Cerebrocrast<smiles>CC(=O)OC(=O)C1=C(C)NC(C)=C(C(C)=O)C1c1ccccc1OC(F)F</smiles>

Foridone (ryodipine)<smiles>CCOC(=O)C1=C(C)NC(C)=C(C(=O)OCC)C1c1cccc([N+](=O)[O-])c1</smiles>

Nitrendipine<smiles>COc1ccc(CCCN(C)CCCN=C(C(C)C)C(C)C)cc1OC</smiles>

Verapamil

FIGURE 1: Structures of the most known 1,4-dihydropyridine derivatives and some non-DHP Ca ${ }^{2+}$ antagonists.

interdisciplinary projects funded by $\mathrm{EU}$, in particular the COST B35 action [51, 52].

3.1. Synthesis of 1,4-Dihydropyridines: Routes and Approaches. Classical 3-component Hantzsch synthesis of DHP compounds [54-57] is usually performed in solutions (including ionic liquids) by heating. Discoveries related to this process and published between 1986 and 1990 are summarized in the review of Sausins and Duburs [57]. In 1993, Kazda [58] has reviewed "twenty years of dihydropyridines," including their synthesis, chemistry, progress in pharmacology, and therapy, and some other applications. Since then, there were many important discoveries in this field and there is a time for a review on "another twenty years of DHPs." It has to be 
<smiles>CC(=O)OC(=O)C1=C(C)NC(C)=C(C(C)=O)C1c1cccc([N+](=O)[O-])c1</smiles>

Lercanidipine<smiles>CC(=O)C1=C(C)NC(C)=C(C(=O)OC(C)C)C1c1cccc2nonc12</smiles>

Isradipine<smiles>CC(=O)C1=C(C)NC(C)=C(C(=O)OCCNCCc2ccccc2)C1c1cccc([N+](=O)[O-])c1</smiles>

Nicardipine<smiles>CCOC(=O)/C=C/c1ccccc1C1C(C(=O)OCC)=C(C)NC(C)=C1C(=O)OCC</smiles>

Lacidipine<smiles>CCC(=O)C1=C(C)NC(N)=C(C(=O)OC2CN(C(c3ccccc3)c3ccccc3)C2)C1c1cccc([N+](=O)[O-])c1</smiles>

Azelnidipine
Felodipine<smiles>CCOC(=O)C1=C(C)NC(C)=C(C(=O)OCC)C1c1cccc(Cl)c1Cl</smiles>

$\mathrm{NO}_{2}$

Bay O 5572<smiles>CC(=O)C1=C(C)NC(C)=C(C(=O)OC2CCCN(Cc3ccccc3)C2)C1c1cccc([N+](=O)[O-])c1</smiles>

Benidipine<smiles>CC(=O)OC(=O)C1=C(C)NC(CN2CC[C@H](OC(=O)C3=C(C)NC(C)=C(C(=O)OCCN4CCN(C(C(=O)OCc5ccccc5)c5cccc([N+](=O)[O-])c5)CC4)C(c4cccc([N+](=O)[O-])c4)C3=C(C)OC(C)=O)C2)=C(C(=O)OC(C)=O)C1C(=O)OCc1ccccc1</smiles>

Manidipine

Barnidipine

Mebudipine<smiles>COc1ccc(C2Sc3ccccc3N(CCN(C)C)C2=O)cc1</smiles>

Diltiazem<smiles>CCCOc1ccc2c(c1)OCO2</smiles>

Semotiadil<smiles>CC(=O)C1=C(C)NC(C#N)=C(C(=O)OC(C)C)C1c1cccc([N+](=O)[O-])c1</smiles>

Nivaldipine

FIGURE 2: Structures of the most known 1,4-dihydropyridine derivatives and some non-DHP Ca ${ }^{2+}$ antagonists.

mentioned that nearby this classical multicomponent synthesis also a process to obtain structurally diversified 1,4-dihydropyridines at sophisticated conditions was recently reviewed by Wan and Liu [59].

Many discoveries relevant for novel routes in DHP designing and synthesis were published and deposited in various databases (see http://www.organic-chemistry.org/ namedreactions/hantzsch-dihydropyridine-synthesis.shtm [60]). For example, http://www.scifinder.com/ [1] database lists approximately 1000 citations on the simple DHP compound, diludine. Reaxys database [61] contains data related to variations in starting materials, intermediates as building 
<smiles>CC(=O)C1=C(C)NC(C)=C(C#N)C1c1ccc(Cl)cc1</smiles>

OSI-1146<smiles>CC(=O)C1=C(C)NC(C)=C(C#N)C1c1ccccc1Cl</smiles>

OSI-3761<smiles>CC(=O)C1=C(C)NC(C)=C(C#N)C1c1ccccc1OC(F)F</smiles>

OSI-9642<smiles>CC1=C(C#N)C(c2ccccc2OC(F)F)C(C(N)=O)=C(C)N1</smiles>

OSI-3701

FIGURE 3: Molecular structures of OSI-1146, OSI-3701, OSI-3761, and OSI-9642 (according to [146]).

blocks, media, and reactions routes. Water and ionic liquids as reaction media, microwave and infrared irradiation, new catalysts, solid phase synthesis, and biotechnology based and green chemistry approaches were also proposed as attractive options for syntheses of DHPs [62-66].

Furthermore, several new dihydropyrimidin- $(2 \mathrm{H})$-ones (DHPMs), close analogues of DHPs, were prepared in the Biginelli reaction under ultrasound irradiation and in the presence of $\mathrm{NH}_{4} \mathrm{Cl}$. Some of these compounds, when tested in vitro at concentrations higher than $100 \mu \mathrm{M}$ [67], showed AOAs, manifested as inhibition of LPO induced by complex $\mathrm{Fe}+$ EDTA and reduction of ROS levels.

Recently, Sun et al. [68] reported about the synthesis and antioxidant activity of a series of novel 3-chalcone-substituted 1,4-dihydropyridine derivatives, based on dimethyl or diethyl 2,6-dimethyl-4-phenyl-1,4-DHP-3,5-dicarboxylate.

3.2. 1,4-Dihydropyridines as Hydrogen Donors. Steric, electrostatic, and hydrophobic descriptors in DHP molecule could serve as its potential pharmacophores [2]. In case of Hantzsch ester this implies partly hydrogenated $\mathrm{N}$ heteroaromatic DHP nucleus itself or its fragments, that is, $\mathrm{NH}$ group or $\mathrm{C}-4 \mathrm{H}$ - atom, as hydrogen donors necessary for the $\mathrm{AO}$ activity and/or carboxylic ester side groups (its $\mathrm{C}=\mathrm{O}$ group and $\mathrm{O}$ atom as hydrogen bond acceptors) in positions 3- and 5- and alkyl side groups in positions 2and 6- (as hydrophobic features) (Grover et al. [33] and Tikhonov and Zhorov [69]). The presence of labile hydrogen atoms (mainly in positions 1,4-) in DHPs molecule assigns significant hydrogen donating ability to these compounds.

DHPs (2,6-dimethyl-1,4-dihydropyridine-3,5-dicarboxylic acid esters) can be oxidized in chemical (Dubur and Uldrikis [70]), electrochemical, enzymatic (Duburs et al. [71]), and biological (including metabolism and biotransformation) systems. As already stated, dihydropyridines (especially unsubstituted in position 4) may transfer the hydrogen, similar to the reduced diphosphopyridine nucleotides, NADH and NADPH (Scheme 1) (Mauzerall and Westheimer [28]), while HEH hydrogen transfer studies and search for novel NADH model compounds are continuously developing (Xie et al. [72]).

Tamagaki et al. [73] observed metal-ion-facilitated oxidations of DHPs with molecular oxygen and hydrogen peroxide. On the other side, Tirzite et al. [74] studied some 1,4DHP derivatives as reductants in relation to trivalent iron.
Hantzsch esters have been extensively utilized as stoichiometric biomimetic reducing agents. Recent summarized literature about DHPs as reducing agents, including references on diludine, may be found on specialized websites: http:// www.organic-chemistry.org/chemicals/reductions/ [75].

DHPs form free radicals in chemical, electrochemical, and biological oxidation processes. The kinetic parameters and pathways of decay of the cationic radicals formed as primary products in the course of electrooxidation of the esters of 1,2- and 1,4-dihydropyridine have been extensively studied [76].

The regenerative system of nicotinamide cofactors may involve oxidizing or reducing reagents, regulating enzymes, and photochemical reactions. Thus, in situ regeneration of the consumed cofactors was observed in the biosystems engineering, which create superior biocatalysts by the reduction of $\operatorname{NAD}(\mathrm{P})^{+}$, which can lead to the 1,4-DHP product (which is the only active form) and to the 1,6DHP compound [77]. The NADPH models of HEHs can be regenerated in situ as biomimetic hydrogen sources by means of transition metal/Brønsted acid catalyzed relay asymmetric hydrogenation [78]. General regeneration strategies were reviewed by Chenault and Whitesides [79]. Based on these strategies, particularly related to methods of preparation and practical use of esters of 2,6-dimethyl-1,4-dihydropyridine3,5-dicarboxylic acid as antioxidants that might be probably applicable for radioprotection and adjuvant treatment against metastases, several patents were prepared [80].

Sambongi et al. [81] have found that the novel watersoluble Hantzsch 1,4-dihydropyridine compound (the potassium salt of 2,6-dimethyl-1,4-dihydropyridine-3,5-dicarboxylic acid monomethyl ester) functions in biological processes through regeneration of NADH. Various parameters related to nicotinamide coenzymes regeneration, especially in a light of chiral compounds, have been published recently [82], while Okamura et al. [83] reported the use of the oxidative conversion of dihydropyridine to pyridinium ion and the metabolic trapping principle as an approach for measuring in vivo cerebral redox states.

3.3. Antioxidant Activity (AOA) and Antiradical Activity (ARA) of 1,4-Dihydropyridines. Antioxidative activity of 1,4DHPs was first evaluated and studied in the Latvian IOS (Tirzit and Duburs [39], Zilber et al. [44], and Dubur et al. [45]). 


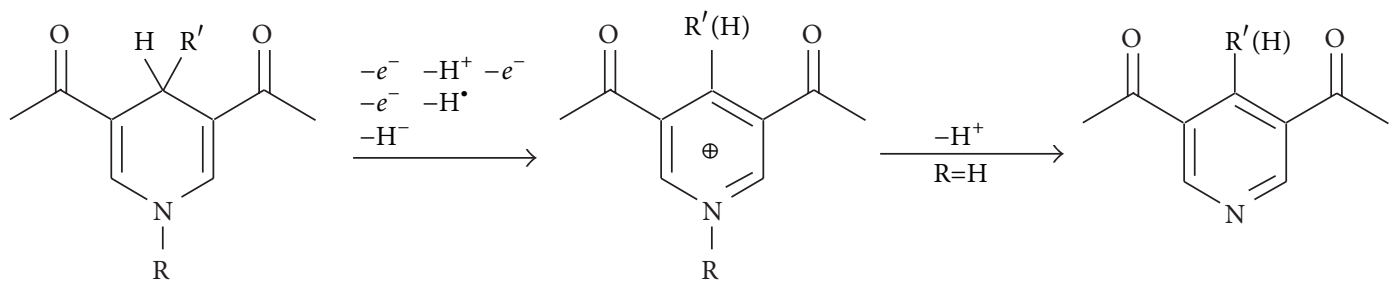

SCHEME 1: Reactions of 1,4-dihydropyridines leading to the formation of pyridine derivatives.

In the field of ARA, pioneering work was made by Schellenberg and Westheimer [84] in 1965. In 1979, Schellenberg [85] revealed the free radical oxidation of a dihydropyridine following Huyser et al. [86] who reported hydroxyl radical quenching by DHPs, especially Hantzsch ester, studying free radical oxidation of DHPs in vitro, in the Fenton system.

AOA and ARA of various 1,4-DHPs were further studied by several different methods in both in vitro and ex vivo/in vivo systems [3, 31, 44-53]. CA nisoldipine, nimodipine, nitrendipine, nifedipine, and nicardipine have AOA that correlates with their lipophilicity (modified Buege and Aust's method of TBA determination, applied in model of rat brain cortex ischemia/reperfusion) [87].

$\mathrm{N}$-Aryl-DHPs, designed as sirtuin activators, were further reported as suitable agents for neuroprotection due to their radical avoidance properties (Hardeland [88]).

1,4-DHPs inhibit free radicals and, consequentially, the cascade of events related to lipid peroxidation. They may influence several stages (initiation and/or propagation) of the lipid peroxidation cascade, which consist of $\sim 10$ reactions [89] (detailed discussion in Section 3.3.1 (2)-(b), Scheme 2).

However, considering the great number of $\mathrm{AO}$ compounds (including DHPs) and the diversity in their action mechanisms [90], in vivo studies are not always convincing and conclusive. Therefore, concise in vitro models are necessary to screen each compound with antioxidative properties. Antioxidants are designed to react readily with oxidizing species and are often extensively oxidized already during incubations at atmospheric oxygen tension (oxidation of some water-soluble DHPs in water (buffer) solutions is very fast, especially in the presence of light). Even during a relatively short incubation period, the concentration can drop drastically, and the real potency of the compound could be underestimated [90].

\subsubsection{Common AOA and ARA Features of Some DHPs}

(1) In Vitro (in Solutions, Emulsions, and Liposomes). Basic molecular principles related to antioxidative and antiradical activity of various antioxidants, including DHPs, were published recently [91]. These data show that DHPs react with various types of free radical species, stable free radicals (DPPH a.o.) and alkyl radicals and with oxygen and nitrogen free radicals. Some derivatives of DHPs may quench a singlet oxygen and may react with peroxynitrite anion [92-95].

Reactivity of DHPs toward alkyl radicals was studied electrochemically [96].
The activity against DPPH radical was found for the 5-acetyl-2-alkylthio-4-aryl-6-methyl-1,4-dihydropyridine-3carboxylic acid nitriles [97], structural analogues of the 5-acetyl(carbamoyl)-6-methylsulfanyl-1,4-DHP-carbonitrile (studied as mitochondriotropic compounds; see further in the text, Section 3.3.1 (2)-(b)). The highest antiradical activity occurred for a compound which contains two hydroxyl groups in the 4-phenyl substituent.

DHPs were proved to decrease oxygen uptake (2-3fold) in the heme (methemoglobin, hematin, hemin, and cytochrome C) catalysis by oxidation of emulsions of esters of unsaturated fatty acids and liposomes of phospholipid phosphatidylcholine (Zilber et al. [44] and Dubur et al. [45]).

Reactivity of nitrosoaryl and nitroaryl derivatives of 1,4DHPs toward alkyl, alkylperoxyl radicals, and ABTS radical cation was found in various LP modeling systems suitable for determination of DHPs AOA and ARE features [98104]. Diludine and foridone and its analogues were shown to inhibit lipid peroxidation through inhibitory effect on lipoxygenase, in emulsions and in reversed micelles (Tsetlin et al. [105] and Panek et al. [106]). In addition to inhibition of thermally initiated oxidation of methyloleate in the solution [107] (where AOA of 4-unsubstituted 3,5-dicarbonylderivatives of 2,6-dimethyl-1,4-DHPs is not linearly dependent on the inhibitor concentration), DHPs derivatives containing hydroxy, alkoxy, or dimethylaminophenyl substituents in position 4 were shown to prevent loss of $\beta$-carotene in the disperse system of $\beta$-carotene and methyllinoleate (Plotniece et al. [108]).

The AOA of DHPs has been detected using different methods in various systems where lipid free radical generation (nonenzymatic, $\mathrm{Fe}^{2+}$-dependent, and/or enzymatic, NADPH-dependent) took the place [109-112]. This activity was further confirmed in vivo, through prevention of damage caused by renal ischemia and reperfusion, as shown for diludine [113].

Some redox properties of calcium antagonist dihydropyridines were revealed through electroanalytical studies [114]. Competitive kinetic procedure was used for exploring the AO capacity of five (four 1,4-DHPs: lacidipine, felodipine, nifedipine, and amlodipine, and one 1,2-DHP compound GR44966) CA and one calcium ion agonist (Bay K 8644). All but one (amlodipine) antagonist displayed an unambiguous AO capacity (crocin test). The calcium agonist DHP revealed no reaction with peroxyl radicals. Lacidipine was the most effective. A calcium agonist Bay K 8644 is quite resistant to oxidation and does not bind $\mathrm{H}^{+}$. This could be important 
fact in the interaction with the target proteins (it should be mentioned that there are no studies on LP with other $\mathrm{Ca}^{2+}$ agonists).

The decreased oxidation potential correlates with $\mathrm{AO}$ capacity and increased basic character. These findings suggest the relevance of the electron density on the DHP ring.

For all the DHP compounds investigated, the overall oxidation process proceeds through two consecutive oneelectron releases: a primary one-electron step accompanied by a fast proton release and the formation of a neutral radical $\left(\mathrm{PyH}^{\circ}\right)$ undergoing a second, much easier one-electron step [114].

The final product is the protonated form of the parent pyridine derivative. This pattern is relevant for the antioxidative activity, since the radical intermediate is far less prone to be reduced than oxidized.

In the case of CA DHPs, the release of protons complicates the overall oxidation process by introducing a "parasitic" side reaction where a coupling between protons and the starting species takes place.

This DHP self-protonation subtracts part of the original species from the electrode process because the parent cationic species are no longer electroactive.

Conversely, the calcium agonist DHP, which is less prone to be oxidized, turned out to be so weak base to be even unable to undergo the self-protonation reaction.

Thus, the combined effect of oxidation potentials and proton binding capacity of DHPs is a key element for the redox transition, relevant for their AO activity. Yet, opposing effects (antagonistic versus agonistic) on protein targets as calcium ion channels connected with protein thiol oxidation to disulfide should be also considered [114].

Kouřimská et al. [115] found AO effect of diludine (HEH) in edible oil. Reactivity of 1,4-DHPs toward SIN-1-derived peroxynitrite was shown by López-Alarcón et al. [116]. Olek et al. [117] discovered antioxidative activity of NADH and its analogue in vitro.

Further see, as referred in several subparts below, Sections 3.4, 3.5, and 3.7.

(2) Ex Vivo (on Lipid Peroxidation in LDL, Mitochondria, Microsomes, and Cells). Main chemical structures of DHPs examined in numerous studies and reviewed in this paper are presented in Figures 1 and 2.

(a) Various DHPs: Calcium Antagonists as Inhibitors of LDL Peroxidation. Free radicals induce peroxidation of LDL. This process proceeds by a chain mechanism which reveals phosphatidylcholine hydroperoxides and cholesteryl ester hydroperoxides as the major primary products [118]. Calcium antagonist DHPs could act as antioxidants on LDL at least in three ways: (1) as inhibitors of isolated LDL peroxidation, caused by various inducers $\left(\mathrm{Cu}^{2+}\right.$ ions, UV light, and xanthine/xanthine oxidase system); (2) if preincubated with cells, preventing against intracellular LDL oxidation; (3) preventing against the harmful effect of oxidized LDL on cells and decreasing cytotoxicity [119-131].

Combined application of ascorbic acid and CA DHPs (amlodipine and felodipine) has an additive (cytoprotective and LDL antioxidant activity) effect [120]. It includes a combination of peroxide-degrading and peroxyl radical scavenging reactions, thus demonstrating the importance of LP during LDL oxidation and cytotoxicity induced by oxidized LDL. Cytoprotection is associated with inhibition of oxidantinduced increases in intracellular free calcium.

Similar to the other model systems, the recorded values of the tested DHPs related to AO activity on LDL LP and related events [119-131] depend on the prooxidant model system and methods used for activity measuring (see Tables 1-5).

Commercial $\mathrm{Ca}^{2+}$ antagonists (including 1,4-DHP derivatives), as well as some other 1,4-DHPs with less CA activity, were shown to decrease the rate of oxidation (detected as TBARS) of low-density lipoprotein (LDL) induced by $\mathrm{Cu}^{2+}$ ions $\left(\mathrm{CuSO}_{4}\right)$ in two different cell lines: U937 human monocyte-like and J774A.1 murine monocyte-macrophage cell line (Rojstaczer and Triggle [119]). The strongest effect was recorded for vitamin $\mathrm{E}$, followed by felodipine, $2-\mathrm{Cl}$ analogue of nifedipine, nifedipine, amlodipine, nitrendipine, verapamil, and diltiazem.

Rojstaczer and Triggle [119] found that CA from different chemical groups had a concentration-dependent effect as antioxidants against LDL oxidation (see Table 1). However, the order of potency (activity rank order, ARO) of the drug(s) again depends on the oxidation system and the antioxidant assay. Both CA and antioxidative effects relate to the 2- (or $o^{-}$, orto-) substituent of the 4-phenyl ring in the same potency order $o>m \gg p$ [119]. On the other hand, the requirement for the 1,4-DHP ring is essential for both $\mathrm{AOA}$ and $\mathrm{Ca}^{2+}$ channel antagonism. A charged substituent at the position $\mathrm{C}$ 2 of the 1,4-DHP ring influences the AO activity (analogous to [46-53]). However, some other factors should not be neglected: for example, although amlodipine has a positively charged amine at this position, this modification makes it less lipophilic and, indirectly, less potent antioxidant.

Similar results were obtained when testing antioxidant effect of CA on LDL peroxidation in bovine aortic endothelial cells (BAECs) (Cominacini et al. [123]; see Tables 2 and 3) as well as in HUVECs (Lupo et al. [129]) (see Table 4).

Cominacini et al. [123] observed antioxidant effect of CCBs and $\alpha$-tocopherol in BAECs. The order of potency (see Tables 2 and 3) [123] was however different than in U937 human monocyte-like and J774A.1 murine monocytemacrophage cells (see Rojstaczer and Triggle [119], Table 1). The tested DHPs were lacidipine, amlodipine, lercanidipine, nimodipine, and nifedipine (in two different intracellular concentrations: 2 and $4 \mathrm{fmol}$ ). ROS production was significantly lowered only by lacidipine (which is the compound with the highest lipophilicity) and lercanidipine; the effect of lacidipine was much more evident than lercanidipine. Surprisingly, amlodipine, nimodipine, and nifedipine had no effect on ROS formation suggesting that the positive effects on the earliest events of atherosclerosis are a peculiarity of lacidipine molecule through its antioxidant activity.

The strong AO action of lacidipine may be related to the lipophilic cinnamic acid side chain, which favors a drug partitioning in the membrane due to favorable physicochemical (hydrophobic) interactions of drug hydrophobic residues 
TABLE 1: Relative structure-function relationships of calcium antagonists (DHPs, verapamil, and diltiazem) and vitamin E. Effect on oxidative modification of isolated ex vivo human low-density lipoprotein using two various oxidation systems (copper (II) ions induced and monocyte induced). Compiled according to data presented by Rojstaczer and Triggle [119].

\begin{tabular}{|c|c|c|c|c|}
\hline \multirow{5}{*}{ Compound } & \multicolumn{4}{|c|}{ Systems of LDL oxidation } \\
\hline & \multicolumn{3}{|c|}{ Copper (II) ions induced system (comparison of three methods) } & \multirow{3}{*}{$\begin{array}{l}\text { Monocyte induced cell } \\
\text { oxidation system } \\
\text { TBARS content of LDL } \\
\text { (in } \% \%)\end{array}$} \\
\hline & & Methods & & \\
\hline & $\begin{array}{l}\text { Reduction of TBARS level of LDL } \\
\text { (relative efficacy) }\end{array}$ & $\begin{array}{c}\text { Degradation of oxidized } \\
{\left[{ }^{125} \mathrm{I}\right] \text { LDL by J774 }} \\
\text { macrophages }\end{array}$ & $\begin{array}{l}\text { Relative electrophoretic } \\
\text { mobility of LDL on } \\
\text { agarose gel }\end{array}$ & \\
\hline & \multicolumn{4}{|c|}{ Relative efficacy (activity rank order (ARO); $\mathrm{ARO}=\mathrm{I}$ for the most effective); effective inhibitor concentration [IC], in $\mu \mathrm{M}$} \\
\hline Amlodipine & $\begin{array}{c}++ \\
(\mathrm{ARO}=\mathrm{IV})\end{array}$ & $\begin{array}{c}++ \\
(\mathrm{ARO}=\mathrm{II}-\mathrm{V})\end{array}$ & $\begin{array}{l}25 \mu \mathrm{M} \\
50 \mu \mathrm{M}\end{array}$ & $\begin{array}{c}25 \mu \mathrm{M} \\
(\mathrm{ARO}=\mathrm{III}-\mathrm{V})\end{array}$ \\
\hline Felodipine & $\begin{array}{l}+++++ \\
(\mathrm{ARO}=\mathrm{I})\end{array}$ & $\begin{array}{c}+++ \\
(\mathrm{ARO}=\mathrm{I}) \\
25 \mu \mathrm{M}, 97 \pm 2 \%\end{array}$ & $50 \mu \mathrm{M}$ & $\begin{array}{c}25 \mu \mathrm{M}, 65 \pm 9 \% \\
(\mathrm{ARO}=\mathrm{II})\end{array}$ \\
\hline Nifedipine & $\begin{array}{c}+++ \\
(\mathrm{ARO}=\mathrm{III})\end{array}$ & $\begin{array}{c}++ \\
(\mathrm{ARO}=\mathrm{II}-\mathrm{V})\end{array}$ & $10 \mu \mathrm{M} ; 50 \mu \mathrm{M}$ & $\begin{array}{l}25 \mu \mathrm{M}, 96 \pm 2 \% \\
\quad(\mathrm{ARO}=\mathrm{I})\end{array}$ \\
\hline $\begin{array}{l}\text { 2-Chloro } \\
\text { analog of } \\
\text { nifedipine }\end{array}$ & $\begin{array}{c}++++ \\
(\mathrm{ARO}=\mathrm{II})\end{array}$ & - & - & - \\
\hline $\begin{array}{l}\text { 4-Nitro } \\
\text { analog of } \\
\text { nifedipine }\end{array}$ & - & $\begin{array}{c}++ \\
(\mathrm{ARO}=\mathrm{II}-\mathrm{V})\end{array}$ & - & $\begin{array}{c}25 \mu \mathrm{M} \\
(\mathrm{ARO}=\mathrm{III}-\mathrm{V})\end{array}$ \\
\hline Nitrendipine & $\begin{array}{c}++ \\
(\mathrm{ARO}=\mathrm{IV})\end{array}$ & - & No effect & - \\
\hline Verapamil & $\begin{array}{c}++ \\
(\mathrm{ARO}=\mathrm{IV})\end{array}$ & $\begin{array}{c}++ \\
(\mathrm{ARO}=\mathrm{II}-\mathrm{V})\end{array}$ & - & $\begin{array}{c}25 \mu \mathrm{M} \\
(\mathrm{ARO}=\mathrm{III}-\mathrm{V})\end{array}$ \\
\hline Diltiazem & $\stackrel{+}{(\mathrm{ARO}}=\mathrm{V})$ & - & No effect & - \\
\hline $\begin{array}{l}\alpha \text {-Tocopherol } \\
\text { (vitamin E) }\end{array}$ & $\begin{array}{l}++++++ \\
(\mathrm{ARO}=\mathrm{I})\end{array}$ & - & $\begin{array}{c}1 \mu \mathrm{M} ; 5 \mu \mathrm{M} ; 10 \mu \mathrm{M} \\
50 \mu \mathrm{M}\end{array}$ & - \\
\hline
\end{tabular}

TABLE 2: Reduction of intracellular ROS in BAECs by CA DHPs. Compiled according to data reported by Cominacini et al. [123].

\begin{tabular}{lc}
\hline Compound & $\begin{array}{c}\text { Cellular amounts of compounds (in fmol/cell) } \\
\text { determining the } 50 \% \text { reduction }\left(\mathrm{IC}_{50}\right) \text { in } \\
\text { intracellular ROS concentrations }\end{array}$ \\
\hline Lacidipine & $4.6 \pm 0.7$ \\
Lercanidipine & $9.2 \pm 0.7$ \\
Amlodipine & $15.3 \pm 0.8$ \\
Nifedipine & $16.4 \pm 0.7$ \\
Nimodipine & $17.2 \pm 0.9$ \\
\hline
\end{tabular}

with polyunsaturated groups of membrane phospholipids. However, DHPs can also reduce the oxLDL-induced ROS concentration by affecting some intracellular ROS producers, such as NADPH oxidases, xanthine oxidase, and cyclooxygenase enzymes. The activity of these enzymes contributes to intracellular ROS elevation [125].

Preincubation of HUVECs with lacidipine inhibited an increase of intracellular ROS caused by oxidized LDL [124].

Lupo et al. [129] have studied the dose-dependent $(1,5$, 10 , and $50 \mu \mathrm{M}$ ) AOA of various CA (verapamil, diltiazem, and DHPs: nifedipine, amlodipine, isradipine, or lacidipine)
TABLE 3: Modulation of ROS formation in BAECs by CA (DHPs and verapamil) and vitamin E. Compiled according to data presented by Cominacini et al. [123].

\begin{tabular}{lc}
\hline & $\begin{array}{c}\text { Method of flow cytometry (reduced } \\
2^{\prime}, 7^{\prime} \text {-dichlorofluorescein diacetate } \\
\text { (DCFH-DA) oxidation by ROS }) \\
\text { Activity rank order }\end{array}$ \\
& $\begin{array}{c}\text { (ARO }=\text { I for the highest activity; ARO }=\text { III for } \\
\text { the mindest activity) } \\
(\text { Effective }[\mathrm{IC}]: 1 ; 5 ; 10 ; 50 \mu \mathrm{M})\end{array}$ \\
\hline Lacidipine & $+++(\mathrm{ARO}=\mathrm{I})$ \\
Lercanidipine & $++(\mathrm{ARO}=\mathrm{II})$ \\
Amlodipine & No effect \\
Nifedipine & No effect \\
Nimodipine & No effect \\
Verapamil & $+($ ARO $=\mathrm{III})$ \\
$\alpha$-Tocopherol & $++($ ARO $=\mathrm{I})$
\end{tabular}

against normolipidemic human blood LDL oxidation compared with $\alpha$-tocopherol by measuring the content of TBARS and the diene formation (see Table 4). 
TABLE 4: Normolipidemic human blood LDL $(0.25 \mathrm{mg} / \mathrm{mL})$ in vitro oxidation in the presence of $5 \mu \mathrm{M} \mathrm{CuSO}_{4}$ and $\mathrm{CA}_{\text {of }} 3$ types $(\mathrm{DHPs}$, verapamil, and diltiazem) and vitamin E. Compiled according to Lupo et al. [129].

\begin{tabular}{|c|c|c|c|c|}
\hline \multirow{3}{*}{ Compound } & \multicolumn{4}{|c|}{ Methods } \\
\hline & \multicolumn{2}{|c|}{$\begin{array}{l}\text { TBARS method (fluorimetry at } 515 \mathrm{~nm} / 533 \mathrm{~nm}, 4 \text { hours } \\
\text { preincubation of LDL with compounds and copper (II) } \\
\text { ions; } 320 \% \text { TBARS increase in control during } 4 \mathrm{~h} \\
\text { period) }\end{array}$} & \multicolumn{2}{|c|}{$\begin{array}{l}\text { Inhibition of conjugated diene formation (at } 234 \mathrm{~nm} \text { ) } \\
\text { expressed as prolongation of induction period (in \%\% } \\
\text { of control). } t_{\text {contr }}=36.8 \mathrm{~min} \text {. }\end{array}$} \\
\hline & $\begin{array}{l}\text { Effective [IC] (in } \mu \mathrm{M}) \text { : } \\
1 \mu \mathrm{M} ; 10 \mu \mathrm{M} ; 50 \mu \mathrm{M}\end{array}$ & $\begin{array}{l}\text { Activity rank order (ARO } \\
\text { = I for the highest activity; } \\
\text { ARO = VII for the } \\
\text { mindest activity) }\end{array}$ & $\begin{array}{l}\text { Effective [IC] (in } \mu \mathrm{M}) \text { : } \\
1 \mu \mathrm{M} ; 5 \mu \mathrm{M} ; 10 \mu \mathrm{M} ; 50 \mu \mathrm{M}\end{array}$ & $\begin{array}{l}\text { Activity rank order (ARO } \\
=\text { I for the highest activity; } \\
\text { ARO = VII for the } \\
\text { mindest activity) }\end{array}$ \\
\hline Nifedipine & $\begin{array}{l}10 \mu \mathrm{M} \\
50 \mu \mathrm{M}\end{array}$ & $\mathrm{ARO}=\mathrm{III}$ & $\begin{array}{c}5 \mu \mathrm{M} \\
10 \mu \mathrm{M}, 150 \% \\
50 \mu \mathrm{M}, 213 \%\end{array}$ & $\mathrm{ARO}=\mathrm{III}$ \\
\hline Amlodipine & $50 \mu \mathrm{M}$ & $\mathrm{ARO}=\mathrm{IV}$ & $\begin{array}{c}5 \mu \mathrm{M} \\
10 \mu \mathrm{M}, 122 \% \\
50 \mu \mathrm{M}, 138 \%\end{array}$ & $\mathrm{ARO}=\mathrm{IV}-\mathrm{VI}$ \\
\hline Isradipine & $50 \mu \mathrm{M}$ & $\mathrm{ARO}=\mathrm{VI}$ & $\begin{array}{l}10 \mu \mathrm{M}, 150 \% \\
50 \mu \mathrm{M}, 183 \%\end{array}$ & $\mathrm{ARO}=\mathrm{IV}-\mathrm{VI}$ \\
\hline Lacidipine & $\begin{array}{l}1 \mu \mathrm{M} \\
10 \mu \mathrm{M} \\
50 \mu \mathrm{M}\end{array}$ & $\mathrm{ARO}=\mathrm{II}$ & $\begin{array}{c}5 \mu \mathrm{M} \\
10 \mu \mathrm{M}, 192 \% \\
50 \mu \mathrm{M}, 283 \%\end{array}$ & $\mathrm{ARO}=\mathrm{II}$ \\
\hline Verapamil & $50 \mu \mathrm{M}$ & $\mathrm{ARO}=\mathrm{V}$ & $\begin{array}{l}10 \mu \mathrm{M}, 150 \% \\
50 \mu \mathrm{M}, 178 \%\end{array}$ & $\mathrm{ARO}=\mathrm{IV}-\mathrm{VI}$ \\
\hline Diltiazem & No effect & No effect $($ ARO $=$ VII $)$ & No effect & No effect $($ ARO $=$ VII $)$ \\
\hline Vitamin E & $\begin{array}{c}1 \mu \mathrm{M} \\
10 \mu \mathrm{M}\left(\mathrm{IC}_{50}\right) \\
50 \mu \mathrm{M}(20 \% \text { of control })\end{array}$ & $\mathrm{ARO}=\mathrm{I}$ & $\begin{array}{c}5 \mu \mathrm{M} ; \\
10 \mu \mathrm{M}, 230 \% ; \\
50 \mu \mathrm{M}, 370 \%\end{array}$ & $\mathrm{ARO}=\mathrm{I}$ \\
\hline
\end{tabular}

TABLE 5: Antiproliferative effect (oxLDL-induced HUVSMCs proliferation) of CA DHPs and simultaneous oxLDL-induced ROS production scavenging. Comparison with N-acetyl-L-cysteine, NAC (intracellular ROS scavenger). Compiled according to data presented by Zou et al., 2012 [130].

Methods

DHP compound Antiproliferative effect against proproliferative effect induced by oxLDL $(50 \mu \mathrm{g} / \mathrm{mL})$ (UV detection of formazan production from tetrazolium salt)
oxLDL-induced ROS production (fluorescent DCF

$\left(2^{\prime}, 7^{\prime}\right.$-dichlorofluorescein) production)

Effective [IC] in $\mu \mathrm{M}$ and I in \%

\begin{tabular}{|c|c|c|c|c|}
\hline Amlodipine & $3 \mu \mathrm{M}$ & $\mathrm{I}=18 \%$ & $3 \mu \mathrm{M} ; 10 \mu \mathrm{M}$ & $\begin{array}{c}\text { No effect } \\
I=20 \%\end{array}$ \\
\hline S(-)-Amlodipine & \multicolumn{2}{|c|}{ No effect } & \multicolumn{2}{|c|}{ No effect } \\
\hline Lacidipine & $\begin{array}{l}10 \mu \mathrm{M} \\
30 \mu \mathrm{M}\end{array}$ & $\begin{array}{l}I=21 \% \\
I=27 \%\end{array}$ & $10 \mu \mathrm{M}$ & $\mathrm{I} \sim 2 / 3$ of control \\
\hline $\begin{array}{l}\text { N-Acetyl-L-cysteine, } \\
\text { NAC }\end{array}$ & & & $\begin{array}{c}5000 \mu \mathrm{M} \\
(5 \mathrm{mM})\end{array}$ & $\mathrm{I}=28 \%$ \\
\hline
\end{tabular}

As presented (Table 4, according to [129]), for diltiazem (poor lipid solubility), no AO was detected, whereas the other CA and $\alpha$-tocopherol have demonstrated AOA at least at concentrations of 10 and $50 \mu \mathrm{M}: \alpha$-tocopherol > lacidipine $>$ nifedipine $>$ isradipine, verapamil, and amlodipine. Additionally, $\alpha$-tocopherol and lacidipine were able to significantly attenuate in vitro LDL oxidation at 1 and $5 \mu \mathrm{M}$. These results have confirmed the highest activity for the strongly lipophilic DHP type CA compound lacidipine. This might be a possible antiatherogenic mechanism of CA, since oxidative modification enhances the atherogenic potential of LDL.

The lipid peroxidation of LDL, promoted either by UV radiation or by copper ions, was inhibited (antioxidant effect) by nisoldipine in a dose-dependent manner $\left(\mathrm{IC}_{50}\right.$ values were evaluated at around $10 \mu \mathrm{M})$, nimodipine was less potent $\left(\mathrm{IC}_{50}\right.$ around $50-100 \mu \mathrm{M}$ ) and nicardipine almost inactive. In addition to this indirect protective effect, CA DHPs nisoldipine and nimodipine exerted direct protective effect on lymphoid 
cells, against toxicity of previously oxidized LDL. The $\mathrm{IC}_{50}$ values were $6 \pm 2$ and $80 \pm 20 \mu \mathrm{M}$, respectively [122]. The inhibition of the cytotoxic effect of LDL oxidized in the presence of DHP type $\mathrm{Ca}^{2+}$ channel blockers correlated well with protection from oxidation by these compounds. Complete protection cannot be obtained because the DHPs are cytotoxic themselves. The potential relevance to the prevention of atherogenesis is envisaged.

DHP type CCB nifedipine was the most effective inhibitor of oxidation promoted either by UV radiation or by copper ions in experiments with cultured lymphoid cells LDL $(2 \mathrm{mg}$ apoB $/ \mathrm{mL}$ ); CCBs from other two CCB classes, diltiazem and verapamil, were only poorly active or completely ineffective [121]. The protective effect of nifedipine occurs at two levels: besides its direct antioxidant effect by inhibition of LDL oxidation, it also exhibits a direct cytoprotective effect against cytotoxicity of oxidized LDL by yet unknown mechanisms. The protective effect of CCBs was not due to an inhibition of LDL uptake. This effect seems to be independent of the inhibition of LDL oxidation per se since LDL was oxidized in the absence of the drug before the incubation with cells. Moreover, this direct protective effect was observed at lower concentrations $\left(\mathrm{IC}_{50}\right.$ of $1 \pm 0.2 \mu \mathrm{M}$ ) compared to the antioxidant effect $\left(\mathrm{IC}_{50}\right.$ of TBARS inhibition is around $10 \pm 2 \mu \mathrm{M}$ at UV promoted and $4 \pm 0.5 \mu \mathrm{M}$ by $\mathrm{Cu}^{2+}$ ions initiated). The AO effect of nifedipine is also correlated with the protection of endogenous tocopherols $\left(\mathrm{IC}_{50}=50 \mu \mathrm{M}\right)$. It was suggested that the $\mathrm{AO}$ effect of CCBs protected cells indirectly from the cytotoxic effect of oxidized LDL [121].

A recent study has reported that beneficial vascular effects of lercanidipine in diabetic rats depend on its antioxidant activity related to attenuating the increase in oxidative stress and in vascular matrix metalloproteinase-2 (MMP2) (Martinez et al. [126]). Lesnik et al. [127] studied the impact of a combination of this calcium antagonist and a $\beta$-blocker atenolol on cell- and copper-mediated oxidation of LDL and on the accumulation and efflux of cholesterol in human macrophages and murine J774 cells. They realized that lercanidipine reduced the oxidative modification of LDL rather than diminished cholesterol accumulation in human foam cells.

Comparing the antioxidative action of CA (DHPs, amlodipine, lacidipine, nifedipine, and isradipine, as well as diltiazem and semotiadil) in the copper-catalyzed oxidation of low-density lipoprotein (LDL) with that of glycated (g)/glycoxidated (go) LDL demonstrated that the strongest $\mathrm{AO}$ effects during long-term LDL glycation are seen for isradipine, lacidipine, nifedipine, and semotiadil [128]. Inhibitory effects were in the range $10^{-5}-10^{-3} \mathrm{M}$. Authors suggested that, due to the increased generation of ROS by glucose-modified LDL, the chain-breaking capacity of CA may be overridden. The AOA of CA depends on their lipophilicity and their ability to incorporate into the LDL particle, that is, to reach the site of peroxidation. CA, like other AOs, significantly retards advanced glycation end products (AGE) formation, whereas initial glycation reactions, such as Amadori product formation, are only weakly inhibited. The observation that both oxidative changes and at least long-term glycation effects are indeed drastically reduced by CA is corroborated by fluorescence analysis, AGE-ELISA, quantitation of lipid peroxidation, and TBARS measurement of long-term g/go LDL.

The effects of lipophilic DHP calcium channel blockers on oxidized LDL-induced proliferation and oxidative stress of vascular smooth muscle cells were also studied [130] (see Table 5).

Lacidipine and amlodipine reduced carotid intimamedia thickness by decreasing proliferative effect of oxLDL, whereas $(S$-)-amlodipine had no antiproliferative effect. ROSMAPKs (mitogen-activated protein kinases) pathway might be involved in the mechanism.

Both 1,4-DHP CCBs lacidipine and nifedipine reduce plasma and LDL oxidation and formation of oxidationspecific epitopes. Their application may also relate to prolonged survival of rats, independently of blood pressure modifications (in the SPSHR model, $1 \mathrm{mg} / \mathrm{kg}$ per day lacidipine and $80 \mathrm{mg} / \mathrm{kg}$ per day nifedipine). These results suggested that the protective effect of these two 1,4-DHP drugs in vivo, as shown in cerebral ischemia and stroke, may in part result from inhibition of LDL oxidative process, although these two drugs possess different lipophilic properties [131]. Both lacidipine ( 0.3 and $1.0 \mathrm{mg} / \mathrm{kg})$ and nifedipine $(80 \mathrm{mg} / \mathrm{kg})$ prolonged lag time of the conjugated diene formation in LDL isolated from arterial wall, and $t_{\max }$. These drugs significantly reduced electrophoretic mobility of oxLDL from SPSHR subjected to X/XO oxidation system. 1,4-DHP CCBs also protected apolipoprotein $\mathrm{B}$, which is important for the binding with macrophage LDL receptor lysine residues. The doses used $\left(>10^{-6} \mathrm{~mol} / \mathrm{L}\right.$ for SPSHR and normotensive WKY rats), however, are 2 to 3 orders of magnitude higher than those inhibiting vascular smooth muscle contraction in vitro and in vivo. They also exceed values that are commonly used in clinical practice. The daily dose of lacidipine for hypertensive patients is $0.07 \mathrm{mg} / \mathrm{kg}$, $\approx 4$ - to 14 -fold lower than the 2 doses used in SPSHR. The maximum daily dose of nifedipine given to hypertensive patients is $2.0 \mathrm{mg} / \mathrm{kg}, \approx 40$ fold lower than what were used [131]. These discrepancies may be related to differences in bioavailability of CA between rats and humans [131].

Accordingly, in routine clinical use, 1,4-DHP CCBs do not reach the concentrations required for antioxidant activity in vitro [131].

Another data concerning the effect of CA DHPs on OS related to LDL is presented under Section 3.5.

(b) Effect of DHPs on Isolated Rat Liver and Heart Mitochondria. As a major cellular source of oxygen radicals (Cadenas $[4,5])$, mitochondria are promising targets for pharmacological and toxicological actions of various membrane-active compounds, including several 1,4-DHP derivatives. Zernig et al. [132] have discovered CA binding sites associated with an inner mitochondrial membrane anion channel.

More than 40-year long research on mitochondrial effects of the DHPs (on their bioenergetics, chemiosmotic properties, and ion fluxes) clearly points them out as mitochondriotropic compounds.

The activity of the first 35 synthesized compounds (derivatives of 1,4-DHP, their heteroaromatic analogues, 
NAD $-\mathrm{H}^{+}$and butylated hydroxytoluene (BHT, BOT)) originally was examined in rat liver mitochondrial LP system, in the presence of $\mathrm{Fe}^{2+}$ ions and using the ultraweak chemiluminescence method (Dubur et al. [89]).

Several 1,4-DHP derivatives, Hantzsch ester diludine and its analogues, were found to be effective antioxidants in this experimental system, changing the kinetics of LP, lengthening the time of the appearance of the maximum of the slow burst of the chemiluminescence (latency, latent period), and diminishing the reaction rate (the tangent of the slope angle during the time in which the amplitude of the slow burst characterizing LP rate increases) and its peak value. Their presence has influenced the reaction constant $K_{6}$, in relation to a very significant reduction of lipid hydroperoxides and/or inactivation of free radicals, as follows:

$$
\mathrm{ROO}^{\bullet}+\mathrm{ROO}^{\bullet} \longrightarrow \mathrm{P}+\mathrm{h}^{*} \text { termination }
$$

( $\mathrm{P}=$ molecular products $)$ or

$$
\mathrm{ROO}^{\bullet}+\mathrm{ROO}^{\bullet}+\mathrm{H}_{2} \mathrm{O} \longrightarrow \mathrm{ROH}+\mathrm{RO}^{\bullet}+{ }^{1} \mathrm{O}_{2}{ }^{*}
$$

In this study, diludine was one of the most active compounds. DHPs had activity similar to the standard synthetic AO-BHT (ionol). However, when plotted against applied concentration and time window, diludine's activity profile differed from that of BHT.

There were also similar studies (using different LP rate experimental detection system and method, Hunter et al. [133]), based on exploring a group of 26 2,6-dimethyl3,5-disubstituted- and 2,6-dimethyl-3,4,5-trisubstituted-1,4dihydropyridines $\left(1,4-\mathrm{H}_{2} \mathrm{Py}=1,4-\mathrm{DHPs}\right)$ and five related pyridines as inhibitors of rat liver Mit swelling $\left(\Delta A_{520} / t\right)$ and $\mathrm{O}_{2}$ uptake by ascorbic acid- (AsA-) dependent lipid peroxidation and as modulators of Mit swelling induced by $\mathrm{Na}^{+}$-linoleate or $\mathrm{Na}^{+}$-pyrophosphate (Velēna et al. [112]).

Some of tested 4-DHPs (4-unsubstituted 3,5-dialkoxycarbonyl-2,6-dimethyl-1,4-DHPs and 3,5-diamido-2,6-dimethyl-1,4-DHPs, both 4-unsubstituted, or those possessing lipophilic 4-aryl- groups) have shown significant $\mathrm{AO}$ and membrane stabilizing activity. These studies further revealed that 1,4-DHPs preferably act as AO during the stages of initiation and prolongation of LP chain reactions, at low concentrations. The studied 1,4-DHPs had $\mathrm{IC}_{50}$ (when $V_{0} / V$ or $\left.\tau / \tau_{0}=2\right) 0.1 \mu \mathrm{M}$ to $100 \mu \mathrm{M}$ and the minimal activity was scored for oxidized (heteroaromatized) derivatives.

At the concentration of $100 \mu \mathrm{M}, 3,5$-di- $n$-butyloxycarbonyl-2,6-dimethyl-1,4-DHP entirely stops mitochondrial swelling in the presence of $0.8 \mathrm{mM} \mathrm{Na}^{+}$-pyrophosphate. At the same concentration, the following compounds alter the mitochondrial swelling rate in the presence of natural protonophore, $\mathrm{Na}^{+}$-linoleate: 3,5-di-p-hydroxyphenoxycarbonyl- and 3,5-di-p-tolyloxycarbonyl-2,6-dimethyl1,4-DHPs, 3,5-diethoxycarbonyl-2,6-dimethyl-pyridine (oxidized form of Hantzsch ester), and more lipophilic 3,5diamyloxycarbonyl-2,6-dimethyl-pyridine. The alteration of swelling may be scored as prolonged, promoted, accelerated, or inhibited. The type of alteration depends on the structure and concentration of 1,4-DHPs, the type of initiators of the swelling process, and the medium composition.
In accord with previously published Janero's results (lack of $\mathrm{AO}$ for $\mathrm{Ca}^{2+}$ antagonists, nifedipine and nicardipine, even at $500 \mu \mathrm{M}$ concentration in LP tests performed on heart membrane [134]), no antioxidative activity for 4-phenyl substituted derivatives of 3,5-dialkoxycarbonyl 1,4-DHP (close analogues of $\mathrm{Ca}^{2+}$ antagonists) was found, contrary to various 4-nitrophenyl 1,4-DHP derivatives, calcium antagonists, for which the significant antioxidant activity was reported [31, 46-53].

Studies made on phosphatidylcholine liposomes (our unpublished data) suggest approximately three and two times more antioxidative activity for $100 \mu \mathrm{M} 4$-unsubstituted DHP compound diludine, when compared to 4-substituted DHPs riodipine/nifedipine and nicardipine, respectively, at methemoglobin-induced LP (oxygraphy).

Inhibition of mitochondrial AsA-dependent LP and stabilization of mitochondria were shown to be characteristic for a large group of 1,4-DHP compounds [112], showing to possess the AOA in simplest in vitro systems (Tirzit and Duburs [39], Zilber et al. [44], and Dubur et al. [45]) based on reactions with the stable free radical 1,1-diphenyl-2picrylhydrazyl (DPPH), LP of fatty acid ester (linethole and methyloleate) emulsions, and phospholipid (phosphatidylcholine) liposomes. Generally, these properties did not coincide with $\mathrm{Ca}^{2+}$ antagonism. Depending on DHP structure, it seems that AOA properties are less specific than $\mathrm{Ca}^{2+}$ antagonist properties. Both properties may be interrelated but not interdependent.

These data show that the presence and the nature of a substituent in position 4 , as well as 3,5-substituents, are important factors for 1,4-DHP antioxidant effects in various systems, that is, AsA-dependent nonenzymatic as well as enzymatic NADPH-dependent lipid peroxidation. Sometimes, the efficacy of inhibition of nonenzymatic LP by 1,4 -DHPs is higher than the inhibition of the enzymatic LP. However, the action may be opposite, stimulation of the LP. Hantzsch ester (HEH, diludine) and its close analogues exhibited significant AOA and membrane stabilizing properties in both AsA-dependent nonenzymatic peroxidation of mitochondria and NADPH-dependent enzymatic LP of microsomes, usually at similar 10 to $100 \mu \mathrm{M}$ concentrations [112].

The order of AO potency ( $\mathrm{IC}_{50}$ values) in vitro depends on drug structure as well as on the experimental conditions and specificity of the biological system. Each method for determination of AOA and ARA has advantages and disadvantages (Karadag et al. [135]).

Accordingly, as reported by Gubskil et al. [136], $\mathrm{IC}_{50}$ for the AsA-dependent LP was $0.25 \mu \mathrm{M}$ and $2.0 \mu \mathrm{M}$ for $1,4-\mathrm{DHP}$ $\mathrm{Ca}^{2+}$ antagonists nitrepine (nitrendipine) and nifedipine, respectively. Takei et al.s $[137,138]$ studies on mitochondrial swelling induced by LP or arachidonic acid in the rat brain determined the $\mathrm{IC}_{50}$ values of $12.7,10.5,156.8$, and $38.4 \mu \mathrm{M}$ for efonidipine, nicardipine, nifedipine, and nimodipine, respectively. For LDL in the copper-induced oxidation system the order of potency was vitamin $\mathrm{E}>$ felodipine $>2$-chlorophenyl analogue of nifedipine $>$ nifedipine $>$ amlodipine, nitrendipine, verapamil, and diltiazem (Rojstaczer and Triggle [119]). 
It was interesting to compare the AOA of DHPs with their susceptibility to oxidation, that is, electron and hydrogen donating properties.

It has been estimated that electron donor substituents in positions 2 and 6 of 1,4-DHP cycle usually promote oxidation, while electron acceptor substituents promote quench oxidation. Stronger electron acceptors in positions 3 and 5 also significantly quench oxidation. These estimations are based on studies including chemical, enzymatic, and electrochemical oxidation of 1,4-DHP derivatives (Dubur and Uldrikis [70], Duburs et al. [71], and Stradin et al. [139]).

On the other hand, diminished AOA of 1,4-DHP relates to presence of substituents in position 4 (both electron donor and electron acceptor) (Velēna et al. [112]).

3,5-Dicarbamoyl substituents possess minimal quenching feature and are followed by benzoyl-, acetyl-, and alkoxycarbonyl- groups. Maximal decrease was obtained with condensed substituents (i.e., oxoindeno- or oxocyclohexeno- groups) and a CN-group. 4-Unsubstituted 3,5-dicarbamoyl derivatives can be easily oxidized and consequentially inactivated, whereas 4-substituted 3,5-dicarbamoyl-1,4DHPs possess an oxidation potential, analogous to the 4unsubstituted 3,5-COOR derivatives. Therefore, they have adequate electron donor properties and are considerably stable. This may be the reason for significant membrane stabilization upon exposure to 4-substituted derivatives. Of importance, their AOA was usually more pronounced in comparison to 4-unsubstituted derivatives.

Among them, 2,6-dimethyl-3,5-difurfuryloxycarbonyl1,4-DHP showed the highest antioxidative activity. In the group of 3,5-dialkoxycarbonyl derivatives, the strongest activity was attributed to compounds with medium length alkyl chains ( $i$-butyl-, $t$-butyl-, and $i$-amyl-substituents), high level of lipophilicity, minimal electron acceptor properties, and moderate steric hindrance, as contrasted to short or long alkyl chain ester derivatives (3,5-dimethoxycarbonyl-, 3,5diethoxycarbonyl derivatives and 3,5-didodecyloxycarbonyl derivative). These data demonstrate the bell-shaped dependence of AOA on alkyl chain length [112] and are in accord with results obtained in liposomes. However, these data differ from those obtained in emulsions, where diludine was the most active compound. Finally, oxidized heteroaromatic derivatives showed only minimal activity.

In both LP systems studied (AsA-dependent in mitochondria and NADPH-dependent in microsomes), some of 1,4-DHPs showed activity similar to classical antioxidant, butylated hydroxytoluene (ionol, BHT) (Velēna et al. [112]). However, there was a significant difference related to concentration and incubation time. It allowed us to postulate that 1,4-dihydropyridines ( $\mathrm{InH})$, acting as antioxidantsreductants and scavengers of reactive oxygen species and lipid free radicals, preferably influence initiation and propagation (prolongation) of lipid peroxidation chain reactions (1)(5), according to Scheme 2. The phenomenon is particularly prominent in the presence of $\mathrm{Fe}^{2+}$ and other ions of variable valency.

Chain break and termination reactions (6)-(10) of the LP reaction cascade [89] were influenced by $1,4-\mathrm{DHPs}$ in a lesser degree than were initiation and propagation steps. This may be important for their therapeutic effects even in the advanced stages of LP.

Scheme 2 (stages of initiation, propagation, and termination of lipid peroxidation chain reactions (1-10)). Initiation and propagation reactions are as follows:

(1) $\mathrm{HOO}^{\bullet}+\mathrm{RH} \rightarrow \mathrm{R}^{\bullet}+\mathrm{H}_{2} \mathrm{O}_{2}(\mathrm{RH}=$ membrane lipid $)$

$\mathrm{HO}^{\bullet}+\mathrm{RH} \rightarrow \mathrm{R}^{\bullet}+\mathrm{H}_{2} \mathrm{O}$

$\mathrm{HOO}^{\bullet}+\mathrm{InH} \rightarrow \mathrm{In}^{\bullet}+\mathrm{H}_{2} \mathrm{O}_{2}(\mathrm{InH}=1,4-\mathrm{DHP})$

$\mathrm{HO}^{\bullet}+\mathrm{InH} \rightarrow \mathrm{In}^{\bullet}+\mathrm{H}_{2} \mathrm{O}$

(2) $\mathrm{R}^{\bullet}+\mathrm{O}_{2} \rightarrow \mathrm{ROO}^{\bullet}\left(\mathrm{R}^{\bullet} ; \mathrm{RO}^{\bullet} ; \mathrm{ROO}^{\bullet}=\right.$ lipid radicals $)$

(3) $\mathrm{ROO}^{\circ}+\mathrm{RH} \rightarrow \mathrm{ROOH}+\mathrm{R}^{\bullet}$

(4) $\mathrm{ROOH}+\mathrm{Fe}^{2+} \rightarrow \mathrm{RO}^{\bullet}+\mathrm{Fe}^{3+}+\mathrm{HO}^{-}$

(5) $\mathrm{RO}^{\bullet}+\mathrm{RH} \rightarrow \mathrm{ROH}+\mathrm{R}^{\bullet} ; \mathrm{R}^{\bullet}+\mathrm{InH} \rightarrow \mathrm{RH}+\mathrm{In}^{\bullet}$

Chain break and termination reactions are as follows:

(6) $\mathrm{ROO}^{\bullet}+\mathrm{ROO}^{\bullet} \rightarrow \mathrm{P}+\mathrm{h}^{*}$ ( $\mathrm{P}=$ molecular products) or $\mathrm{ROO}^{\bullet}+\mathrm{ROO}^{\bullet}+\mathrm{H}_{2} \mathrm{O} \rightarrow \mathrm{ROH}+\mathrm{RO}^{\bullet}+{ }^{1} \mathrm{O}_{2}{ }^{*}$

(7) $\mathrm{ROO}^{\bullet}+\mathrm{InH} \rightarrow \mathrm{ROOH}+\mathrm{In}^{\bullet}(\mathrm{ROOH}=$ membrane lipid peroxides)

(8) $\mathrm{RO}^{\bullet}+\mathrm{In}^{\bullet-} \rightarrow \mathrm{Y}(\mathrm{Y}=$ molecular products $)$

(9) $\mathrm{ROO}^{\bullet}+\mathrm{Fe}^{2+} \rightarrow \mathrm{Fe}^{3+}+\mathrm{X}(\mathrm{X}=$ molecular products $)$

(10) $\mathrm{RO}^{\bullet}+\mathrm{RO}^{\bullet-} \rightarrow \mathrm{Y}(\mathrm{Y}=$ molecular products)

In the reversible swelling of mitochondria accompanying LP (initiated by mixture of $5 \mathrm{mM}$ GSSG/1 mM GSH), several 1,4-DHPs showed low or no activity, manifested only as a decrease of the swelling amplitude, without a rate decrease. An addition of GSH ( $4 \mathrm{mM})$ or ATP to swollen mitochondria caused their contraction in both control and tested system. It may be suggested that 1,4 -DHPs, acting as antioxidants in mitochondria, preferably influence LP reactions initiated by ions with variable valency or their complexes with heme type compounds: methemoglobin, hemin, hematin, and so forth (Velēna et al. [112]). If the peroxidation process has a maximal velocity and 50 percent of initial $\mathrm{O}_{2}$ were consumed, 1,4-DHPs cannot completely break the chain reactions and prevent subsequent membrane damage: by addition of DHP substance at $10 \mu \mathrm{M}$ concentration at the moment of 50 percent oxygen consumption, the subsequent oxygen uptake proceeded unchanged. This observation is important for the application of DHPs as inhibitors of initiation and, to a lesser degree, propagation stages of LP chain reactions.

The influence of 1,4-DHPs on Mit swelling is not strictly associated with their own oxidation. There is the possibility that the labilizing (or stabilizing) effect relates to surface activity (connected with substituent lipophilicity) or may be the consequence of complexation with some -OH (or $-\mathrm{CH}_{3}$ ) group sensitive receptors at the mitochondrial membrane. Namely, a bathochromic shift of the absorption band maximum (about $10 \mathrm{~nm}$ ) was observed in the visible region before swelling. However, after swelling in the presence of $\mathrm{Na}^{+}$ linoleate, the spectrum returns to its initial value [112].

Some 1,4-DHPs not only protect mitochondria against swelling caused by AsA-dependent LP, salts of fatty acids 
in vitro [112], but also have beneficial effects on repairing their integrity in vivo, after exposure to irradiation, hepatotoxins, ischemia, hypoxia, or hypothermia. Some of them were shown to normalize the process of intracellular reparation and physiological regeneration of ultrastructures. They were also shown to stimulate reparative processes. If pretreated with 1,4-DHPs, irradiated mitochondria will not swell (Ivanov et al. [140, 141]).

Diludine, ionol, and some other AOs, mitochondria protectors, act as anti-ischemic agents. If applied prophylactically in vivo, they may prevent ischemic and reperfusion lesions in heart, kidney, and other organs (Bilenko et al. [113]). The effect is dependent on applied dose, timing, and way of application. When added onto the cryoconservation medium for mitochondria preservation, 1,4-DHPs prevented decrease of membrane potential, normalized facilitated respiration, and prevented loss of mitochondrial $\mathrm{Na}^{+}$and $\mathrm{Ca}^{2+}$ ions, after thawing ([112], see citation number 36 (Subbota et al., Kharkov, 1984) therein). Diludine was stronger protector, when compared to ionol.

CA drug foridone (riodipine) was shown to possess cardioprotective features, primarily due to is protective effect on mitochondria exposed to OS $[142,143]$.

Similarly, the DHP water-soluble antiarrhythmic compound glutapyrone inhibits initiation of LP by free radicals in erythrocytes and heart mitochondria. Its cardioprotective effect has been experimentally shown in heart mitochondrial membranes, especially during deep hypothermia (Utno et al. [144]).

Cerebrocrast was effective in several translation models mimicking pathological situations, known to be associated with cellular OS. The potential protective action of 1,4DHP derivatives (4-substituted compounds: cerebrocrast, gammapyrone, glutapyrone, and 4-unsubstituted drug diethone) has been studied in rat liver, in experimental models relevant for oxidative stress and mitochondrial bioenergetics (Fernandes et al. [145]). When succinate was used as the respiratory substrate, higher concentrations $(>25 \mu \mathrm{M})$ of cerebrocrast depressed respiratory control ratio (RCR), ADP to oxygen ratio $(\mathrm{ADP} / \mathrm{O})$, state 3 , and uncoupled respiration rates, transmembrane potential (deltapsi), and the phosphate carrier rate. At the same time, state 4 respiration rate was three times increased. At concentrations lower than $25 \mu \mathrm{M}$, cerebrocrast inhibited mitochondrial IMAC and partially prevented $\mathrm{Ca}^{2+}$-induced opening of the mitochondrial PTP. Gammapyrone, glutapyrone, and diethone did not induce these phenomena. When applied at concentrations up to $100 \mu \mathrm{M}$, cerebrocrast, gammapyrone, and glutapyrone did not affect $\mathrm{ADP} / \mathrm{Fe}^{2+}$-induced LP of mitochondria in rat liver (as measured by oxygen consumption and TBARS formation). On the other hand, low diethone concentrations (up to $5 \mu \mathrm{M}$ ) inhibited it in a dose-dependent manner. Diethone also prevented against deltapsi dissipation induced by LP initiated by $\mathrm{ADP} / \mathrm{Fe}^{2+}$. Based on these data, it may be speculated that cerebrocrast (inhibition of the IMAC) and diethone (acting as an $\mathrm{AO}$ ) may provide effective protection of mitochondria during OS. Cerebrocrast has shown some therapeutic potential for treatment of several pathological conditions related to cellular OS [145].
5-Acetyl(carbamoyl)-6-methylsulfanyl-1,4-DHP-carbonitriles (Figure 3) with minor differences in their molecular structure, displaying antioxidant and antiradical activities in vitro, show different biological activities. Namely, 4- $p$ chlorophenyl derivative OSI-1146 displays AO and antiradical activities in cardiovascular OS models, whereas OSI-3701 and OSI-3761 display hepatoprotective activity. Thus, these compounds may be potentially useful for treating several pathological processes, including those associated with OS (Fernandes et al. [146]). However, besides mitochondria, the cellular targets for their pharmacological actions have not been fully investigated [146]. All these compounds increase the susceptibility of Mit to MPT. The most potent is OSI-3701, although it does not affect bioenergetic parameters.

Although all these compounds protected mitochondria against LP induced by the oxidant pair ADP/Fe ${ }^{2+}$, OSI-1146 was shown to be the most potent. Current data point out mitochondria as potential targets for protective and toxic actions of DHPs, suggesting that the potential for their use as therapeutic agents should also take into consideration their toxic effects on mitochondria (Fernandes et al. [146]).

Several structurally different DHP derivatives (antioxidant diludine (diethone), as a 4-unsubstituted DHP, 4-substituted DHPs: CA foridone (bicyclic compound), and the 4phenyldiethone compound where phenyl group is joined to the DHP in position 4) inhibited the 1-methyl-4-phenylpyridinium iodide $\left(\mathrm{MPP}^{+}\right)$induced ROS production in cerebellar granule cells (CGC) with a distinct potency order: foridone (2,6-dimethyl-3,5-dimethoxycarbonyl-4-(o-difluoromethoxyphenyl)-1,4-dihydropyridine) > 2,6-dimethyl-3,5diethoxycarbonyl-4-phenyl-1,4-dihydropyridine $>$ diludine. They also reversed the $\mathrm{MPP}^{+}$-induced decrease of the mitochondrial membrane potential in the same order (Klimaviciusa et al. [147]). Accordingly, it was postulated that the classical two-ring (bicyclic) structure of DHP derivatives represents an advantage in relation to neuroprotection and ROS defense and is independent on compound's properties related to calcium ions.

Novel adamantane-containing 1,4-DHP compounds (Klimaviciusa et al. [148]) were also found to improve mitochondrial functions $\left(\mathrm{MPP}^{+}\right.$model) (Klimaviciusa et al. [148]). Klusa et al. [149] have discovered antineurotoxic effects of 1,4-DHP taurine derivative, tauropyrone, recorded as Mit function improvement.

Many 1,4-DHPs, including $\mathrm{Ca}^{2+}$ antagonists and $\mathrm{AO}$, modify LP processes and influence mitochondrial function in various organs (liver, heart, kidney, and brain) in a different way and degree. Their beneficial action, oxygen or lipid free radical scavenging, antioxidative effects, binding with or intercalating into phospholipid bilayer, regulation of ion gating, and regulation of mitochondrial permeability transition pores (Tirzit and Duburs [39], Zilber et al. [44], and Dubur et al. [45]), separately or in combination with each other, depends on two strong elements: (1) their individual structure including nature of substituents and their positions and (2) the nature of the biological system. For example, the direction of LP (inhibition of promotion) was shown to depend on structure and concentration of applied 
1,4-DHPs as well as stages of chain reactions. Accordingly, mitochondrial swelling may be prolonged (retarded), accelerated (promoted), or inhibited (Velēna et al. [112]).

Therefore, there is a ground for 1,4-dihydropyridines, either $\mathrm{Ca}^{2+}$ antagonists or antioxidants, to be nominated as useful tools in development of "mitochondrial drugs" related to the control of OS.

(c) DHPs as AOs in Endoplasmic Reticulum (Inhibition of NADPH-Dependent LP System): Inhibition of NADPH Oxidase by DHPs. Elevated level of NADPH oxidase 4- (NOX4-) derived hydrogen peroxide $\left(\mathrm{H}_{2} \mathrm{O}_{2}\right)$ joined with concomitant decrease of nitric oxide (NO) mediated signaling and reactive oxygen species scavengers are considered to be central factor in molecular pathogenesis of fibrosis (Sampson et al. [150]). Inhibition of microsomal NADPH-dependent LP, with particular focus on NADPH oxidases (NOX1-5 and DUOX1), may be very important for neuro-, cardio-, and hepatoprotection (Velēna et al. [112], Leto and Geiszt [151], Griendling et al. [152], and Chen et al. [153]). Endoplasmic reticulum may be an important target, as this is where 1,4DHPs could display their antioxidative properties (Velēna et al. [112], Leto and Geiszt [151], Griendling et al. [152], and Chen et al. [153]).

However, the initiation of LP in the NADPH-dependent microsomal system does not appear to involve either superoxide or hydrogen peroxide, since neither SOD nor catalase can inhibit it. On the other hand, reduced iron plays an important role in both the initiation and propagation of NADPH-dependent microsomal lipid peroxidation (Hochstein and Ernster [154] and Repetto et al. [111]).

Many DHPs possess inhibitory activity not only towards AsA-dependent LP in mitochondria but also towards NADPH-dependent LP, as shown in isolated rat liver microsomes (Velēna et al. [112]). This means that these compounds interact with the shared parts (nonenzymatic and enzymatic) of LP pathways.

Microcalorimetry and fluorescent probes procedures were used for studying the interaction of alpha-tocopherol and 1,4-DHPs with endoplasmic reticulum membranes and model systems, human serum albumin, and phospholipid bilayers [155]. Modification of microviscosity of the endoplasmatic reticular membranes depends on localization of antioxidants within the protein structures or phospholipid phase. Increase of membrane structuralization under the influence of 1,4-DHPs blocked their antioxidant action in spontaneous and induced lipid peroxidation.

Inhibition of rat heart and liver microsomal lipid peroxidation by nifedipine was observed [156], while Goncalves et al. [157] found antioxidant effect of calcium antagonists on microsomal membranes isolated from different brain areas.

Nitroaryl-1,4-DHPs are both calcium channel antagonists and antioxidant agents (Letelier et al. [158, 159]), commonly used for treatment of cardiovascular diseases. These drugs must be metabolized through cytochrome P450 oxidative system (NADPH-cytochrome $\mathrm{P} 450$ reductase), mainly localized in the hepatic endoplasmic reticulum. Several lipophilic drugs generate OS while being metabolized by this cellular system. Thus, DHP antioxidant properties may prevent the
OS associated with hepatic biotransformation of drugs. Various commercial and new nitro-phenyl-DHPs were studied against LP using rat liver microsomes under oxidative stress [159].

Incubation of rat liver microsomes with the $4^{\prime}$-nitro4-phenyl-1,4-DHP compounds (2,6-dimethyl-4-( $4^{\prime}$-nitrophenyl)-1,4-dihydropyridin-3,5-diethyl-dicarboxylate and N-ethyl-2,6-dimethyl-4-( $4^{\prime}$-nitrophenyl)-1,4-dihydropyridin-3,5-dimethyl-dicarboxylate) results in an inhibition of LP, the UDPGT (UDP-glucuronyltransferase) oxidative activation, and the microsomal thiol oxidation induced by $\mathrm{Fe}^{3+}$ /ascorbate, a generator system of ROS. This effect was also produced by nitrofurantoin and naphthalene in the presence of NADPH.

Interestingly, $\mathrm{IC}_{50}$ of DHPs obtained from microsomal LP assays decreased to the same extent as the microsomal thiols oxidation provoked by $\mathrm{Fe}^{3+} /$ ascorbate [159]. Nevertheless, the AO effects of a nitrophenyl-DHP compound, in which hydrogen at position one of the DHP ring was replaced by the ethyl group, were significantly weaker. Authors speculated that DHPs can resemble NADH, transferring one hydrogen atom of 4-position $\left(\mathrm{H}^{-}\right)$to anion superoxide and another of the 1-position $\left(\mathrm{H}^{+}\right)$by way of a cationic radical intermediate to generate pyridine derivatives and water [159].

The AO effects of various tested DHP derivatives ( $m$ - and $p-\mathrm{NO}_{2}$ phenyl as well as methyl or ethyl and isopropyl-DHP 3,5-dicarboxylate derivatives) were not significantly different. The authors assumed that the - $\mathrm{NH}$ - group of the dihydropyridine ring could contribute both to the development of the calcium channel antagonism and to the antioxidative properties of DHPs [159].

Prevention of the membrane LP seemingly depends on the concentration of potential antioxidants, such as vitamin E or even 1,4-DHP in lipids. However, only the differences in synthetic DHPs lipophilicity cannot explain significant variations of DHPs concentration in microsomal membrane and cannot clarify the strength of their antioxidative activity. This work [159] has further demonstrated that 1,4-DHPs may prevent the OS induced by biotransformation of some drugs, for example, antibiotic nitrofurantoin. Simultaneous administration of DHPs and nitrofurantoin may be beneficial in reducing nitrofurantoin side effects.

While most of Ca antagonist 1,4-DHPs are metabolized by CYP3A4 (Guengerich et al. [160]), not all of them are good inhibitors of its activity. Thus, nicardipine, but not nifedipine and nitrendipine, inhibits CYP3A4 in vitro [53]. Interaction of different DHPs with various types of cytochrome P450 was described by Carosati et al. [53]. It was also reported that DHP class calcium channel blockers reduce the antiplatelet effect of clopidogrel (Park et al. [161]). This implies the mutual interactions of both drugs with CYP3A4.

(3) In Vivo. Evaluation of nifedipine effects on Saccharomyces cerevisiae was recently published (Asma and Reda [162]). Surprisingly, nifedipine exercised a toxic effect on Saccharomyces cerevisiae shown through measuring cellular proliferation, respiratory activity, and the level of some biomarkers (CAT and MDA). 
However, majority of data obtained on various animal cells and tissues by other authors show the protective role of DHPs against both LP and oxidative stress [113, 163, 164].

The AOA attributed to many 1,4-DHPs, $\mathrm{Ca}^{2+}$ antagonists and other compounds, reflecting on catalytic LDL peroxidation (see Section 3.3.1 (2) and Section 3.5), should encourage their testing for treating cardiovascular diseases and/or alterations of lipid metabolism.

The possibility that 1,4-DHP-based calcium antagonists exert an antiatherosclerotic action ( $v i a$ inhibition of LDL oxidation and other mechanisms) has been proved by many experimental data [165] and several clinical trials. Besides antihypertensive effect, nicardipine was shown to possess antioxidative and antielastase activity $[165,166]$. These properties may be useful for prevention of inflammatory reaction which is relevant for hypertension pathogenesis.

1,4-DHPs administration inhibits LDL oxidation mediated by oxygen radicals, leading to decreased carotid intimal media thickness and reduced progression of coronary atherosclerosis [130]. It additionally preserves Apo B-100 integrity against ROS. Of importance, antiatherogenic mechanisms differ between animals and humans (primarily in the stage of conversion of aldehydes to carboxylic acids) (Parthasarathy et al. [167]).

For example, furyl-DHP compound (FDP-1, diethyl 2,6dimethyl-4-(furyl)-1,4-dihydropyridine-3,5-dicarboxylate) was shown to act as an antioxidant (decreasing MDA, GOT, and FFA release of ischemic myocardium and inhibiting $\mathrm{Ca}-$ ATPase of erythrocyte membranes), preventing against heart myocardium ischemia-reperfusion injury and arrhythmia, when applied (in rats) at $10 \mathrm{mg} / \mathrm{kg}$ (Liu et al. [168]).

Similarly, antioxidative effects of azelnidipine and amlodipine prevented neuronal damage by CCBs, after transient focal ischemia in rats (Lukic-Panin et al. [169]).

Allanore et al. [170] found that both nifedipine and nicardipine significantly decrease the mean level of plasma markers for oxidative stress in patients suffering from systemic sclerosis.

Antioxidants may be considered as promising neuroprotective compounds. Still, while experimental data demonstrate neuroprotective effect in vitro and in animal models, clinical evidence is still unsatisfactory and insufficient [171].

(a) Role of Metabolism of DHPs in Their AOA. Metabolic pathways and "bioavailability" of the probable AOA compound determine antioxidant activity in vivo. Antioxidant metabolites may vary in stability and activity leading to two opposite scenarios: lack or presence of activity, substantially contributing to the overall AOA [172]. Metabolic biotransformation of DHPs includes oxidation (heteroaromatization), side chain ester group cleavage (deesterification), and 4substituent abstraction a.o. [160]. None of the DHPs metabolites was shown to be more toxic than original, reduced form of the compound. The commonly detected metabolites of the DHPs do not seem to possess the AO activity (with some exceptions as in the case of metabolites of nifedipine and its analogues, including nitrosonifedipine $[173,174])$ (see further in Section 3.5). Due to DHPs intrinsic instability, achieving and maintaining an adequate concentration may be problematic both in vitro and in vivo.

(b) Role of Concentration and Lipophilicity (Membrane/Water or Lipid/Water Partition Coefficients) of DHPs in Their Action as AOs and Antiradical Compounds. Antioxidative effects of any antioxidant depend on its concentration at the site of action. This parameter is hardly measurable, especially in two-phase systems, representing one of obstacles in comparison to AOA upon applying various compounds [172]. It is often incorrectly assumed that the concentrations in the aqueous solution and at the site of action are the same. However, even when the concentration in the aqueous phase may be well controlled, the concentration at the site of action in the lipid matrix of the membranes might fluctuate between different test compounds, depending on a difference in lipophilicity [175]. The prevention of the membrane LP also seems to be dependent on the DHP concentration in the lipid matrix (Mason and Trumbore [46]) and its amphiphilicity. For example, AOA of diludine is associated with its lipophilicity and consequential ability to be incorporated into liposomes (Panasenko et al. [176]). It was also found that diludine easily incorporates into the outer monolayer of erythrocyte membranes [176].

Membrane/buffer partition coefficients (lambda) were directly measured in the sarcolemma and sarcoplasmic reticulum membranes for three CA DHPs. The obtained values were in a broad range between 5000 and 150000 (Herbette et al. [177]). These drugs interact primarily with the membrane bilayer component but may also bind to proteins, both nonreceptors and receptors. The intrinsic forward rate constants for DHP binding to sarcolemmal calcium channel receptors were apparently not strongly dependent on their membrane partition coefficients. For example, nimodipine $($ lambda $=6300)$ had a forward rate constant of $6.8 \pm 0.6 \times$ $10^{6} / \mathrm{M} / \mathrm{s}$, whereas the forward rate constant for Bay P 8857 $($ lambda $=149000)$ was $1.4 \pm 0.8 \times 10^{7} / \mathrm{M} / \mathrm{s}$. Since these DHPs are highly liposoluble, model calculations for this binding reaction demonstrated that these rates on lipid solubility would probably not be reflected in the experimental forward rate constants. In addition, the intrinsic forward rate constant for nimodipine binding to sarcolemmal calcium channel receptors was found not to be linearly dependent on the viscosity of the buffer medium over a fivefold range. The rate of drug nonspecific binding to nonreceptor protein present in highly purified sarcoplasmic reticulum membranes appears to be extremely fast, at least $10^{3}$ times faster than specific drug binding to the receptor in the sarcolemma. Authors concluded that partitioning into the lipid bilayer matrix of the sarcolemma could be a general property of CA DHPs and may be a prerequisite for their binding to sarcolemmal membrane receptors (Herbette et al. [177]).

The binding of DHP calcium channel agonists and antagonists (including those with $\mathrm{AO}$ properties) to receptors in cardiac sarcolemmal membranes is a complex reaction that may involve an interaction with the lipid bilayer matrix of the sarcolemma (Herbette et al. [178]). Belevitch et al. [179] studied the binding of DHP CCBs (riodipine and nifedipine) and verapamil to model and biological membranes by 
fluorescence analysis. The consistent location of $\mathrm{Ca}$ agonist Bay K 8644 was determined to be within the region of the first few methylene segments of the fatty acyl chains of the membranes (Mason et al. [180]). This position is near to that observed for the DHP calcium channel antagonists nimodipine and Bay P 8857.

The majority of studies on OS were performed with DHPs with various lipophilicity, but only a few studies reported amphiphilicity of DHP derivatives. Amphiphilic DHP derivative K-2-11 reduced the cellular generation of ROS. It also revealed complete reversal of multidrug resistance (MDR) of the resistant cells. K-2-11 was more efficient than well-known MDR inhibitor verapamil. Cytotoxic effects of anticancer drug doxorubicin were enhanced by K-2-11 in both MDR and parental, nonresistant cell line (Cindric et al. [181]). K-2-11 suppresses increase of ROS and consequentially prevents NF$\kappa \mathrm{B}$ activation leading to decreased expression of MDR1 and increased expression of antiapoptotic genes. This signaling switch is necessary for restoring the chemosensitivity of cancer cells. This phenomenon is characteristic both for 1,4-DHPs [182] (18 novel asymmetrical DHPs bearing 3pyridyl methyl carboxylate and alkyl carboxylate moieties at C3 and C5 positions, resp., as well as nitrophenyl or heteroaromatic rings at $\mathrm{C} 4$ ) and for their oxidized forms, pyridine compounds (Zhou et al. [183]).

3.4. Dependence of AOA of DHPs on the Experimental System. $\mathrm{AO}$ effect of DHPs depends on their structure and the experimental system used (in vitro model system, subcellular organelle, and cells, ex vivo and in vivo). Ideally, for the evaluation of the profile and value of DHPs AO properties, each compound should be tested in as many systems as possible (Dubur et al. [45]).

Lipidomics studies have been traditionally explored for studying AOA of DHPs. Proteomics methods are less represented and are mostly focused on the properties of DHPs related to scavenging of protein free radicals. So far, there are no studies on the role of DHPs in scavenging nitrosoperoxycarbonate, the reactive species formed out of peroxynitrite, in the presence of carbon dioxide. Although it was shown that albumin binds diludine, no studies revealed the relevance of this effect for the AOA of diludine.

There are findings showing that dihydropyridine calcium antagonists (DHPs CA) could indirectly play a beneficial, protective role during development of atherosclerosis. Namely, Berkels et al. [184] have studied antioxidative properties of four substances: the DHP prototype CA, nifedipine, the long-acting CA, lacidipine, the DHP calcium channel agonist, Bay K 8644, and the bulky DHP derivate, Bay O 5572, in three different models: (1) in an in vitro superoxide anion generating system (hypoxanthine/xanthine oxidase) for testing the "pure" antioxidative effect, (2) in an artificial membrane preparation (dimyristoylphosphatidylcholine) for mimicking a more physiological environment, and (3) under conditions of stimulated ROS release (hyperglycemia) from native endothelial cells derived from porcine coronary arteries.

The study also revealed the potential correlation between lipophilic and AO properties of DHPs. In the first model,
Bay K 8644 was significantly more effective in scavenging superoxide anions than lacidipine, Bay O 5572, or nifedipine (micro- to millimolar concentration range). Addition of an artificial membrane preparation resulted in an enhanced $\mathrm{AO}$ effect, with lacidipine being the most effective DHP in quenching radicals (low micromolar concentration range). In the third model, mimicking hyperglycemia $(30 \mathrm{mmol} / \mathrm{L})$, nifedipine was significantly more potent antioxidant (therapeutical nanomolar concentration range) than the other DHPs. Calculated lipophilicity of these four substances (lacidipine > Bay O $5572>$ Bay K $8644>$ nifedipine) was positively correlated with antioxidative potential only in the second experimental model. It has been concluded that $\mathrm{AO}$ properties of DHP substances need to be tested in various models for demonstrating that nifedipine exhibits ROSquenching properties in a therapeutic concentration range [184].

3.4.1. AOA of DHPs in Isolated Cells and Cell Cultures (Comparison with Other Simplest Systems). Although DHPs possess neuromodulatory and/or antimutagenic properties, the mechanisms of action related to these phenomena are not entirely elucidated. Borovic et al. [185] have studied 1,4dihydroisonicotinic acid (1,4-DHINA) derivatives of 1,4DHP, water-soluble analogues of a well-known AO diludine (diethone): 2,6-dimethyl-3,5-diethoxycarbonyl-1,4-dihydroisonicotinic acid, sodium 2-(2,6-dimethyl-3,5-diethoxycarbonyl-1,4-dihydropyridine-4-carboxamido)glutamate, glutapyrone and sodium 2-(2,6-dimethyl-3,5-diethoxycarbonyl1,4-dihydropyridine-4-carboxamido)ethane-sulphate, tauropyrone as $\mathrm{AO}$ and bioprotectors (Figure 4 ).

1,4-DHINA's activities were studied in comparison to Trolox by N,N-diphenyl- ${ }^{\prime}$-picrylhydrazyl (DPPH ${ }^{\bullet}$ ), deoxyribose degradation, $\mathrm{ABTS}^{\circ}$ radical scavenging, and AOA (antioxidative capacity method) assays; copper-induced LP of cultured rat liver cells (MDA determination by HPLC and 4-hydroxynonenal-protein conjugates by dot-blot); ${ }^{3} \mathrm{H}$ thymidine incorporation and trypan blue assay for liver cells growth and viability. Ic decreased the amount of 4-HNEprotein adducts. In all assays, Ia was the most potent AO, able to completely abolish copper induced LP of liver cells, while Ic only slightly decreased it. Thus, AOA is important activity principle of Ia, which was even superior to Trolox in treated cell cultures. Ia (and its analogues) are easily oxidized in the Fenton system (Rubene et al. [186]), exerting ARA too.

3.5. Peculiarities Related to Antioxidative and Antiradical Activity of Some 1,4-DHPs: Ca Antagonists. Nine commercialized, structurally and functionally different DHPs, CA, will be discussed further. Their common feature is ability to prevent OS. This also counts for some of their metabolites, as already discussed. The comparative effects of some DHPs, CA, on oxidative stress-induced modification of LDL were already reviewed in Section 3.3.1 (2)-(a). AOA of CA DHPs was discussed in Sections 3.3.1 (2)-(b) and 3.3.1 (2)-(c).

3.5.1. Nifedipine and Its Close Analogues. Nifedipine, verapamil, and antiarrhythmic-antihypoxic drug, stobadin, were shown to depress lipid peroxidation of phosphatidylcholine 
<smiles>CCOC(=O)C1=C(C)NC(C)=C(C(=O)OCC)C1C(=O)O</smiles>

1,4-DHINA<smiles>CCOC(=O)C1=C(C)NC(C)=C(C(=O)OCC)C1C(=O)NC(C(N)=O)C(N)=O</smiles>

Glutapyrone<smiles>CCOC(=O)C1=C(C)NC(C)=C(C(=O)OCC)C1C(=O)OCC</smiles>

Gammapyrone<smiles>CCOC(=O)CNC(=O)C1C(C(=O)OCC)=C(C)NC(C)=C1C(=O)OCC</smiles>

Tauropyrone

FIgURE 4: Derivatives of 1,4-dihydroisonicotinic acid (1,4-DHINA).

liposomes (Ondriaš et al. [187]). However, data obtained in some other experimental systems are conflicting.

In an in vitro model of sarcolemmal membrane lipid peroxidation, three calcium blockers (nifedipine, verapamil, and diltiazem) exhibited concentration-dependent $(10-400 \mu \mathrm{M})$ inhibitory effects $[188,189]$. Nifedipine, the most effective calcium blocker, was more than two-fold potent compared to propranolol, achieving significant effect at $10 \mu \mathrm{M}$. Nifedipine protective role on LP using reduced glutathione as model marker was recently described (Ray et al. [190]). Antiperoxidative properties of CA nifedipine and its analogues were explored in different systems/pathogenic processes: atherogenesis (Henry [165]), brain focal ischemia (Yamato et al. [191]), nephroprotection related to cyclosporine intake (Chander and Chopra [192]), and hepatoprotection related to intake of diethyldithiocarbamate (Gaafa et al. [193]). Recent data suggest that nifedipine action as protector for endothelial cells proceeds independently from its CA properties.

The absence of antioxidant effects of nifedipine and diltiazem on myocardial membrane lipid peroxidation, opposite to nisoldipine and propranolol, was also described [194]. Nisoldipine and propranolol were shown to have a concentration-dependent antiperoxidant effect, with $\mathrm{IC}_{50}$ values of 28.2 and $50.1 \mu \mathrm{M}$, respectively. Finally, nisoldipine appeared to possess dual antiperoxidant mechanisms, involving both preventive and chain-breaking properties.

These findings were confirmed in some other studies, including reports on the lack of antioxidative activity of nifedipine and nicardipine, even at $500 \mu \mathrm{M}$ concentration in heart membrane lipid peroxidation tests [134]. Similarly, ROS formation in bovine aorta smooth muscle cells was not affected by addition of amlodipine, nimodipine, and nifedipine [123].
(1) Metabolites of Nifedipine and Its Analogues as Antioxidants and Regulators of OS. Antioxidant activity of nifedipine, 3,5-dimethoxycarbonyl-2,6-dimethyl-4-(2-nitrophenyl)-1,4dihydropyridine, was originally studied in vitro by Kirule et al. [195] and Tirzit et al. [196]. According to the kinetic data of peroxide accumulation and the ESR spectra (inhibition of the autoxidation of methyl oleate in presence of nifedipine) $\mathrm{AO}$ action was exerted by the formation of nitroso analogue of the oxidized nifedipine, nitroso nifedipine: 2,6-dimethyl4-(2-nitrosophenyl)-3,5-pyridine dicarboxylate (NO-NIF). This nitroso aromatic derivative can form nitroxyl radicals exhibiting remarkable AOA in the presence of unsaturated fatty acids and lipids [196].

The primary species of free radicals that have been obtained and identified were ion radicals of the nitrophenyl type (Ogle et al. [76]). Such a mechanism coincides with mechanisms proposed afterwards by Núñez-Vergara et al. [96], López-Alarcón et al. [103], Valenzuela et al. [104], Fukuhara et al. [174], and Yáñez et al. [197].

There are also data showing that nitroso compounds may inhibit LP by direct radical trapping and subsequent formation of stable nitroxide radicals. It was further found that the reactivity between the synthesized 1,4-DHP derivatives with alkylperoxyl radicals involves electron transfer reactions. This is documented by the presence of pyridine as a final product of the reaction and complete oxidation of the nitroso group in the case of the nitrosoaryl 1,4-dihydropyridine derivatives (Valenzuela et al. [104]). Tested compounds reacted faster toward alkylperoxyl radicals and ABTS radical cation than alkyl ones (López-Alarcón et al. [103]).

Nitrosonifedipine, a photodegradation product of nifedipine, significantly recovers cellular damage induced by tumor necrosis factor-alpha. It also prevents toxic effects of cumene peroxide which hampers integrity of cell membranes through oxidative stress. Its positive effects are equal to Trolox-C. 
As a result, nitrosonifedipine was already a long time ago claimed as a candidate for a new class of antioxidative drugs (Kirule et al. [195]), cellular protectors against oxidative stress in glomerular endothelial cells [174].

Moreover, Misik et al. [198], Ondriaš et al. [199], and Staško et al. [200] studied AOA of nifedipine and its oxidized nitroso analogue. NO-NIF prevents the progression of type 2 diabetic nephropathy associated with endothelial dysfunction through selective AO effects (Ishizawa et al. [201]). NONIF administration reduces albuminuria and proteinuria as well as glomerular expansion without affecting glucose metabolism or systolic blood pressure. NO-NIF also suppresses renal and systemic OS and decreases the expression of intercellular adhesion molecule-1 (ICAM-1), a marker of endothelial cell injury, in the glomeruli of the KKAy mice. Similar effects were achieved in endothelial nitric oxide synthase (eNOS) knockout mice. Moreover, NO-NIF suppresses urinary angiotensinogen (AGT) excretion and intrarenal AGT protein expression in proximal tubular cells in the KKAy mice. On the other hand, hyperglycemia-induced mitochondrial superoxide production was not attenuated by NO-NIF in cultured endothelial cells.

Fujii and Berliner found EPR evidence for free radical adducts of nifedipine in vivo [202]. The nature of these radicals was surmised by comparing the reaction of illuminated nitrosonifedipine with polyunsaturated fatty acids. Surprisingly, identical radical spectra were detected from excised liver doped with nonilluminated nifedipine, suggesting that this drug can be enzymatically converted in vivo to its nitroso analogue without the requirement for illumination. This is one of the first reports of in vivo EPR evidence for a class of unsaturated fatty acid radical conjugates resulting from the normal metabolism of a common drug.

Díaz-Araya et al. [173] studied some 4-nitrophenyl-DHPs on $\mathrm{Fe}^{3+}$ initiated LP in rat brain slices. LP, as measured by MDA formation, was inhibited by all the tested nitroaryl derivatives of 1,4-DHP over a wide range of concentrations. On the basis of both time course and $\mathrm{IC}_{50}$ experiments the tentative order of AOA on rat brain slices was nicardipine $>$ nisoldipine $>$ (R,S/S,R)-furnidipine $>(\mathrm{R}, \mathrm{R} /$ $\mathrm{S}, \mathrm{S})$-furnidipine $>$ nitrendipine $>$ nimodipine $>$ nifedipine. 1,4-DHP derivatives that lack a nitro group in the molecule (isradipine and amlodipine) also inhibited LP in rat brain slices but at higher concentrations than that of nitrosubstituted derivatives. All tested compounds reduced and oxidized nitrosoaryl derivatives (2,6-dimethyl-4-(2-nitrosophenyl)-3,5-pyridinedicarboxylic acid dimethyl ester (photooxidation product of nifedipine - NTP) a.o.) and were more potent inhibitors of LP than their parent molecules (Valenzuela et al. [104]).

The electrooxidation process of 4-nitrosoaromatic DHPs is a strongly $\mathrm{pH}$-dependent (two-electron two-proton mechanism): ECEC type of mechanism, that is, the sequence: $e^{-} / \mathrm{H}^{+} / e^{-} / \mathrm{H}^{+}$at $\mathrm{pH}>8.5$; ECCE mechanism $\left(e^{-} / \mathrm{H}^{+} / \mathrm{H}^{+} / e^{-}\right)$ at $\mathrm{pH}<8.5$ dominates. Reduction reaction of nitroso group is as follows: $\mathrm{R}-\mathrm{NO}+2 e^{-}+2 \mathrm{H}^{+} \rightarrow \mathrm{RNHOH}$ (Bollo et al. [203]).
3.5.2. Lacidipine. It is a generic DHP type antihypertensive CA, 3,5-diethyl 4-\{2-[(1E)-3-(tert-butoxy)-3-oxoprop-1-en-1yl]phenyl -2,6-dimethyl-1,4-dihydropyridine-3,5-dicarboxylate.

Ursini [204] described redox behaviour of lacidipine and showed its tissue protective features. Cristofori et al. studied antiatherosclerotic activity, in addition to lacidipine's CA and AO properties [205]. Lacidipine reduced the extent of atherosclerotic area in hypercholesterolemic apoE-deficient mice (these mice show widespread vascular lesions which closely resemble the inflammatory fibrous plaques seen in humans in atherosclerosis). The reduction may be associated with the capacity of the drug to maintain endothelial NO levels at concentrations useful to protect against vascular damage. This work suggested that DHPs modulate vascular relaxation via increased release of NO.

Herbette et al. [178] remarked optimal hydrophobicity of lacidipine due to cinnamic acid substituent, so membrane interactions and facilitation of the treatment of atherosclerosis could proceed (see also Section 3.3.1 (2)-(a)).

3.5.3. Amlodipine. Amlodipine (Norvasc), (RS)-3-ethyl 5-methyl 2-[(2-aminoethoxy)methyl]-4-(2-chlorophenyl)6-methyl-1,4-dihydropyridine-3,5-dicarboxylate (AML), has an antioxidant effect on vessels in vitro and is a 3 rd generation of charged dihydropyridine CCB that is widely used for the treatment of hypertensive patients.

Amlodipine was shown to have the highest affinity (amlodipine $>$ verapamil $\gg$ diltiazem) for the membrane bilayer $\left(K_{p}=10^{4}\right)$. It produced the significant changes in membrane thermodynamic properties, including a reduction in the thermal phase transition temperature $(-11 \%)$, enthalpy $(-14 \%)$, and cooperative unit size $(-59 \%)$, relative to the control, phosphatidylcholine liposomes (Mason et al. [49]).

Amlodipine AOA is related to its reductant nature or hydrogen donor properties, respectively. Its ability for donating protons and electrons to the lipid peroxide molecules blocks the LP process.

Amlodipine and even its enantiomers (Zhang et al. [206]) act as ROS and NOS effectors in several model systems of OS. Antioxidant properties of amlodipine were recently reviewed by Vitolina et al. [32]. Both in vitro and in vivo studies of amlodipine AO properties revealed inhibition of lipids oxidative damage, primarily those associated with cellular membranes and lipoprotein particles (LDL) (Mason et al. [50]).

Under controlled experimental conditions in vitro amlodipine showed AOA and ARA, by inhibition of lipid peroxide formation and trapping ROS. Its scavenging activity for hydroxyl and peroxyl radicals at concentrations as low as $10.0 \mathrm{nmol} / \mathrm{L}$ (which is remarkably less compared to the classical antioxidants, GSH, uric acid, and Trolox) was shown to be independent of the calcium channel modulation (Franzoni et al. [207]).

AML showed efficiency as scavenger of peroxyl radicals (TOSC assay: $5945 \pm 544$ units/mg), significantly stronger $(>50 \%, P<0.001)$ than GSH $(2733 \pm 636$ units $/ \mathrm{mg})$ and $70 \%$ weaker $(P<0.0001)$ than uric acid $(18144 \pm 696$ units $/ \mathrm{mg})$ and Trolox (17522 \pm 734 units/mg). 
Of interest, the scavenging capacity of AML towards hydroxyl radicals (1455 \pm 154 units/mg) was $320 \%$ higher $(P<0.00001)$ than that of GSH $(358 \pm 112$ units $/ \mathrm{mg}), 20 \%$ higher than that of uric acid (1198 \pm 121 units/mg), and $100 \%$ higher than that of Trolox (759 \pm 143 units/mg).

Amlodipine was shown to increase enzyme activity of paraoxonase $(\mathrm{PON})$ and glutathione peroxidase (GSH-Px). However, it also decreases glutathione reductase (GSSG-R) activity and diminishes the concentration of the endogenous antioxidant $\alpha$-tocopherol (vitamin E). Moreover, AML in a concentration of $2 \mathrm{ng} / \mathrm{mL}$ decreased the content of malonic dialdehyde and activity of superoxide dismutase in the blood (Gatsura [208]).

Verapamil and amlodipine produced a potent antiischemic effect and reduced area of myocardial infarction in rats. The observed changes were accompanied by inhibition of LP. In contrast to verapamil, in vitro application of AML in a dose of $50 \mathrm{ng} / \mathrm{mL}$ decreased hemoglobin affinity for oxygen. When present in a concentration of $2 \mathrm{ng} / \mathrm{mL}$, AMD decreased the content of MDA and activity of SOD in the blood.

On the other hand, amlodipine shows no activity related to inhibition of macrophage superoxide release and cell migration, which occurs as a consequence of decreased TNF $\alpha$ induced $\mathrm{O}_{2}{ }^{\bullet}$ release.

Amlodipine-induced reduction of OS in the brain is associated with sympathoinhibitory effects in stroke-prone spontaneously hypertensive rats (SHRSP) (Hirooka et al. [209]). Antihypertensive treatment with amlodipine reduced OS in all examined areas of the brain and decreased blood pressure without a reflex increase in sympathetic nerve activity. Nicardipine, another CA DHP, surprisingly, was significantly less active than amlodipine.

3.5.4. Lercanidipine. Tomlinson and Benzie reported AO effect of lercanidipine [210], which is well known as antihypertensive drug Zanidip, 2[(3,3-diphenylpropyl)(methyl)amino]-1,1-dimethylethyl methyl 2,6-dimethyl-4-(3-nitrophenyl)-1,4-dihydropyridine-3,5-dicarboxylate. Comparative data about this drug AOA were presented in parts of this paper about other individual CA DHPs and in the part about the ex vivo DHPs effects on LDL.

3.5.5. Nimodipine. Nimodipine (ND), commercially known as Nimotop, is 3-(2-methoxyethyl) 5-propan-2-yl 2,6-dimethyl-4-(3-nitrophenyl)-1,4-dihydropyridine-3,5-dicarboxylate. It is centrally active CA.

Treatment with glutathione blocked and with nimodipine attenuated neuronal cell death, caused by prolonged exposure of cell culture to 4-HNE (Faraqui [211]).

Nascimento et al. [212] found AO effect of nimodipine in young rats after pilocarpine- (PIL-) induced (in $400 \mathrm{mg} / \mathrm{kg}$ ) seizures. The PIL administration increased the striatal catalase (CAT) activity. The administration of $\mathrm{ND}, 30 \mathrm{mg} / \mathrm{kg}$, 30 min before PIL, preserved normal value of CAT activity. On the other hand, no difference was detected in the animals treated with lower dose, $10 \mathrm{mg} / \mathrm{kg}$. These results confirm the neuroprotective/antiepileptic effect of ND in young rats, suggesting that this drug acts positively on lipid peroxidation (in both doses). Nimodipine cannot induce these effects via blockade of $\mathrm{Ca}^{2+}$ channel.

Ismailoglu et al. [213] studied the therapeutic effects of melatonin and nimodipine in rats after cerebral cortical injury. These beneficial effects in rats after cerebral cortical injury seemed to be related to AOA of nimodipine.

3.5.6. Benidipine. Licensed in Japan and South Asia as CA (CCB) benidipine possesses AO properties. Chemically, it is 5-methyl 3-[(3R)-1-(phenylmethyl)piperidin-3-yl] 2,6-dimethyl-4-(3-nitrophenyl)-1,4-dihydropyridine-3,5-dicarboxylate (or its hydrochloride, (4R)-rel-3,5-pyridinedicarboxylic acid, 1,4-dihydro-2,6-dimethyl-4-(3-nitrophenyl)-, 3-methyl 5-[(3R)-1-(phenylmethyl)-3-piperidinyl] ester, hydrochloride $(1: 1))$.

Benidipine influences processes connected with OS in several ways. It prevents lysophosphatidylcholine- (lysoPC)induced injury and ROS production in human aortic endothelial cells (HAECs) (Matsubara and Hasegawa [214]). Matsubara et al. [215] explained this effect, based on stimulation of nitric oxide release.

LysoPC is a component of oxidized low-density lipoproteins (oxLDLs), which plays an important role in the pathogenesis of atherosclerosis. Pretreatment with benidipine (0.3$3 \mu \mathrm{mol} / \mathrm{L}$ ) for $24 \mathrm{~h}$ protected against lysoPC-induced cytotoxicity in the HAECs through inhibition of both lysoPCstimulated ROS production and caspase-3/7-like activation, with a similar potency. Since caspase-3/7 is involved in executing the apoptotic process, the reduction of the activity of this enzyme by benidipine may explain the antiapoptotic effect of the drug. However, benidipine did not suppress lysoPC-induced phosphorylation of mitogen-activated protein kinases and $\mathrm{Ca}^{2+}$ influx in HAECs. These results suggest that the antioxidant properties of benidipine may be responsible for its ability to inhibit ROS production, a possible reason for reduced activation of caspase-3/7. In conclusion, benidipine suppresses lysoPC-induced endothelial dysfunction through inhibition of ROS production, which is due at least in part to its antioxidant effect, and not through the inhibition of L-type voltage-dependent calcium channels.

Matsubara and Hasegawa [216] examined the effects of benidipine on cytokine-induced expression of adhesion molecules and chemokines (chemoattractants), which are important for the adhesion of monocytes to endothelium. Pretreatment of HAECs with benidipine $(0.3-10 \mu \mathrm{mol} / \mathrm{L})$ for $24 \mathrm{~h}$ significantly suppressed cytokine-induced vascular cell adhesion molecule-1 (VCAM-1) and intracellular cell adhesion molecule-1 (ICAM-1) mRNA and protein expression, resulting in reduced adhesion of THP-1 monocytes. Benidipine also suppressed induction of monocyte chemoattractant protein-1 (MCP-1) and interleukin-8. Benidipine also inhibited redox-sensitive transcriptional nuclear factor$\kappa \mathrm{B}(\mathrm{NF}-\kappa \mathrm{B})$ pathway, as determined by Western blotting of inhibitory $\kappa \mathrm{B}(\mathrm{I} \kappa \mathrm{B})$ phosphorylation and luciferase reporter assay. Results of analysis using optical isomers of benidipine and antioxidants suggest that these inhibitory effects were dependent on pharmacological effects other than $\mathrm{Ca}^{2+}$ antagonism. Benidipine may thus have anti-inflammatory properties and benefits for the treatment of atherosclerosis. 
Benidipine was also shown to inhibit ROS production in polymorphonuclear leukocytes and oxidative stress in saltloaded stroke-prone spontaneously hypertensive rats (Matsubara et al. [217]).

It should be mentioned that other DHPs also have endothelial AO actions [218].

3.5.7. Azelnidipine (AZL). Azelnidipine, 3-[1-[di(phenyl)methyl]azetidin-3-yl] 5-propan-2-yl 2-amino-6-methyl4-(3-nitrophenyl)-1,4-dihydropyridine-3,5-dicarboxylate (AZL), CAS number: 123524-52-7, is commercially available 4-nitroaryl-DHP type calcium antagonist with long-acting antihypertensive action (long-acting CA (CCB)) and a low reported incidence of tachycardia. It additionally possesses beneficial effects in OS and diabetic conditions.

Azelnidipine prevents cardiac dysfunction in streptozotocin-diabetic rats by reducing intracellular calcium accumulation (altering intracellular $\mathrm{Ca}^{2+}$ handling proteins), OS, and apoptosis (Kain et al. [219]). AZL can reduce the superoxide production. It exerts its protective effects by targeting the NADPH oxidase and mitochondrial redox enzymes. AZLtreated diabetic rats express enhanced level of bcl-2 in the lysates of heart muscle indicating that AZL plays protective role in cardiac apoptosis.

It has been previously observed that azelnidipine inhibits tumor necrosis factor-alpha-induced endothelial cell (EC) oxidative stress through its $\mathrm{AO}$ properties (Nakamura et al. [220]). Azelnidipine, but not nitrendipine, completely inhibits the Ang II-induced ROS generation in ECs (Matsui et al. [221]).

Furthermore, azelnidipine, but not nitrendipine, was found to partially restore decreased pigment epitheliumderived factor (PEDF) mRNA levels in Ang II-exposed ECs. This study suggests that AZL influence depends on its antioxidative properties. Authors concluded that upregulation of PEDF by azelnidipine may become a therapeutic target for the treatment of diabetic retinopathy associated with hypertension.

Antihypertensive agents with $\mathrm{AO}$ effects are potentially useful for diabetic patients with hypertension. While DHP type CA are among the most frequently used antihypertensive drugs, azelnidipine has been reported to have a unique AO effect in vitro and in vivo, in experimental animals (Ohmura et al. [222]). In hypertensive diabetic patients, azelnidipine treatment for 12 weeks induced a more significant decrease in erythrocyte $\mathrm{LOOH}$ level than amlodipine, although the values related to blood pressure during each treatment remained comparable. These data confirm the usefulness of LOOH level in erythrocyte membrane as a marker of OS in vivo and indicate that azelnidipine has a unique antioxidative property in humans.

Daikuhara et al. [223] reported the results of the OLCA study, based on combination of (1) olmesartan and a calcium channel blocker (azelnidipine) or (2) candesartan and a CCB amlodipine in two groups of diabetic hypertensive patients. Patients treated with the first combination presented highly persistent early morning antihypertensive effect and stronger decrease in heart rate, fasting blood glucose and HbAlc levels, and microalbuminuria, when compared to patients treated with the combination (2). Because diabetes is associated with severe chronic OS the observed results might be at least in a part due to the AOA of azelnidipine.

In favor of this are findings of Abe et al. [224] who found additive antioxidative effects of azelnidipine on angiotensin receptor blocker olmesartan treatment for type 2 diabetic patients with albuminuria.

Similarly, the AOA of thiazolidinediones (insulin sensitizer) and their effect on cardiovascular function in type 2 diabetic model rats and also those of some DHPs (nifedipine, amlodipine, or AZL, commonly used antianginal and antihypertensive agents) in cultured human endothelial cells LP were examined (Mizushige [225]). The AOA was evaluated by measuring 8-iso-prostaglandine $\mathrm{F}_{2 \alpha}$ concentration and azelnidipine exhibited potent AOA.

Insulin (INS) resistance combined with hyperinsulinemia is involved in the generation of OS. A relationship exists between increased production of ROS and the diverse pathogenic mechanisms involved in diabetic vascular complications, including nephropathy. Manabe et al. [226] revealed that high doses of INS augmented mesangial cell proliferation through generation of intracellular ROS and activation of redox signaling pathways. Cell proliferation was increased in a dose-dependent manner by high doses of INS $(0.1-10 \mu \mathrm{M})$ but was inhibited by $0.1 \mu \mathrm{M}$ AZL. Namely, the INS-increased phosphorylation of mitogen activated protein kinase/extracellular signal-regulated kinase 1/2 (MAPK/ERK $1 / 2$ ) was inhibited by $0.1 \mu \mathrm{M}$ AZL. The same AZL concentration blocked intracellular ROS production more effectively than $0.1 \mu \mathrm{M}$ nifedipine. The NADPH oxidase inhibitor, apocynin (0.01-0.1 $\mu \mathrm{M})$, prevented INS-induced mesangial cell proliferation. So, azelnidipine inhibits insulin-induced mesangial cell proliferation by inhibiting the production of ROS. Therefore azelnidipine may have the potential to protect against the onset of diabetic nephropathy and slow its progression.

Azelnidipine inhibited $\mathrm{H}_{2} \mathrm{O}_{2}$-induced cell death in neonatal rat cardiomyocytes (Koyama et al. [227]). Azelnidipine and nifedipine did not affect the $\mathrm{H}_{2} \mathrm{O}_{2}$-induced activation of extracellular signal-regulated protein kinases (ERK) and p38 MAPK (mitogen-activated protein kinase). In contrast, azelnidipine, but not nifedipine, inhibited $\mathrm{H}_{2} \mathrm{O}_{2}$-induced cJun $\mathrm{NH}_{2}$-terminal kinases (JNK) activation. Authors concluded that azelnidipine has inhibited the $\mathrm{H}_{2} \mathrm{O}_{2}$-induced JNK activation and cardiac cell death. Therefore azelnidipine may have cardioprotective effects against OS.

A specific atheroprotection activity of azelnidipine relates to inhibition of TNF- $\alpha$-induced activator protein-1 activation and interleukin-8 expression in human umbilical vein endothelial cells (HUVEC), through suppression of NADPH oxidase-mediated reactive oxygen species generation (Nakamura et al. [220]). TNF- $\alpha$ could play a central role in pathogenesis of insulin resistance and accelerated atherosclerosis in the metabolic syndrome. The concentration of AZL found to be effective in these in vitro experiments is within therapeutic range. As EC do not possess voltage-operated L-type calcium channels, it is suggested that the beneficial effects of azelnidipine are not likely due to CA property but to its unique $\mathrm{AO}$ 
ability. Furthermore, it has been recently found that serum levels of monocyte chemoattractant protein-1, a biomarker for subclinical atherosclerosis, were significantly decreased by the AZL treatment in patients with essential hypertension. In this paper [220], authors hypothesize that, due to its unique TNF- $\alpha$ signal modulatory activity and antioxidative property, azelnidipine may be a promising DHP for targeting diabetes and cardiovascular diseases in hypertensive patients with metabolic syndrome.

Shinomiya et al. [228] evaluated its AOA in cultured human arterial EC, under OS. Azelnidipine has shown a potent antioxidative effect that could be of significant clinical benefit when combined with its long-lasting antihypertensive action and low incidence of tachycardia.

Azelnidipine inhibited TGF- $\beta 1$ and angiotensin II- (Ang II-) activated $\alpha 1(\mathrm{I})$ collagen mRNA expression in hepatic stellate cells (HSCs) (Ohyama et al. [229]). Furthermore, TGF- $\beta 1$ - and Ang II-induced OS and TGF- $\beta 1$-induced p38 and JNK phosphorylation were reduced in HSCs treated with AZL. Azelnidipine significantly decreased inflammatory cell infiltration, profibrotic genes expression, HSC activation, LP, oxidative DNA damage, and fibrosis in liver of $\mathrm{CCl}_{4}$ - or TAA-treated mice. Finally, AZL prevented decrease of the expression of some $\mathrm{AO}$ enzymes and accelerated regression of liver fibrosis in $\mathrm{CCl}_{4}$-treated mice. Hence, the antifibrotic mechanism of AZL against $\mathrm{CCl}_{4}$-induced liver fibrosis in mice may have been due to an increased level of AO defense. As azelnidipine is widely used in clinical practice without serious adverse effects, it may provide an effective new strategy for antifibrotic therapy.

3.5.8. Manidipine. Manidipine, (2-[4-(diphenylmethyl)piperazin-1-yl] ethyl methyl 2,6-dimethyl-4-(3-nitrophenyl)-1,4dihydropyridine-3,5-dicarboxylate), is a DHP CCB with reported nephroprotective properties. Calò et al. [230] studied effect of manidipine on gene expression and protein level of OS related proteins: p22(phox) (human neutrophil cytochrome b light chain (CYBA)) and heme oxygenase-1, HO-1. Relevance for antihypertensive effects was revealed. The study assessed the effect of manidipine on normal subjects' monocyte gene and protein expression of OS related proteins such as p22phox, a NADPH oxidase system subunit, critical in generating $\mathrm{O}_{2}{ }^{--}$, and $\mathrm{HO}-1$, induced by and protective against OS. Manidipine was compared with the ACE inhibitor captopril and the CCB nifedipine, in the presence and in the absence of sodium arsenite $\left(\mathrm{NaAsO}_{2}\right)$ as an inducer of OS. Monocyte p22phox (CYBA) mRNA production was reduced by both manidipine and captopril, while no changes were induced by nifedipine. Manidipine increased monocyte HO-1 mRNA production, while nifedipine and captopril showed no effect. The effects of manidipine on $\mathrm{p} 22$ phox and $\mathrm{HO}-1$ gene expression in the presence of OS were also confirmed at the protein level. Thus, manidipine seems to suppress $\mathrm{p} 22$ phox and to increase the HO-1 mRNA production and protein level. The manidipine-induced increase of HO-1 gene and protein expression seems to be a peculiar effect of this drug since it is not observed with captopril and nifedipine. This effect, together with the reduction of p22phox mRNA production, could play a role in its protective mechanism against OS.

3.5.9. Mebudipine. The protective effect of mebudipine $(1,4-$ dihydro-2,6-dimethyl-4-(3-nitrophenyl)-3,5-pyridinedicarboxylic acid 3-methyl-5-tert-butyl ester; BAY-n-6391) was revealed on OS and LP (MDA decrease, SOD, GPX, and catalase increase) in myocardial ischemic-reperfusion injury in male rats (Ghyasi et al. [231]).

There are articles about other commercial and experimental DHPs on OS, but we have reviewed only the most commonly studied compounds. Effects of other commercial CA DHPs on OS are also mentioned in several parts of this review.

3.6. 1,4-DHPs: Ca Agonists and Their AOA and ARA. For the most popular calcium agonist DHP Bay K 8644 no reaction with peroxyl radicals was registered (Toniolo et al. [114]). However, interaction with other compounds possessing AOA and ARA (quercetin) was found.

Opposite to that, AO N-acetylcysteine (NAC) diminished increase in $\mathrm{Ca}^{2+}$ transient amplitude and cell shortening induced by ISO and forskolin, whereas NAC had no effect on the (S)-(-)-methyl-1,4-dihydro-2,6-dimethyl-3-nitro-4(2-trifluoromethylphenyl)pyridine-5-carboxylate-(-)-Bay K 8644-induced increases (Andersson et al. [232]).

Increased vasoconstriction responses to Bay K 8644 ( $3 \times$ $10^{-7}-3 \times 10^{-5} \mathrm{M}$ ) were significantly decreased by pyridoindole antioxidant stobadine treatment in diabetes (Ceylan-Isik et al. [233]).

The functional interaction between two L-type $\mathrm{Ca}^{2+}$ channel activators, quercetin and Bay $\mathrm{K}$ 8644, has been investigated in vascular smooth muscle cells. Biological ARA compound quercetin at nutritionally meaningful concentrations limited the responsiveness of vascular L-type $\mathrm{Ca}^{2+}$ channels to the pharmacological stimulation operated by Bay $\mathrm{K} 8644$. These data contribute to a better understanding of quercetin effects on experimental in vivo cardioprotection (Saponara et al. [234]). Thus, these findings indicated that although Bay K 8644 does not exert potent and direct AOA, yet acting as calcium agonist it may affect efficiency of $\mathrm{AO}$ substances and vice versa.

Interaction of grapefruit juice (containing quercetin and its analogues) with DHPs CA diminished effectiveness of CA action of DHPs (Sica [235]).

\subsection{Interpretations of the Mechanism(s) of Radical Scavenging and AOA by DHPs}

3.7.1. Molecular Mechanism(s) of Radical Scavenging and AOA of DHPs in the Model Systems. 3,5-Dicarbonyl-1,4-dihydropyridine derivatives possess powerful bis- $\beta$-carbonylvinyl-amino conjugation and for that reason cannot be considered as ordinary amino antioxidants. The electron and/or $\mathrm{H}$ donation from DHPs ensures their reductant role and results in AOA and ARA. Oxidation reaction from DHPs results in production of corresponding heteroaromatic pyridine derivatives. 
Detailed studies were made about substituent in DHP ring positions: 1,4-, namely, 4-unsubstituted-; 4-substituted: 4-alkyl-; 4-aryl-; 4-alkylaryl- a.o.; 2,6-; 3,5- (diacetyl or dialkoxycarbonyl chain a.o.) electronic and steric effects on AOA and ARA of DHPs [44, 45, 51], see Sections 3.3.1 and 3.5. The bell-shaped dependence of DHPs AOA on the 3,5-dialkoxycarbonyl- chain length was observed [44, $45,107,109,112]$, with the maximum activity at $\mathrm{C}_{2} \mathrm{H}_{5}$ $\mathrm{C}_{4} \mathrm{H}_{9}$. Decrease of $\mathrm{AOA}$ and incorporation into liposomes for DHPs with alkyl chains longer than $\mathrm{R}>\mathrm{C}_{4} \mathrm{H}_{9}$ further were clarified as probable tendency to self-aggregation of these compounds ([51] and citation number 245 therein). Electron acceptor/electron donor properties are relevant for expression of AOA or ARA of 3,5-disubstituted DHPs. 3,5-Diacylsubstituted and 3,5-dicarbanilido- and 3,5-dipyridylamidosubstituted DHPs are more active as AOs as their 3,5dicyano-substituted analogues, which have electron acceptor properties [186].

Dubur et al. [89] observed overwhelming steric influence of substituents in position 4 of the DHP ring. Gaviraghi et al. $[163,164]$ proposed that AO activity of DHPs is partly dependent on capacity of the 1,4-DHP ring to donate electrons to the propagating radical $\left(\mathrm{ROO}^{\circ}\right.$ or $\left.\mathrm{RO}^{\circ}\right)$ and to reduce it to a less reactive form. The abstraction (donation) of electron and/or $\mathrm{H}$ in the oxidation and LP reactions takes place from all 3,5-dicarbonyl-1,4-DHP systems and results in the formation of corresponding pyridine derivatives (Augustyniak et al. [51]). The physicochemical mechanism of ARA and AOA of 1,4-DHP has been extensively studied and discussed (Mulder et al. [236]), but precise mechanisms of their activity need further clarification.

The reactivity of C-4 substituted 1,4-DHPs possessing either secondary or tertiary nitrogen atom in the DHP ring toward alkyl, alkylperoxyl radicals, and ABTS radical cation was determined in aqueous media at pH 7.4 [103]. These compounds reacted faster toward alkylperoxyl radicals and ABTS radical cation than alkyl ones. N-Ethyl-substituted DHPs showed the lowest reactivity.

The 4-methyl substituted DHP was the most reactive compound in previously mentioned reactions (LópezAlarcón et al. [103]). However, it was less active (0.68 versus 1.0) than Trolox-C. DHPs having electron-donating substituents (4-Me-DHP and $p-\mathrm{MeO}-\mathrm{Phe}-\mathrm{DHP}$ ) showed the highest kinetic rate constants toward ABTS radical cation; $p$ nitro-Phe-DHP, a compound with an electron-withdrawing substituent, showed a lower kinetic rate constant; and Nalkyl-DHP compounds show kinetic rate constants lower than the -NH-DHP.

Hydrogen at the 1-position of the DHP ring was revealed, according to the deuterium kinetic isotope effect studies, to be involved in the proposed ARA mechanism. This fact is mostly noticeable in the case of alkyl radicals. N-Ethyl-substituted DHPs show the lowest reactivity when compared to Trolox or nisoldipine. In all cases, the respective pyridine derivative was detected as the main product of the reaction (LópezAlarcón et al. [103]). Authors indicate that the kinetic rate constants toward alkyl, alkylperoxyl, and ABTS radical cation depend on the nature of the substituents in the C-4 position of DHP and the presence of the secondary amine group in the dihydropyridine ring, that is, the presence of the hydrogen in 1-position.

Yáñez et al. [197] have studied the reactivity of 11 derivatives of 1,4-DHPs (including commercial CA) with alkylperoxyl radicals and ABTS radical cation. The tested 1,4-DHPs were 8.3-fold more reactive towards alkylperoxyl radicals than to the ABTS cation radical. All commercial 1,4-DHP type CCBs were weaker than Trolox-C. The participation of the hydrogen atom in the 1-position appears to be very relevant for exhibited reactivity. Hantzsch ester (diludine) was again found to be the most active compound in the reaction with alkylperoxyl radicals, 2.3-fold more active than Trolox. The photodegradation product of nifedipine (nitrosophenyl derivative of pyridine) also showed a high activity. Kinetic rate constants for the reaction between 1,4DHP compounds and alkylperoxyl radicals exhibited a fairly good linear correlation with the oxidation peak potential of DHP derivatives. However, the activity of tested 1,4DHPs towards ABTS radical cation showed an independence between kinetic rate constants and oxidation peak potentials.

Kirule et al. [195] and Tirzit et al. [196] studied mechanism of AOA of 4-nitrophenyl-1,4-DHPs, nifedipine and its analogues, involving formation of 4 - $\left(2^{\prime}\right.$-nitrosophenyl)-pyridine derivative (as active principle) as a result of intramolecular redox reaction, using chemical, electrochemical, and biochemical approaches (see Sections 3.3.1 and 3.5.1).

Núñez-Vergara et al. [237] reported the electrochemical oxidation of C4-hydroxyphenyl-substituted 1,4-DHP derivatives. The oxidation proceeds via formation of the unstable dihydropyridyl radical, as confirmed by controlled-potential electrolysis (CPE) and ESR experiments. This type of 1,4DHPs has significant activity towards the radicals even when compared with commercial 1,4-DHP drugs with well-known antioxidant ability.

It was observed that nicardipine preferentially targets $\mathrm{RO}^{\circ}$ radicals and is inactive against ROO'. Lacidipine, on the other hand, is equally active towards both types of radicals (Gaviraghi et al. [164]). The cytoprotective effect against exposure to $\mathrm{H}_{2} \mathrm{O}_{2}$ was more significant for lacidipine $\left(\mathrm{ID}_{50}=\right.$ $14 \mathrm{nM}$, its $\log P=5.4$, membrane partition $=136000$, assumes position located $7 \AA$ near to the membrane center; other less lipophilic DHPs located $12-16 \AA$ far from the center) as compared to amlodipine, nifedipine, and nicardipine, in smooth muscle cell culture (Gaviraghi et al. [164]). Oxidative effect of $\mathrm{H}_{2} \mathrm{O}_{2}$ shifts the Ca channel toward an open state. Thus, the redox property of CCBs DHPs may augment their CCB properties.

Oxidation of pharmacologically active Hantzsch 1,4dihydropyridines was found by electrogenerated superoxide, using a voltammetric approach in DMSO solutions (Ortiz et al. [238] and Ortiz et al. [239]). Raghuvanshi and Singh [240] have also reported oxidative aromatization of these DHPs, induced by superoxide.

Chemiluminescence (CL) was used in the studies analyzing the antioxidant activity of 12 various 4 -flavonil-1,4dihydropyridine derivatives (Kruk et al. [241]) on a chemical system involving a superoxide radical anion. These derivatives showed structural similarity to flavonoids, with respect to the presence of rings $\mathrm{A}, \mathrm{B}$, and $\mathrm{C}$. The results obtained in 
this study indicate that the tested derivatives may catalyze conversion of superoxide radicals, through mimicking the activity of superoxide dismutase by delivering $\mathrm{H}^{+}$for reaction:

$$
\mathrm{O}_{2}{ }^{-\bullet}+\mathrm{O}_{2}{ }^{-\bullet}+2 \mathrm{H}^{+} \longrightarrow \mathrm{H}_{2} \mathrm{O}_{2}+{ }^{1} \mathrm{O}_{2}
$$

The enhanced emission of the light in the presence of tested compounds was significant and related to stimulated production of $\mathrm{H}_{2} \mathrm{O}_{2}$ and ${ }^{1} \mathrm{O}_{2}$ from $\mathrm{O}_{2} \cdot$. The latter species were removed from the reaction mixture by the following sequence of reactions:

$$
\begin{gathered}
\mathrm{O}_{2}{ }^{-\cdot} \longrightarrow \mathrm{HO}_{2}{ }^{+} \\
\mathrm{HO}_{2}{ }^{\cdot}+\mathrm{O}_{2}{ }^{--} \longrightarrow \mathrm{HO}_{2}{ }^{-}+{ }^{1} \mathrm{O}_{2} \\
2 \mathrm{HO}_{2}{ }^{\bullet} \longrightarrow \mathrm{H}_{2} \mathrm{O}_{2}+{ }^{1} \mathrm{O}_{2} \\
2\left({ }^{1} \mathrm{O}_{2}\right) \longrightarrow\left(\mathrm{O}_{2}\right)_{2}+\mathrm{h}^{*}
\end{gathered}
$$

or to take part in spontaneous dismutation of $\mathrm{H}_{2} \mathrm{O}_{2}$ :

$$
2 \mathrm{H}_{2} \mathrm{O}_{2} \longrightarrow 2 \mathrm{H}_{2} \mathrm{O}+{ }^{1} \mathrm{O}_{2}
$$

The authors have offered an original concept of action for 4flavonil-1,4-dihydropyridine derivatives unrelated to that of $\mathrm{O}_{2}{ }^{\bullet}$ radical-trapping, chain-breaking antioxidants. Instead, they showed that these compounds act similar to superoxide dismutases, converting $\mathrm{O}_{2}{ }^{*}$ to $\mathrm{H}_{2} \mathrm{O}_{2}$. Hydrogen peroxide is less toxic for cells than $\mathrm{O}_{2}{ }^{*}$ because it is predominantly removed by peroxidases and catalases. Finally, AO effect of these DHPs differed from those mediated by flavonoids with a catechol structure of ring $\mathrm{B}$, which are well-known ${ }^{1} \mathrm{O}_{2}$ quenchers.

Mulder and collaborators came to similar conclusions, especially related to molecular mechanisms of antioxidative activity of DHPs [236]. The AO properties of Hantzsch 1,4-dihydropyridine esters and two dibenzo-1,4-dihydropyridines, 9,10-dihydroacridine (DHAC) and N-methyl-9,10-dihydroacridine (N-Me-DHAC), have been explored by determining the autoxidation of styrene or cumene at $30^{\circ} \mathrm{C}$. These experiments showed that Hantzsch esters are virtually inactive as chain-breaking antioxidants (CB-AOs), contrary to the findings observed by López-Alarcón et al. [103] who used CB-AOA in aqueous media at $\mathrm{pH}$ 7.4. Their reactivity toward peroxyl radicals was shown to be some 5 orders of magnitude lower than that of the excellent CB-AO, 2,2,5,7,8pentamethyl-6-hydroxy-chroman (PMHC).

DHAC was found to be $\sim 10$ times less reactive than PMHC kinetic measurements using DHAC, N-deuterioDHAC, and N-Me-DHAC, pointing out the abstraction of $\mathrm{N}-\mathrm{H}$ hydrogen in DHAC by peroxyl radicals, despite the fact that the calculated $\mathrm{C}-\mathrm{H}$ bond dissociation enthalpy (BDE) in $\mathrm{DHAC}$ is about $11 \mathrm{kcal} / \mathrm{mol}$ lower than the $\mathrm{N}-\mathrm{H}$ BDE. The rates of hydrogen atom abstraction by the 2,2-diphenyl-1picrylhydrazyl radical $\left(\mathrm{DPPH}^{\bullet}\right)$ have also been determined for the same series of compounds. The trends in the peroxyl ${ }^{\circ}$ and $\mathrm{DPPH}^{\bullet}$ rate constants were found to be similar [236].

Tirzit et al. [242] have observed quenching of singlet oxygen by DHPs. This observation paved the ground for further research related to reactions of DHPs with hydroxyl radicals (Tirzit et al. [243]), singlet oxygen (Kazush et al. [94]), and mechanisms of action. A series of 1,4-DHP derivatives in NAD-H-Cu ${ }^{2+}-\mathrm{H}_{2} \mathrm{O}_{2}$ system inhibited forming of the hydroxyl radical $\left(\mathrm{HO}^{\circ}\right)$, while 1,4 -DHP derivatives with electron donor substituents in the molecule were shown to be capable themselves of generating $\mathrm{HO}^{\circ}$ in the presence of $\mathrm{Cu}^{2+}$ and $\mathrm{H}_{2} \mathrm{O}_{2}$. Rubene et al. [186] also described interaction of 1,4-DHP derivatives with Fenton's reagent, which produces hydroxyl radical $\left(\mathrm{HO}^{\circ}\right)$. Rate constants of the DHPs reaction (1st order) with $\mathrm{HO}^{\circ}$ radical were high: in the range $10^{9} \mathrm{~L} \times \mathrm{mol} \times \mathrm{sec}^{-1}$, close to that of $\mathrm{NADH}$, cysteine and thiourea. 3,5-Diacetyl- derivatives reacted faster compared to 3,5-dialkoxycarbonyl- ones. The reaction rate decrease was observed in the case of substitution at position 4 as compared to 4 -unsubstituted DHPs. Some DHPs having electron donor $-\mathrm{COO}^{-}$groups in the 3,5- or 2,6- positions of DHP ring reacted immediately (having rate constants higher as $10^{9} \mathrm{~L} \times \mathrm{mol} \times \sec ^{-1}$ ). Rate constants with $\mathrm{HO}_{2}{ }^{*}$ and $\mathrm{O}_{2}{ }^{--}$radicals were of lower degree. Thus DHPs acting as oxygen radical scavengers could effectively inhibit ROS related reactions of LP initiation stage.

Nifedipine and nitrendipine reactivity toward singlet oxygen was also studied [244]. Nifedipine was shown to be a good scavenger of excited oxygen, mainly via physical deactivation with values of the total rate constant ranging from $20.8 \times 10^{5} \mathrm{M}^{-1} \mathrm{~s}^{-1}$ (in dioxane) to $93.0 \times 10^{5} \mathrm{M}^{-1} \mathrm{~s}^{-1}$ (in propylene carbonate). The less reactive pathway generated a photooxidation product. For that reason, a mechanism involving a perepoxide-like encounter complex in the first step of the reaction path was proposed (see [244], Figures 8 and 9 therein). The dependence was observed on solvent microscopic parameters of the total rate constant for the reaction between singlet oxygen and 1,4-DHPs. These findings show that nifedipine possesses stronger protective activity in biological systems than nitrendipine.

Density-functional-theory (DFT) calculations made by Wang et al. [245] confirmed the former experimental observations that Hantzsch ester, diludine, is potent antioxidant with high $\mathrm{H}$ atom-donating ability and relatively low prooxidant activity. Possible reaction pathways for radicals derived from 1,4-dihydropyridine and the resonance modes for radical species were given [245].

Moreover, two ethoxycarbonyl (EtOCO) substituents at $\mathrm{C}(2)$ and $\mathrm{C}(6)$ should further enhance Hantzsch ester, diludine $\mathrm{H}$-atom-donating ability due to resonance effects. However, DHPs should be used in nonpolar rather than in polar solvents since, in the latter, not $\mathrm{H}$-atom but electron transfer is preferred in the radical scavenging process [245].

Mulder et al. [246] proposed that quantum-thermochemical calculations must be used with caution to indicate "a promising lead antioxidant," as they criticized the densityfunctional-theory (DFT) calculations made by Wang et al. [245]. 
3.7.2. Possible Mechanisms of DHPs ARA and AOA in the Biological Systems: Interaction with Other OS Modifiers. Some of these mechanisms were already described (Sections 3.3.1 (2)(b); 3.3.1 (2)-(c); 3.3.1 (3)-(b); 3.5).

Enzymatic sources of ROS with confirmed functional role in hypertension are NADPH oxidase, NO synthase (NOS), xanthine oxidase, and cyclooxygenase. Godfraind [3] has reviewed $\mathrm{AO}$ effects and protective action of calcium channel blockers (CCBs). Yao et al. [247] observed antioxidant effects (as inhibition of LP) for cardio- and neuroprotective CCBs (3-300 $\mu \mathrm{mol} / \mathrm{L}$ ), including $7 \mathrm{DHPs}$, in homogenates of rat brain. $\mathrm{IC}_{50}$ values $(\mu \mathrm{M})$ were as follows: nifedipine (51.5) > barnidipine (58.6) $>$ benidipine (71.2) $>$ nicardipine (129.3) $>$ amlodipine (135.5) > nilvadipine (167.3) > nitrendipine $(252.1)>$ diltiazem $(>300)=$ verapamil $(>300)$. There are also research articles describing the $\mathrm{AO}$ properties of CCBs through direct scavenging effect or through preservation of the endogenous SOD activity. These findings indicate that CCBs may also act by reducing the production of vasoconstrictors, angiotensin, and endothelin.

When present in concentrations that can be achieved in plasma, CCBs may inhibit LP formation [3]. This AO activity seems to be typical for high lipophilic CCBs because their chemical structure facilitates proton-donating and resonance-stabilization mechanisms that quench the free radical reaction. Their insertion in the membrane, near polyunsaturated fatty acids at relatively high concentrations, potentiates proton donation (or atomary $\mathrm{H}$ ) to lipid peroxide molecules, thereby blocking the peroxidation process. The remaining unpaired free electron associated with the $\mathrm{CCB}$ molecule can be stabilized in well-defined resonance structures associated with the DHP ring (Mason et al. [48]).

The radical reaction (according to Godfraind [3]) that describes the AO effects of a DHP CCBs is $\mathrm{LOO}^{*}+$ DHP $\rightarrow \mathrm{LOOH}+\mathrm{DHP}^{*}$ (where $\mathrm{LOO}^{*}$ is lipid peroxide radical), which in general is reaction (7) of the LP reaction cascade consisting of $\sim 10$ reactions (Scheme 2) [89].

As the rate constants of in vitro interaction of 4substituted DHPs with peroxyl radicals are three orders of magnitude lower than that of the vitamin $\mathrm{E}$ derivative, these DHPs must be considered as weak AO (Ursini [204]). However, due to partition coefficient of DHPs in membranes and in case of specific binding, high local concentration of DHPs may be obtained.

DHPs without CCB properties, for instance Bay w 9798, although structurally related to nifedipine, inhibit TNF$\alpha$-induced vascular cell adhesion molecule- 1 expression in endothelial cells by suppressing reactive oxygen species generation [248].

Mitrega et al. [249] have discovered that antiarrhythmic and hemodynamic effects of oxidized heteroaromatic DHPs, oxy nifedipine, oxy nimodipine, oxy nitrendipine, and oxy nisoldipine, suggest that CCB DHPs and their metabolites could act at least in two ways: targeting OS related events as reductants (see Section 3.5.1 (1)) and/or bypassing OS related metabolic routes. Authors postulated that, contrary to current belief, NIF metabolites are pharmacologically active. ATP sensitive potassium channels were mentioned as a target.
3.8. DHPs: Anti- or Prooxidants? Several substances (ascorbic acid being the most commonly studied) can serve either as antioxidants or as prooxidants, depending on given conditions (Herbert [250]). Therefore, Halliwell [251] has reported dilemma related to polyphenols as possible antioxidants and prooxidants, causing experimental artifacts (about 25) by oxidation of antioxidant compounds in the cell culture media. Nevertheless, it is generally accepted opinion that polyphenols act as antioxidants in vivo. Studies on DHPs also face such a dilemma. The exact roles (anti- or prooxidative) of any specific DHP depend on its structure, applied/achieved concentration, and specificity of the target/experimental testing system.

This situation resembles the case of antioxidative effects of tocopherol, which depends on the fate of the secondary radical as proposed by Winterbourn [252]. The question was "Vitamin E - Pro- or Antioxidant?":

Antioxidant:

$$
\begin{aligned}
& \mathrm{LOO}^{\bullet}+\mathrm{Toc} \\
& \longrightarrow \text { LOOH }+\mathrm{Toc}^{\cdot}\left(\mathrm{Toc}^{\bullet}=\alpha \text {-tocopheryl radical }\right) \\
& \mathrm{Toc}^{\bullet}+\mathrm{LOO}^{\bullet} \\
& \longrightarrow \text { chain termination of lipid peroxidation }
\end{aligned}
$$

Prooxidant:

$$
\text { Toc }^{\bullet}+\text { Lipid-H } \longrightarrow \text { Lipid }^{\bullet} \text { (in LDL particles) }
$$

This example shows that, generally speaking, any $\mathrm{AO}$ must fulfil several criteria to be considered as an effective compound physiologically:

(i) It must be able to functionally interact with endogenous scavengers, even at low concentrations.

(ii) It must affect endogenous pathways of OS.

(iii) It should not have undesirable adverse effect.

(iv) It should manifest the antioxidant efficacy dependent on the oxidant.

(v) It must discriminate among different strategies needed for 1-electron and 2-electron processes.

(vi) Radical scavengers can be prooxidant unless linked to a radical sink (Winterbourn [252]).

According to these statements, DHPs could be effective as AO under physiological conditions in vivo (Godfraind [3] and others $[30,31,38])$ and in vitro in various experimental systems (cell and tissue) (see Sections $3.3 ; 3.4 ; 3.5$ ).

Hence, calcium antagonists appeared to disrupt the fine balance between the production and scavenging of ROS. Nifedipine, verapamil, and diltiazem were shown to induce significant oxidative stress in the epididymal sperm (increased MDA and decreased catalase and superoxide dismutase activity). This may be the reason for the induction of male infertility [253].

The dualism of 1,4-DHP effects has been recorded as inhibition or promotion of LP, as quenching or initiating 
oxygen and nitrogen free radical chain reactions, radioprotecting or radiosensitizing, antagonizing or synergizing $\mathrm{Ca}^{2+}$ in electromechanical coupling, as well as in the membrane stabilization or labilization.

3.9. Could DHPs Be Involved in Antioxidative Stress? Before being applied in vivo, the optimal dose and optimal time intervals for DHPs application must be known. Namely, while ROS have been traditionally considered as toxic byproducts of aerobic metabolism, we know nowadays that ROS may act as essential signaling molecules, needed for the control of many different physiological processes. Whether the role of ROS will be damaging, protective, or signaling depends on the delicate equilibrium between time- and location-specific ROS production and scavenging. Accordingly, the imbalance of the increased $\mathrm{AO}$ potential, so-called antioxidative stress, could be dangerous similar to chronic OS, in particular in case of extended exposure. Inappropriate interventions in the oxidative homeostasis by excessive antioxidants especially in case of chronic exposure to antioxidants might have very negative effects as was published in the ATBC study, showing an increased cancer incidence in smokers treated by excessive beta-carotene [254]. Therefore, overconsumption of any natural or synthetic AO, including DHPs, as dietary supplements or drugs, must be avoided in order to suppress oxidative damage and must not disrupt the wellintegrated antioxidant defense network (Poljsak [255] and Poljsak and Milisav [256]). This is especially important when administrating lipid-soluble antioxidants that can be stored in biomembranes, thus not only attenuating or preventing LP but also affecting physiological effects of the natural antioxidants, in particular tocopherol. The interrelationship with the status of endogenous antioxidants/prooxidants should be followed.

DHPs primarily suppress the initiation stages of LP process. They do not entirely stop the LP propagation. Acting synergistically with tocopherol, diludine may prevent pathological excess of ROS production within the lipid moiety of the cellular membranes and LDL. However, due to its low solubility and fast metabolism, its concentration in the cells is low. For that reason, it cannot cause antioxidative stress, even if used for an extended period of time. Thus diludine (diethone) could be only a mild antioxidant; it has potential for restoring the pool of natural antioxidants (as synergist of $\alpha$-tocopherol and polyphenols) in the cells.

Moreover, DHPs CA used for cardioprotection and vasodilatation as commercial drugs in low concentrations are fast metabolized via CYP3A4, and for that reason their application does not induce cellular AO stress [53, 160]. However Godfraind and Salomone [257] have postulated no evidence that allows recommending dietary supplementation with antioxidants for the primary or secondary prevention of cardiovascular disease.

So far, there are no reports on antioxidative stress caused by some DHPs, diludine and its analogues. Diludine and its analogues therefore could act as adaptogens supporting hormetic effects of mild oxidative stress. These compounds may act as potential multisided modulators of Yin-Yang cycles of redox and cell functions (the electroplasmic cycle) (Wagner et al. [258]).

\section{Conclusions}

1,4-Dihydropyridines (1,4-DHPs) have broad spectrum of OS modulating activities. DHPs have reducing and lipid peroxidation inhibitor properties, act as reductants in simple chemical systems, and stabilize various biological systems (LDL, mitochondria, microsomes, cells, and tissues) against OS. Examples and peculiarities and mechanisms of antioxidant activity (AOA) and antiradical activity (ARA) as well as stress-protective effect of DHPs including commercial calcium antagonists (CA) were highlighted. These activities depend on various structural parameters related to DHPs (presence and character of substituents), lipophilicity, and depth of the incorporation in the biological membranes. They also depend on the experimental model system for exploring the lipid peroxidation or oxidative stress. Stress-protective effect of some metabolites of CA (nifedipine) is reviewed. Although some DHPs, including CA, have prooxidant properties (on epididymal sperm cells), they can generally be considered as potent antioxidants. Therefore, comparison of the AOA and ARA of different DHPs (mutually and with other AOs) was described in detail. According to the data presented, the DHPs might be considered as bellwether among synthetic compounds targeting OS and as a kind of pharmacological measure for respective field of organic and medicinal chemistry.

\section{Abbreviations}

$\begin{array}{ll}\text { AD: } & \text { Alzheimer disease } \\ \text { AO(s): } & \text { Antioxidant(s) } \\ \text { AOA: } & \text { Antioxidant activity } \\ \text { ARA: } & \text { Antiradical activity } \\ \text { CA: } & \text { Calcium antagonist(s) } \\ \text { CCB: } & \text { Calcium channel blocker } \\ \text { DHP(s): } & \text { Dihydropyridine(s) } \\ \text { DNA: } & \text { Deoxyribonucleic acid } \\ \text { HEH: } & \text { Hantzsch ester } \\ \text { 4-HNE: } & \text { 4-Hydroxy-2-nonenal } \\ \text { IMAC: } & \text { Inner membrane anion channel } \\ \text { Lox: } & \text { Lipoxygenase } \\ \text { LP: } & \text { Lipid peroxidation } \\ \text { MDA: } & \text { Malonyl dialdehyde } \\ \text { Mit: } & \text { Mitochondria } \\ \text { NADH: } & \text { Reduced nicotinamide adenine } \\ & \text { dinucleotide } \\ \text { NADPH: } & \text { Reduced nicotinamide adenine } \\ & \text { dinucleotide phosphate } \\ \text { NO: } & \text { Nitrogen oxide } \\ \text { OS: } & \text { Oxidative stress } \\ \text { PD: } & \text { Parkinson's disease } \\ \text { RNS: } & \text { Reactive nitrogen species } \\ \text { ROS: } & \text { Reactive oxygen species } \\ \text { SOD: } & \text { Superoxide dismutase } \\ \text { TBARS: } & \text { Thiobarbituricacid reactive substan }\end{array}$

TBARS: Thiobarbituric acid reactive substances

TG: Triglycerides. 


\section{Conflict of Interests}

The authors declare that there is no conflict of interests regarding the publication of this paper.

\section{Acknowledgments}

Authors from Latvian IOS acknowledge ESF 2013/0002/1DP/ 1.1.1.2.0/13/APIA/VIAA/011 and National Research Programme PUBLIC HEALTH/Biomedicine of the Republic of Latvia for financial support, administration of the Institute for technical support, and Rufus Smits, Ph.D., for consultations in English. The support of Cooperation in European System of Science and Technology (COST) Domain of Chemistry, Molecular Sciences and Technologies (CMST) was of highest importance for preparation of this paper.

\section{References}

[1] Database, SciFinder.com, keyword: 1,4-Dihydropyridines, https://scifinder.cas.org/, http://www.cas.org/products/scifinder.

[2] D. J. Triggle, "1,4-Dihydropyridines as calcium channel ligands and privileged structures," Cellular and Molecular Neurobiology, vol. 23, no. 3, pp. 293-303, 2003.

[3] T. Godfraind, "Antioxidant effects and the therapeutic mode of action of calcium channel blockers in hypertension and atherosclerosis," Philosophical Transactions of the Royal Society B: Biological Sciences, vol. 360, no. 1464, pp. 2259-2272, 2005.

[4] E. Cadenas, "Mitochondrial free radical production and cell signaling," Molecular Aspects of Medicine, vol. 25, no. 1-2, pp. 1726, 2004.

[5] E. Cadenas, "Free radicals, oxidative stress, and diseases," in Lecture, PSC 616, p. 38, Missouri University of Science and Technology, Rolla, Mo, USA, http://www.carnicominstitute .org/articles/enrique_cadenas.pdf.

[6] K. Rahman, "Studies on free radicals, antioxidants, and co-factors," Clinical Interventions in Aging, vol. 2, no. 2, pp. 219-236, 2007.

[7] V. Bocci and G. Valacchi, "Free radicals and antioxidants: how to reestablish redox homeostasis in chronic diseases?" Current Medicinal Chemistry, vol. 20, no. 27, pp. 3397-3415, 2013.

[8] M. Valko, C. J. Rhodes, J. Moncol, M. Izakovic, and M. Mazur, "Free radicals, metals and antioxidants in oxidative stressinduced cancer," Chemico-Biological Interactions, vol. 160, no. 1, pp. 1-40, 2006.

[9] G. Bartosz, "Reactive oxygen species: destroyers or messengers?” Biochemical Pharmacology, vol. 77, no. 8, pp. 1303-1315, 2009.

[10] R. Visconti and D. Grieco, "New insights on oxidative stress in cancer," Current Opinion in Drug Discovery and Development, vol. 12, no. 2, pp. 240-245, 2009.

[11] R. N. Kujundžić, N. Žarković, and K. G. Trošelj, "Pyridine nucleotides in regulation of cell death and survival by redox and non-redox reactions," Critical Reviews in Eukaryotic Gene Expression, vol. 24, no. 4, pp. 287-309, 2014.

[12] B. Halliwell and J. M. C. Gutteridge, "The definition and measurement of antioxidants in biological systems," Free Radical Biology and Medicine, vol. 18, no. 1, pp. 125-126, 1995.

[13] V. D. Kancheva and O. T. Kasaikina, "Bio-antioxidants-a chemical base of their antioxidant activity and beneficial effect on human health," Current Medicinal Chemistry, vol. 20, no. 37, pp. 4784-4805, 2013.

[14] H. V. Panglossi, Ed., Frontiers in Antioxidants Research, Nova Science Publishers, New York, NY, USA, 2006.

[15] E. B. Burlakova, E. M. Molochkina, and G. A. Nikiforov, "Hybrid antioxidants," Oxidation Communications, vol. 31, no. 4, pp. 739-757, 2008, http://membrane.ustc.edu.cn/paper/pdf/ Hybrid\%20Antioxidants.pdf.

[16] A. Bast and G. R. M. M. Haenen, "Ten misconceptions about antioxidants," Trends in Pharmacological Sciences, vol. 34, no. 8, pp. 430-436, 2013.

[17] E. B. Burlakova, A. V. Alesenko, E. M. Molochkina, N. P. Palmina, and N. G. Khrapova, Bioantioxidants for Radiation Damage and Malignant Growth, Nauka, Moscow, Russia, 1975 (Russian).

[18] J. Fang, T. Seki, and H. Maeda, "Therapeutic strategies by modulating oxygen stress in cancer and inflammation," Advanced Drug Delivery Reviews, vol. 61, no. 4, pp. 290-302, 2009.

[19] M. Valko, D. Leibfritz, J. Moncol, M. T. D. Cronin, M. Mazur, and J. Telser, "Free radicals and antioxidants in normal physiological functions and human disease," International Journal of Biochemistry and Cell Biology, vol. 39, no. 1, pp. 44-84, 2007.

[20] M. Jimenez-Del-Rio and C. Velez-Pardo, "The bad, the good, and the ugly about oxidative stress," Oxidative Medicine and Cellular Longevity, vol. 2012, Article ID 163913, 13 pages, 2012.

[21] C. D. Kamat, S. Gadal, M. Mhatre, K. S. Williamson, Q. N. Pye, and K. Hensley, "Antioxidants in central nervous system diseases: preclinical promise and translational challenges," Journal of Alzheimer's Disease, vol. 15, no. 3, pp. 473-493, 2008.

[22] A. Pompella, H. Sies, R. Wacker et al., "The use of total antioxidant capacity as surrogate marker for food quality and its effect on health is to be discouraged," Nutrition, vol. 30, no. 7-8, pp. 791-793, 2014.

[23] Z. Ye and H. Song, "Antioxidant vitamins intake and the risk of coronary heart disease: meta-analysis of cohort studies," European Journal of Cardiovascular Prevention and Rehabilitation, vol. 15, no. 1, pp. 26-34, 2008.

[24] P. Knekt, J. Ritz, M. A. Pereira et al., "Antioxidant vitamins and coronary heart disease risk: a pooled analysis of 9 cohorts," The American Journal of Clinical Nutrition, vol. 80, no. 6, pp. 15081520, 2004.

[25] A. C. Carr and M. C. M. Vissers, "Synthetic or food-derived vitamin C-are they equally bioavailable?" Nutrients, vol. 5, no. 11, pp. 4284-4304, 2013.

[26] R. Tabrizchi, "Edaravone Mitsubishi-Tokyo," Current Opinion in Investigational Drugs, vol. 1, no. 3, pp. 347-354, 2000.

[27] K. Kikuchi, S. Tancharoen, N. Takeshige et al., "The efficacy of edaravone (radicut), a free radical scavenger, for cardiovascular disease," International Journal of Molecular Sciences, vol. 14, no. 7, pp. 13909-13930, 2013.

[28] D. Mauzerall and F. H. Westheimer, "1-Benzyldihydronicotinamide-a model for reduced DPN," Journal of the American Chemical Society, vol. 77, no. 8, pp. 2261-2264, 1955, Chemical Abstracts, vol. 50, Article ID 2588i, 1956.

[29] F. Bossert and W. Vater, "1,4-Dihydropyridines-a basis for developing new drugs," Medicinal Research Reviews, vol. 9, no. 3, pp. 291-324, 1989.

[30] G. Swarnalatha, G. Prasanthi, N. Sirisha, and C. Madhusudhana Chetty, "1,4-Dihydropyridines: a multtifunctional molecule- a review," International Journal of ChemTech Research, vol. 3, no. 1, pp. 75-89, 2011. 
[31] M. Cataldi and F. Bruno, "1,4-Dihydropyridines: the multiple personalities of a blockbuster drug family," Translational Medicine@UniSa, vol. 4, no. 2, pp. 12-26, 2012, http://www.ncbi.nlm .nih.gov/pmc/articles/PMC3728803/.

[32] R. Vitolina, A. Krauze, G. Duburs, and A. Velena, "Aspects of the amlodipine pleiotropy in biochemistry, pharmacology and clinics," International Journal of Pharmaceutical Sciences and Research, vol. 3, no. 5, pp. 1215-1232, 2012.

[33] D. Grover, S. N. Mokale, and M. T. Shete, "Dihydropyridine: a novel pharmacophore," International Journal of Pharmaceutical Erudition, vol. 1, no. 2, pp. 16-29, 2011, http://pharmaerudition.org/ContentPaper/2011/1-RV-3\%20Final\%2016-29.pdf.

[34] A. M. Vijesh, A. M. Isloor, S. K. Peethambar, K. N. Shivananda, T. Arulmoli, and N. A. Isloor, "Hantzsch reaction: synthesis and characterization of some new 1,4-dihydropyridine derivatives as potent antimicrobial and antioxidant agents," European Journal of Medicinal Chemistry, vol. 46, no. 11, pp. 5591-5597, 2011.

[35] P. Mehta and P. Verma, "Antimicrobial activity of some derivatives of 1,4-dihydropyridines," Journal of Chemistry, vol. 2013, Article ID 865128, 4 pages, 2013.

[36] P. Olejníková, L. Švorc, D. Olšovská et al., "Antimicrobial activity of novel C2-substituted 1,4-dihydropyridine analogues," Scientia Pharmaceutica, vol. 82, no. 2, pp. 221-232, 2014.

[37] S. Sepehri, H. Perez Sanchez, and A. Fassihi, "Hantzsch-type dihydropyridines and biginelli-type tetra-hydropyrimidines: a review of their chemotherapeutic activities," Journal of Pharmacy \& Pharmaceutical Sciences, vol. 18, no. 1, pp. 1-52, 2015, https://ejournals.library.ualberta.ca/index.php/JPPS/article/ view/23836/17863.

[38] S. A. Khedkar and P. B. Auti, "1,4-Dihydropyridines: a class of pharmacologically important molecules," Mini-Reviews in Medicinal Chemistry, vol. 14, no. 3, pp. 282-290, 2014.

[39] G. D. Tirzit and G. Ya. Duburs, "1,4-dihydropyridines as inhibitors of free-radical reactions," Chemistry of Heterocyclic Compounds, vol. 8, no. 1, pp. 126-127, 1972, Translated from Khimiya Geterotsiklicheskikh Soedinenii, no.1, pp. 133-134, 1972 (Russian).

[40] I. Bogeski, R. Kappl, C. Kummerow, R. Gulaboski, M. Hoth, and B. A. Niemeyer, "Redox regulation of calcium ion channels: chemical and physiological aspects," Cell Calcium, vol. 50, no. 5, pp. 407-423, 2011.

[41] S. A. Giller, G. Y. Dubur, Y. R. Uldrikis et al., "Diludine. [The method to obtain 3,5-dicarbonylderivatives of 2,6-dimethyl1,4-dihydropyridines]," Authors certificate of USSR no. 300465, 1971 [Byull. Izobret., no.13, p. 95, 1971], and following patents: Patent of England no. 1294650, 1973; Patent of France no. 2055458, 1971; Patent of Japan no. 702883, 1973; Patent of Holland no. 149787, 1976; Patent of Italy no. 969022, 1974; Patent of FRG no. 2036403, 1978; US Patent no. 3883673, 1975; US Patent no. 3948924, 1976.

[42] S. A. Giller, G. Y. Dubur, Y. R. Uldrikis et al., "Improvements in or relating to the stabilization of carotene," GB Patent no. 1294650, 1972.

[43] S. A. Giller, G. Y. Dubur, Y. R. Uldrikis et al., "Stabilization of carotene," US Patent no. 3883673, 1975, Chemical Abstracts, vol. 83, Article ID 95193, 1975.

[44] Yu. A. Zilber, G. Ya. Dubur, K. K. Kumsar, and A. Kh. Velena, "The effect of antioxidants on the peroxidation of bimolecular phospholipid membranes," Latvijas PSR ZA Vēstis, Izvestia Akademii Nauk Latviyskoy SSR, vol. 6, pp. 80-82, 1971 (Russian), translated from the original Russian, Doc. Accesion
No. AD0771751, distributed by NTIS, U.S. Department of Commerce, http://www.dtic.mil/dtic/tr/fulltext/u2/771751.pdf.

[45] G. Ya. Dubur, Yu. A. Zilbers, A. Kh. Velena, A. O. Kumerova, and G. D. Tirzitis, "Multistage study of regulation of peroxidation processes in biological membranes by antioxidants of 1,4dihydropyridine group," Izvestiya Akademii Nauk Latviyskoy SSR, vol. 336, no. 7, pp. 65-68, 1975 (Russian).

[46] R. P. Mason and M. W. Trumbore, "Differential membrane interactions of calcium channel blockers. Implications for antioxidant activity," Biochemical Pharmacology, vol. 51, no. 5, pp. 653-660, 1996.

[47] R. P. Mason, M. F. Walter, M. W. Trumbore, E. G. Olmstead Jr., and P. E. Mason, "Membrane antioxidant effects of the charged dihydropyridine calcium antagonist amlodipine," Journal of Molecular and Cellular Cardiology, vol. 31, no. 1, pp. 275-281, 1999.

[48] R. P. Mason, I. T. Mak, M. W. Trumbore, and P. E. Mason, "Antioxidant properties of calcium antagonists related to membrane biophysical interactions," American Journal of Cardiology, vol. 84, no. 4, pp. 16-22, 1999.

[49] R. P. Mason, M. W. Trumbore, and P. E. Mason, "Membrane biophysical interaction of amlodipine and antioxidant properties," Drugs, vol. 59, no. 2, pp. 9-16, 2000 (French).

[50] R. P. Mason, P. Marche, and T. H. Hintze, "Novel vascular biology of third-generation L-type calcium channel antagonists. Ancillary actions of amlodipine," Arteriosclerosis, Thrombosis, and Vascular Biology, vol. 23, no. 12, pp. 2155-2163, 2003.

[51] A. Augustyniak, G. Bartosz, A. Čipak et al., "Natural and synthetic antioxidants: an updated overview," Free Radical Research, vol. 44, no. 10, pp. 1216-1262, 2010.

[52] T. Grüne, N. Zarkovic, and K. Kostelidou, "Lipid peroxidation research in Europe and the COST B35 action 'Lipid Peroxidation Associated Disorders"' Free Radical Research, vol. 44, no. 10, pp. 1095-1097, 2010.

[53] E. Carosati, P. Ioan, M. Micucci et al., "1,4-Dihydropyridine scaffold in medicinal chemistry, the story so far and perspectives (part 2): action in other targets and antitargets," Current Medicinal Chemistry, vol. 19, no. 25, pp. 4306-4323, 2012.

[54] U. Eisner and J. Kuthan, "The chemistry of dihydropyridines," Chemical Reviews, vol. 72, no. 1, pp. 1-42, 1972, http://www.sciencemadness.org/talk/files.php?pid=138742\&aid=6475.

[55] J. Kuthan and A. Kurfurst, "Development in dihydropyridine chemistry," Industrial \& Engineering Chemistry Product Research and Development, vol. 21, no. 2, pp. 191-261, 1982.

[56] A. Sausinš̌ and G. Duburs, "Synthesis of 1,4-dihydropyridines by cyclocondensation reactions," Heterocycles, vol. 27, no. 1, pp. 269-289, 1988.

[57] A. E. Sausins and G. Y. Duburs, "Synthesis of 1,4-dihydropyridines in cyclocondensation reactions (review)," Chemistry of Heterocyclic Compounds, vol. 28, no. 4, pp. 363-391, 1992, Translated from: Khimiya Geterotsiklicheskikh Soedinenii, no. 4, pp. 435-467, 1992 (Russian).

[58] S. Kazda, "Twenty years of dihydropyridines", in Dihydropyridines. Progress in Pharmacology and Therapy, W.-D. Busse, B. Garthoff, and F. Seuter, Eds., pp. 1-12, Springer Verlag, Berlin, Germany, 1993.

[59] J.-P. Wan and Y. Liu, "Recent advances in new multicomponent synthesis of structurally diversified 1,4-dihydropyridines," RSC Advances, vol. 2, no. 26, pp. 9763-9777, 2012.

[60] http://organic-chemistry.com/, http://www.organic-chemistry .org/namedreactions/hantzsch-dihydropyridine-synthesis.shtm. 
[61] Reaxys, Database.

[62] J. Tuttle, "Structure, mechanism and reactivity of hantzsch esters," in MacMillan Lab Group Meeting, (08/25/04), p. 33, 2004, http://www.princeton.edu/chemistry/macmillan/groupmeetings/JBT\%20Hantzsch.pdf.

[63] A. Saini, S. Kumar, and J. S. Sandhu, "Hantzsch reaction: recent advances in Hantzsch 1,4-dihydropyridines," Journal of Scientific \& Industrial Research, vol. 67, pp. 95-111, 2008.

[64] L. L. W. Cheung, S. A. Styler, and A. P. Dicks, "Rapid and convenient synthesis of the 1,4-dihydropyridine privileged structure," Journal of Chemical Education, vol. 87, no. 6, pp. 628-630, 2010.

[65] A. Kumar, R. A. Maurya, S. Sharma, M. Kumar, and G. Bhatia, "Synthesis and biological evaluation of N-aryl-1,4-dihydropyridines as novel antidyslipidemic and antioxidant agents," European Journal of Medicinal Chemistry, vol. 45, no. 2, pp. 501509, 2010.

[66] R. S. Kumar, A. Idhayadhulla, A. J. Abdul Nasser, and J. Selvin, "Synthesis and anticoagulant activity of a new series of 1,4dihydropyridine derivatives," European Journal of Medicinal Chemistry, vol. 46, no. 2, pp. 804-810, 2011.

[67] H. A. Stefani, C. B. Oliveira, R. B. Almeida et al., "Dihydropyrimidin- $(2 \mathrm{H})$-ones obtained by ultrasound irradiation: a new class of potential antioxidant agents," European Journal of Medicinal Chemistry, vol. 41, no. 4, pp. 513-518, 2006.

[68] H. Sun, C. Shang, L. Jin, and J. Zhang, "Synthesis and antioxidant activity of a series of novel 3-chalcone-substituted 1,4dihydropyridine derivatives," Heterocyclic Communications, vol. 18, no. 5-6, pp. 239-243, 2012.

[69] D. B. Tikhonov and B. S. Zhorov, "Structural model for dihydropyridine binding to L-type calcium channels," The Journal of Biological Chemistry, vol. 284, no. 28, pp. 19006-19017, 2009.

[70] G. Y. Dubur and Y. R. Uldrikis, "The oxidation of 1,4-dihydropyridines," Chemistry of Heterocyclic Compounds, vol. 6, no. 1, pp. 80-84, 1970, Translated from: Khimiya Geterotsiklicheskikh Soedinenii, no. 1, pp. 83-88, 1970 (Russian).

[71] G. Ya. Duburs, A. O. Kumerova, and Ya. R. Uldrikis, "Enzymic oxidation of hydrogenated pyridines with peroxidase-hydrogen peroxide system," Latvijas PSR ZA Vestis, vol. 73, no. 7, pp. 73-77, 1970 (Russian), Chemical Abstracts, vol. 73, Article ID 94913g, 1970.

[72] K. Xie, Y.-C. Liu, Y. Cui, J.-G. Wang, Y. Fu, and T. C. W. Mak, “Nmethyl-(R)-3-(tert-butyl)-sulfinyl-1,4-dihydropyridine: a novel NADH model compound," Molecules, vol. 12, no. 3, pp. 415-422, 2007.

[73] S. Tamagaki, T. Mimura, and W. Tagaki, "Metal-ion-facilitated oxidations of dihydropyridines with molecular oxygen and hydrogen peroxide," Journal of the Chemical Society, Perkin Transactions 2, no. 10, pp. 1645-1650, 1990.

[74] D. Tirzite, G. Tirzitis, and D. Antipova, "Reductive ability of 1,4dihydropyridine derivatives in relation to ions of trivalent iron," Chemistry of Heterocyclic Compounds, vol. 35, no. 5, pp. 592594, 1999.

[75] Hantzsch Ester (HEH), Organic-Chemistry.org, http://www .organic-chemistry.org/chemicals/reductions/hantzsch-ester .shtm.

[76] J. Ogle, J. Stradins, and L. Baumane, "Formation and decay of free cation-radicals in the course of electro-oxidation of 1,2- and 1,4-dihydropyridines (Hantzsch esters)," Electrochimica Acta, vol. 39, no. 1, pp. 73-79, 1994.

[77] A. Weckbecker, H. Gröger, and W. Hummel, "Regeneration of nicotinamide coenzymes: principles and applications for the synthesis of chiral compounds," in Biosystems Engineering I: Creating Superior Biocatalysts, C. Wittmann and R. Krull, Eds., vol. 120 of Advances in Biochemical Engineering/Biotechnology, pp. 195-242, Springer, Berlin, Germany, 2010.

[78] W. Du and Zh. Yu, "Biomimetic in situ regeneration of cofactors $\mathrm{NAD}(\mathrm{P})^{+}$and $\mathrm{NAD}(\mathrm{P}) \mathrm{H}$ models hantzsch esters and dihydrophenanthridine," Synlett, vol. 23, no. 9, pp. 1300-1304, 2012.

[79] H. K. Chenault and G. M. Whitesides, "Regeneration of nicotinamide cofactors for use in organic synthesis," Applied Biochemistry and Biotechnology, vol. 14, no. 2, pp. 147-197, 1987.

[80] Y. R. Uldrikis, A. A. Zidermane, E. A. Biseniex, I. E. Preisa, G. Y. Dubur, and G. D. Tirzit, "Esters of 2,6-dimethyl-1,4-dihydropyridine-3,5-dicarboxylic acid and method of obtaining thereof," WO 8000345 Al, 1978, http://worldwide.espacenet .com/publicationDetails/biblio?DB=EPODOC\&II $=1 \& \mathrm{ND}=3 \&$ adjacent $=$ true $\&$ locale $=$ en $\_E P \& F T=D \&$ date $=19800306 \& C C=$ WO\&NR=8000345A1\&KC=A1.

[81] Y. Sambongi, H. Nitta, K. Ichihashi, M. Futai, and I. Ueda, "A novel water-soluble Hantzsch 1,4-dihydropyridine compound that functions in biological processes through NADH regeneration," Journal of Organic Chemistry, vol. 67, no. 10, pp. 34993501, 2002.

[82] A. Weckbecker, H. Gröger, and W. Hummel, "Regeneration of nicotinamide coenzymes: principles and applications for the synthesis of chiral compounds," in Biosystems Engineering I. Creating Superior Biocatalysts, Ch. Wittmann and R. Krull, Eds., vol. 120 of Advances in Biochemical Engineering/Biotechnology, pp. 195-242, Springer Verlag, Berlin, Germany, 2010.

[83] T. Okamura, T. Kikuchi, A. Nagamine et al., "An approach for measuring in vivo cerebral redox states using the oxidative conversion of dihydropyridine to pyridinium ion and the metabolic trapping principle," Free Radical Biology and Medicine, vol. 38, no. 9, pp. 1197-1205, 2005.

[84] K. A. Schellenberg and F. H. Westheimer, "A free-radical oxidation of a dihydropyridine ${ }^{*}, 1 \mathrm{a}$, The Journal of Organic Chemistry, vol. 30, no. 6, pp. 1859-1862, 1965.

[85] K. A. Schellenberg, "Reaction of hydroxyl radical with thymidine. Scavenging by a dihydropyridine," Federation Proceedings, vol. 38, no. 3 I, p. 1433, 1979.

[86] E. S. Huyser, J. A. K. Harmony, and F. L. McMillian, "Peroxide oxidations of dihydropyridine derivatives," Journal of the American Chemical Society, vol. 94, no. 9, pp. 3176-3180, 1972.

[87] A. Sakamoto, S. T. Ohnishi, and R. Ogawa, "Inhibition of lipid peroxidation by some dihydropyridine derivatives," Journal of Anesthesia, vol. 7, no. 2, pp. 193-197, 1993.

[88] R. Hardeland, "Review. Neuroprotection by radical avoidance: search for suitable agents," Molecules, vol. 14, no. 12, pp. 50545102, 2009.

[89] G. Ya. Dubur, A. Kh. Velena, V. M. Gukasov, and Yu. A. Vladimirov, "Regulation of peroxidation of mitochondrial membrane lipids initiated by $\mathrm{Fe}^{2+}$ ions by antoxidants of the 1,4-dihydropyridine series in experiments in vitro," Biomeditsinskaya Khimiya, vol. 22, no. 5, pp. 665-673, 1976 (Russian), Chemical Abstracts, vol. 88, Article ID 2640, 1977.

[90] G. R. M. M. Haenen, M. J. T. J. Arts, A. Bast, and M. D. Coleman, "Structure and activity in assessing antioxidant activity in vitro and in vivo: a critical appraisal illustrated with the flavonoids," Environmental Toxicology and Pharmacology, vol. 21, no. 2, pp. 191-198, 2006.

[91] G. Tirzitis and G. Bartosz, "Determination of antiradical and antioxidant activity: basic principles and new insights," Acta Biochimica Polonica, vol. 57, no. 2, pp. 139-142, 2010. 
[92] G. R. Buettner and R. P. Mason, "Spin-trapping methods for detecting superoxide and hydroxyl free radicals in vitro and in vivo," in Critical Reviews of Oxidative Stress and Aging: Advances in Basic Science, Diagnostics and Intervention, R. G. Cutler and H. Rodriguez, Eds., vol. 1, chapter 2, pp. 27-38, World Scientific, London, UK, 2003.

[93] M. M. Tarpey and I. Fridovich, "Methods of detection of vascular reactive species. Nitric oxide, superoxide, hydrogen peroxide, and peroxynitrite," Circulation Research, vol. 89, no. 3, pp. 224-236, 2001.

[94] E. Y. Kazush, E. I. Sagun, G. D. Tirzit, and G. Y. Dabur, "Quenching of singlet oxygen by electron donating derivatives of 1,4-dihydropyridine," Chemistry of Heterocyclic Compounds, vol. 30, no. 5, pp. 562-563, 1994.

[95] G. Tirzitis, E. Kazush, and G. Duburs, "Reaction of 1,4dihydropyridine derivatives with peroxynitrite anion," Chemistry of Heterocyclic Compounds, vol. 34, no. 3, pp. 321-323, 1998 (Russian), Translated from Khimiya Geterotsiklicheskikh Soedinenii, no. 3, pp. 355-357, 1998.

[96] L. J. Núñez-Vergara, C. López-Alarcón, P. A. Navarrete-Encina, A. M. Atria, C. Camargo, and J. A. Squella, "Electrochemical and EPR characterization of 1,4-dihydropyridines. Reactivity towards alkyl radicals," Free Radical Research, vol. 37, no. 1, pp. 109-120, 2003.

[97] D. Tirzite, A. Krauze, A. Zubareva, G. Tirzitis, and G. Duburs, "Synthesis and antiradical activity of 5-acetyl-2-alkylthio-4aryl-6-methyl-1,4-dihydropyridine-3-carboxylic acid nitriles," Chemistry of Heterocyclic Compounds, vol. 38, no. 7, pp. 795800, 2002.

[98] H. Ohkawa, N. Ohishi, and K. Yagi, "Assay for lipid peroxides in animal tissues by thiobarbituric acid reaction," Analytical Biochemistry, vol. 95, no. 2, pp. 351-358, 1979.

[99] N. Zarkovic, "4-Hydroxynonenal as a bioactive marker of pathophysiological processes," Molecular Aspects of Medicine, vol. 24, no. 4-5, pp. 281-291, 2003.

[100] M. Parola, G. Bellomo, G. Robino, G. Barrera, and M. U. Dianzani, "4-Hydroxynonenal as a biological signal: molecular basis and pathophysiological implications," Antioxidants and Redox Signaling, vol. 1, no. 3, pp. 255-284, 1999.

[101] T. Lovaković, M. Poljak-Blazi, G. Duburs et al., "Growth modulation of human cells in vitro by mild oxidative stress and 1,4-dihydropyridine derivative antioxidants," Collegium Antropologicum, vol. 35, no. 1, pp. 137-141, 2011.

[102] R. van den Berg, G. R. M. M. Haenen, H. van den Berg, and A. Bast, "Applicability of an improved Trolox equivalent antioxidant capacity (TEAC) assay for evaluation of antioxidant capacity measurements of mixtures," Food Chemistry, vol. 66, no. 4, pp. 511-517, 1999.

[103] C. López-Alarcón, P. Navarrete, C. Camargo, J. A. Squella, and L. J. Núñez-Vergara, "Reactivity of 1,4-dihydropyridines toward alkyl, alkylperoxyl radicals, and ABTS radical cation," Chemical Research in Toxicology, vol. 16, no. 2, pp. 208-215, 2003.

[104] V. Valenzuela, P. Santander, C. Camargo, J. A. Squella, C. LópezAlarcón, and L. J. Núñez-Vergara, "1,4-Dihydropyridines: reactivity of nitrosoaryl and nitroaryl derivatives with alkylperoxyl radicals and ABTS radical cation," Free Radical Research, vol. 38, no. 7, pp. 715-727, 2004.

[105] L. G. Tsetlin, N. A. Chebotareva, B. I. Kurganov, A. K. Velena, G. Y. Dubur, and V. Z. Lankin, "Study of 1,4-dihydropyridines as lipoxygenase inhibitors with the use of hydrated reversed micelles," Pharmaceutical Chemistry Journal, vol. 22, no. 6, pp. 425-428, 1988 (Russian).
[106] J. Panek, Z. Reblova, L. Kocirkova et al., "Antioxidant activity of dihydropyridine derivatives," Czech Journal of Food Sciences, vol. 18, pp. 144-145, 2000.

[107] G. Tirzitis, I. Kirule, and G. Duburs, "Antioxidationsaktivität der 3,5-dicarbonylderivate des 2,6-demethyl-1,4-dihydropyridins," Fett Wissenschaft Technologie/Fat Science Technology, vol. 90, no. 10, pp. 411-413, 1988.

[108] M. Plotniece, G. Tirzitis, Y. Uldrikis et al., "Synthesis of 1,4dihydropyridine derivatives having an oxy-, alkoxy-, or dimethylaminophenyl substituent in the 4 position, their antioxidant activity, and their binding to phospholipid membranes," Chemistry of Heterocyclic Compounds, vol. 32, no. 10, pp. 1166-1172, 1996, Translated from: Khimiya Geterotsiklicheskikh Soedinenii, no. 10(352), pp. 1358-1365, 1996 (Russian).

[109] D. Y. Rubene, V. S. Sharov, V. I. Olenev, G. D. Tirzit, G. Y. Dubur, and Y. A. Vladimirov, "Use of chemiluminescent method for the evaluation of antioxidant activity of some derivatives of 1,4dihydropyridine," Russian Journal of Physical Chemistry A, vol. 55, no. 2, pp. 511-512, 1981 (Russian).

[110] M. C. R. Symons and J. M. C. Gutteridge, Free Radicals and Iron: Chemistry, Biology, and Medicine, Oxford Science Publications, Oxford University Press, Oxford, UK, 1998.

[111] M. Repetto, J. Semprine, and A. Boveris, "Lipid peroxidation: chemical mechanism, biological implications and analytical determination," in Lipid Peroxidation, A. Catala, Ed., Section I: Lipid Peroxidation: Chemical Mechanisms, Antioxidants, Biological Implications; of Biochemistry, Genetics and Molecular Biology, chapter 1, pp. 3-30, InTech, Rijeka, Croatia, 2012.

[112] A. Velēna, J. Zilbers, and G. Duburs, "Derivatives of 1,4dihydropyridines as modulators of ascorbate-induced lipid peroxidation and high-amplitude swelling of mitochondria, caused by ascorbate, sodium linoleate and sodium pyrophosphate," Cell Biochemistry and Function, vol. 17, no. 4, pp. 237-252, 1999.

[113] M. V. Bilenko, L. N. Shelenkova, G. Y. Dubur, and A. K. Velena, "Use of antioxidants to prevent renal damage during acute ischemia and reperfusion," Bulletin of Experimental Biology and Medicine, vol. 96, no. 3, pp. 1195-1198, 1983, Translated from: Byulleten' Éksperimental'noi Biologii i Meditsiny, vol. 96, no. 9, pp. 8-11, 1983 (Russian).

[114] R. Toniolo, F. Tubaro, F. Ursini, and G. Bontempelli, "An electroanalytical investigation on the redox properties of calcium antagonist dihydropyridines," Electroanalysis, vol. 15, no. 10, pp. 855-861, 2003.

[115] L. Kouřimská, J. Pokorný, and G. Tirzitis, “The antioxidant acitivity of 2,6-dimethyl-3,5-diethoxycarbonyl-1,4-dihydropyridine in edible oils," Nahrung, vol. 37, no. 1, pp. 91-93, 1993.

[116] C. López-Alarcón, H. Speisky, J. A. Squella, C. Olea-Azar, C. Camargo, and L. J. Núñez-Vergara, "Reactivity of 1,4-dihydropyridines toward SIN-1-derived peroxynitrite," Pharmaceutical Research, vol. 21, no. 10, pp. 1750-1757, 2004.

[117] R. A. Olek, W. Ziolkowski, J. J. Kaczor, L. Greci, J. Popinigis, and J. Antosiewicz, "Antioxidant activity of NADH and its analogue-an in vitro study," Journal of Biochemistry and Molecular Biology, vol. 37, no. 4, pp. 416-421, 2004.

[118] E. Niki, N. Noguchi, and N. Gotoh, "Inhibition of oxidative modification of low density lipoprotein by antioxidants," Journal of Nutritional Science and Vitaminology, vol. 39, supplement, pp. S1-S8, 1993.

[119] N. Rojstaczer and D. J. Triggle, "Structure-function relationships of calcium antagonists: effect on oxidative modification of low density lipoprotein," Biochemical Pharmacology, vol. 51, no. 2, pp. 141-150, 1996. 
[120] A. Sevanian, L. Shen, and F. Ursini, "Inhibition of LDL oxidation and oxidized LDL-induced cytotoxicity by dihydropyridine calcium antagonists," Pharmaceutical Research, vol. 17, no. 8, pp. 999-1006, 2000.

[121] A. Negre-Salvayre and R. Salvayre, "Protection by $\mathrm{Ca}^{2+}$ channel blockers (nifedipine, diltiazem and verapamil) against the toxicity of oxidized low density lipoprotein to cultured lymphoid cells," British Journal of Pharmacology, vol. 107, no. 3, pp. 738744, 1992.

[122] A. Nègre-Salvayre, G. Fitoussi, M. Troly, and R. Salvayre, "Comparative cytoprotective effect of dihydropyridine calcium channel blockers against the toxicity of oxidized low density lipoprotein for cultured lymphoid cells," Biochemical Pharmacology, vol. 44, no. 12, pp. 2379-2386, 1992.

[123] L. Cominacini, A. F. Pasini, U. Garbin et al., "Antioxidant activity of different dihydropyridines," Biochemical and Biophysical Research Communications, vol. 302, no. 4, pp. 679-684, 2003.

[124] L. Cominacini, U. Garbin, A. Fratta Pasini et al., "Oxidized lowdensity lipoprotein increases the production of intracellular reactive oxygen species in endothelial cells: inhibitory effect of lacidipine," Journal of Hypertension, vol. 16, no. 12, part 2, pp. 1913-1919, 1998.

[125] H. M. Lander, "An essential role for free radicals and derived species in signal transduction," The FASEB Journal, vol. 11, no. 2, pp. 118-124, 1997.

[126] M. L. L. Martinez, E. Rizzi, M. M. Castro et al., "Lercanidipine decreases vascular matrix metalloproteinase-2 activity and protects against vascular dysfunction in diabetic rats," European Journal of Pharmacology, vol. 599, no. 1-3, pp. 110-116, 2008.

[127] P. Lesnik, C. Dachet, L. Petit et al., "Impact of a combination of a calcium antagonist and a $\beta$-blocker on cell- and coppermediated oxidation of LDL and on the accumulation and efflux of cholesterol in human macrophages and murine J774 cells," Arteriosclerosis, Thrombosis, and Vascular Biology, vol. 17, no. 5, pp. 979-988, 1997.

[128] G. Sobal, E. J. Menzel, and H. Sinzinger, "Calcium antagonists as inhibitors of in vitro low density lipoprotein oxidation and glycation," Biochemical Pharmacology, vol. 61, no. 3, pp. 373-379, 2001.

[129] E. Lupo, R. Locher, B. Weisser, and W. Vetter, "In vitro antioxidant activity of calcium antagonists against LDL oxidation compared with $\alpha$-tocopherol," Biochemical and Biophysical Research Communications, vol. 203, no. 3, pp. 1803-1808, 1994.

[130] J. Zou, Y. Li, H.-Q. Fan, and J.-G. Wang, "Effects of dihydropyridine calcium channel blockers on oxidized low-density lipoprotein induced proliferation and oxidative stress of vascular smooth muscle cells," BMC Research Notes, vol. 5, article 168, 2012.

[131] C. Napoli, S. Salomone, T. Godfraind et al., "1,4-Dihydropyridine calcium channel blockers inhibit plasma and LDL oxidation and formation of oxidation-specific epitopes in the arterial wall and prolong survival in stroke-prone spontaneously hypertensive rats," Stroke, vol. 30, no. 9, pp. 1907-1915, 1999.

[132] G. Zernig, I. Graziadei, T. Moshammer, C. Zech, N. Reider, and H. Glossmann, "Mitochondrial $\mathrm{Ca}^{2+}$ antagonist binding sites are associated with an inner mitochondrial membrane anion channel," Molecular Pharmacology, vol. 38, no. 3, pp. 362-369, 1990.

[133] F. E. Hunter Jr., A. Scott, P. E. Hochstein et al., "Studies of the mechanism of ascorbate-induced swelling and lysis of isolated liver mitochondria," The Journal of Biological Chemistry, vol. 239, pp. 604-613, 1964.
[134] D. R. Janero, B. Burghardt, and R. Lopez, "Protection of cardiac membrane phospholipid against oxidative injury by calcium antagonists," Biochemical Pharmacology, vol. 37, no. 21, pp. 41974203, 1988.

[135] A. Karadag, B. Ozcelik, and S. S. Saner, "Review of methods to determine antioxidant capacities," Food Analytical Methods, vol. 2, no. 1, pp. 41-60, 2009.

[136] Y. I. Gubskiŭ, N. V. Litvinova, and E. V. Shnurko-Tabakova, "Antioxidant and antiradical activity of various classes of antioxidants," Ukrainskiu Biokhimicheskiu Zhurnal, vol. 66, no. 4, pp. 114-116, 1994 (Russian).

[137] M. Takei, M. Hiramatsu, and A. Mori, "Inhibitory effects of calcium antagonists on mitochondrial swelling induced by lipid peroxidation or arachidonic acid in the rat brain in vitro," Neurochemical Research, vol. 19, no. 9, pp. 1199-1206, 1994.

[138] M. Takei, M. Hiramatsu, R. Edamatsu, and A. Mori, "Free radical scavenging by calcium antagonists," Neurosciences, vol. 20, no. 2, pp. 75-82, 1994.

[139] Ya. P. Stradin, G. Ya. Dubur, Yu. A. Beilis, Ya. R. Uldrikis, and A. F. Korotkova, "Voltammetry of 1,4-dihydropyridine derivatives. I. Potentials of electrochemical oxidation of 3,5-diacyland 3,5-di(alkoxycarbonyl)-1,4-dihydropyridines in acetonitrile," Chemistry of Heterocyclic Compounds, no. 1, pp. 84-87, 1972 (Russian).

[140] E. V. Ivanov, T. V. Ponomarjova, G. N. Merkusev et al., "Ein neuer Haut-Radioprotektor Diethon (experimentelle Untersuchung)," Radiobiologia, Radiotherapia, vol. 31, no. 1, pp. 6978, 1990 .

[141] E. V. Ivanov, T. V. Ponomareva, G. N. Merkushev et al., "Radiation modulating properties of derivates of 1,4-dihydropyridine and 1,2,3,4,5,6,7,8,9,10-decahydroacridine-1,8 dione," Radiatsionnaia Biologiia, Radioecologiia, vol. 44, no. 5, pp. 550-559, 2004 (Russian).

[142] R. O. Vitolinia, D. A. Berzinia, A. K. Velena, I. A. Vutsina, A. A. Kimenis, and G. Y. Duburs, "The protective effects of the calcium antagonist foridon in acute myocardial ischaemia," Kardiologiya, vol. 27, no. 3, pp. 90-93, 1987 (Russian).

[143] A. H. Velena, G. Ya. Duburs, R. O. Vitolina et al., "Effect of ryodipine on electromechanical parameters of heart and vessels, cAMP phosphodiesterase activity and swelling-contraction cycle of mitochondria," Arzneimittelforschung, vol. 35, no. 6, pp. 907-914, 1985.

[144] L. I. Utno, Z. E. Lipsberga, A. A. Silova, M. I. Girgensone, E. A. Bisenieks, and G. I. Ia, "Cardioprotective properties of a 1,4dihydropyridine derivative, glutapyrone, in deep hypothermia," Biulleten' Eksperimental'no ̌ Biologii i Meditsiny, vol. 108, no. 11, pp. 558-561, 1989 (Russian).

[145] M. A. S. Fernandes, M. S. Santos, J. A. F. Vicente et al., "Effects of 1,4-dihydropyridine derivatives (cerebrocrast, gammapyrone, glutapyrone, and diethone) on mitochondrial bioenergetics and oxidative stress: a comparative study," Mitochondrion, vol. 3, no. 1, pp. 47-59, 2003.

[146] M. A. S. Fernandes, M. S. Santos, A. J. M. Moreno et al., "Effects of 5-acetyl(carbamoyl)-6-methylsulfanyl-1,4-dihydropyridine5-carbonitriles on rat liver mitochondrial function," Toxicology in Vitro, vol. 23, no. 7, pp. 1333-1341, 2009.

[147] L. Klimaviciusa, A. Kalda, A. Kaasik et al., "Neuroprotective activity of 1,4-dihydropyridine derivatives: structure determinants," Proceedings of the Latvian Academy of Sciences B: Natural, Exact, and Applied Sciences, vol. 61, no. 1-2, pp. 33-37, 2007. 
[148] L. Klimaviciusa, M. A. S. Fernandes, N. Lencberga et al., "Targeting the mitochondria by novel adamantane-containing 1,4-dihydropyridine compounds," in Bioenergetics, K. B. Clark, Ed., pp. 257-272, InTech, 2012.

[149] V. Klusa, L. Klimaviciusa, G. Duburs, J. Poikans, and A. Zharkovsky, "Anti-neurotoxic effects of tauropyrone, a taurine analogue," Advances in Experimental Medicine and Biology, vol. 583, pp. 499-508, 2006.

[150] N. Sampson, P. Berger, and Ch. Zenzmaier, "Redox signaling as a therapeutic target to inhibit myofibroblast activation in degenerative fibrotic disease," BioMed Research International, vol. 2014, Article ID 131737, 14 pages, 2014.

[151] T. L. Leto and M. Geiszt, "Role of Nox family NADPH oxidases in host defense," Antioxidants \& Redox Signaling, vol. 8, no. 9-10, pp. 1549-1561, 2006.

[152] K. K. Griendling, D. Sorescu, and M. Ushio-Fukai, "NAD(P)H oxidase: role in cardiovascular biology and disease," Circulation Research, vol. 86, no. 5, pp. 494-501, 2000.

[153] H. Chen, Y. S. Song, and P. H. Chan, "Inhibition of NADPH oxidase is neuroprotective after ischemia-reperfusion," Journal of Cerebral Blood Flow and Metabolism, vol. 29, no. 7, pp. 12621272, 2009.

[154] P. Hochstein and L. Ernster, "ADP-activated lipid peroxidation coupled to the TPNH oxidase system of microsomes," Biochemical and Biophysical Research Communications, vol. 12, no. 5, pp. 388-394, 1963.

[155] I. I. Gubskiü, A. G. Goriushko, N. V. Litvinova et al., "Antioxidant properties and membranotropic effect of certain derivatives of 1,4-dihydropyridine," Ukrainskiŭ Biokhimicheskiŭ Zhurnal, vol. 71, no. 4, pp. 35-39, 1999 (Russian).

[156] F. Engineer and R. Sridhar, "Inhibition of rat heart and liver microsomal lipid peroxidation by nifedipine," Biochemical Pharmacology, vol. 38, no. 8, pp. 1279-1285, 1989.

[157] T. Goncalves, A. P. Carvalho, and C. R. Oliveira, "Antioxidant effect of calcium antagonists on microsomai membranes isolated from different brain areas," European Journal of Pharmacology, vol. 204, no. 3, pp. 315-322, 1991.

[158] M. E. Letelier, P. Izquierdo, L. Godoy, A. M. Lepe, and M. Faúndez, "Liver microsomal biotransformation of nitro-aryl drugs: mechanism for potential oxidative stress induction," Journal of Applied Toxicology, vol. 24, no. 6, pp. 519-525, 2004.

[159] M. E. Letelier, P. Entrala, C. López-Alarcón et al., "Nitroaryl-1,4dihydropyridines as antioxidants against rat liver microsomes oxidation induced by iron/ascorbate, Nitrofurantoin and naphthalene," Toxicology in Vitro, vol. 21, no. 8, pp. 1610-1618, 2007.

[160] F. P. Guengerich, W. R. Brian, M. Iwasaki, M.-A. Sari, C. Bäärnhielm, and P. Berntsson, "Oxidation of dihydropyridine calcium channel blockers and analogues by human liver cytochrome P-450 IIIA4," Journal of Medicinal Chemistry, vol. 34, no. 6, pp. 1838-1844, 1991.

[161] S. H. Park, S.-W. Rha, W.-Y. Shin et al., "AS-160 Calcium channel blockers of dihydropyridine class reduce the antiplatelet effect of Clopidogrel?: what is clinical impact," The American Journal of Cardiology, vol. 107, no. 8, supplement, p. 47A, 2011.

[162] C. Asma and D. M. Reda, "Evaluation of dihydropyridine calcium antagonist effects on the stress bioindicator organism Saccharomyces cerevisiae," Annals of Biological Research, vol. 4, no. 10, pp. 40-46, 2013, http://scholarsresearchlibrary .com/ABR-vol4-iss10/ABR-2013-4-10-40-46.pdf.

[163] G. Gaviraghi, A. M. Pastorino, E. Ratti, and D. G. Trist, "Calcium channel blockers with antioxidant activity", in Free
Radicals, Lipoprotein Oxidation and Atherosclerosis, G. Bellomo, G. Finardi, E. Maggi, and E. Rice-Evans, Eds., pp. 431-456, Richelieu Press, London, UK, 1995.

[164] G. Gaviraghi, A. M. Pastorino, E. Ratti, and D. G. Trist, "Antioxidant dihydropyridines, a new and comprehensive therapy for free radical-induced cardiovascular diseases," in Free Radicals in Biology and Environment, F. Minisci, Ed., vol. 27 of NATO ASI Series, pp. 193-221, Springer, Dordrecht, The Netherlands, 1997.

[165] P. D. Henry, "Antiperoxidative actions of calcium antagonists and atherogenesis," Journal of Cardiovascular Pharmacology, vol. 18, supplement 1, pp. S6-S10, 1991.

[166] F. Kouoh, B. Gressier, T. Dine et al., "Antioxidant effects and anti-elastase activity of the calcium antagonist nicardipine on activated human and rabbit neutrophils - a potential antiatherosclerotic property of calcium antagonists?" Cardiovascular Drugs and Therapy, vol. 16, no. 6, pp. 515-520, 2002.

[167] S. Parthasarathy, D. Litvinov, K. Selvarajan, and M. Garelnabi, "Lipid peroxidation and decomposition-conflicting roles in plaque vulnerability and stability," Biochimica et Biophysica Acta, vol. 1781, no. 5, pp. 221-231, 2008.

[168] D.-Q. Liu, Z.-Q. Pang, D.-H. Zhao, and B.-H. Sheng, "Effects of furyl-dihydropyridines I on lipid peroxides of ischemic myocardium and ATPases activity of erythrocyte membranes in rats," Acta Pharmacologica Sinica, vol. 12, no. 3, pp. 253-256, 1991.

[169] V. Lukic-Panin, T. Kamiya, H. Zhang et al., "Prevention of neuronal damage by calcium channel blockers with antioxidative effects after transient focal ischemia in rats," Brain Research, vol. 1176, no. 1, pp. 143-150, 2007.

[170] Y. Allanore, D. Borderie, H. Lemaréchal, O. G. Ekindjian, and A. Kahan, "Acute and sustained effects of dihydropyridine-type calcium channel antagonists on oxidative stress in systemic sclerosis," American Journal of Medicine, vol. 116, no. 9, pp. 595600, 2004.

[171] I. Casetta, V. Govoni, and E. Granieri, "Oxidative stress, antioxidants and neurodegenerative diseases," Current Pharmaceutical Design, vol. 11, no. 16, pp. 2033-2052, 2005.

[172] M. J. T. J. Arts, Assessing antioxidant activity [Ph.D. thesis], Maastricht University, Maastricht, The Netherlands, 2007, http://arno.unimaas.nl/show.cgi?fid=8676.

[173] G. Díaz-Araya, L. Godoy, L. Naranjo, A. Squella, M. E. Letelier, and L. J. Núñez-Vergara, "Antioxidant effects of 1,4-dihydropyridine and nitroso aryl derivatives on the $\mathrm{Fe}^{+3}$ /ascorbatestimulated lipid peroxidation in rat brain slices," General Pharmacology: The Vascular System, vol. 31, no. 3, pp. 385-391, 1998.

[174] Y. Fukuhara, K. Tsuchiya, Y. Horinouchi et al., "Protective effect of photodegradation product of nifedipine against tumor necrosis factor $\alpha$-induced oxidative stress in human glomerular endothelial cells," Journal of Medical Investigation, vol. 58, no. 1-2, pp. 118-126, 2011.

[175] W. Stengel, M. Jainz, and K. Andreas, "Different potencies of dihydropyridine derivatives in blocking T-type but not L-type $\mathrm{Ca}^{2+}$ channels in neuroblastoma-glioma hybrid cells," European Journal of Pharmacology, vol. 342, no. 2-3, pp. 339-345, 1998.

[176] O. M. Panasenko, D. J. Tirzite, G. D. Tirzitis, and G. J. Duburs, "Effect of some 1,4-dihydropyridine derivatives on structural organization of erythrocyte membranes," Biologicheskie Membrany (Biochemistry (Moscow) Series A: Membrane and Cell Biology), vol. 1, pp. 919-925, 1984 (Russian).

[177] L. G. Herbette, Y. M. H. Vant Erve, and D. G. Rhodes, "Interaction of 1,4 dihydropyridine calcium channel antagonists with 
biological membranes: lipid bilayer partitioning could occur before drug binding to receptors," Journal of Molecular and Cellular Cardiology, vol. 21, no. 2, pp. 187-201, 1989.

[178] L. G. Herbette, P. E. Mason, G. Gaviraghi, T. N. Tulenko, and R. P. Mason, "The molecular basis for lacidipine's unique pharmacokinetics: optimal hydrophobicity results in membrane interactions that may facilitate the treatment of atherosclerosis," Journal of Cardiovascular Pharmacology, vol. 23, supplement 5, pp. S16-S25, 1994.

[179] G. V. Belevitch, G. Y. Dubur, G. E. Dobretsov, N. K. Kurek, and M. M. Spirin, "Calcium antagonists, riodipine, nifedipine and verapamil, binding to model and biological membranes: fluorescence analysis," Biologicheskie Membrany (Biochemistry (Moscow) Series A: Membrane and Cell Biology), vol. 5, pp. 768-776, 1988 (Russian).

[180] R. P. Mason, G. E. Gonye, D. W. Chester, and L. G. Herbette, "Partitioning and location of Bay K 8644, 1,4-dihydropyridine calcium channel agonist, in model and biological membranes," Biophysical Journal, vol. 55, no. 4, pp. 769-778, 1989.

[181] M. Cindric, A. Cipak, J. Serly et al., "Reversal of multidrug resistance in murine lymphoma cells by amphiphilic dihydropyridine antioxidant derivative," Anticancer Research, vol. 30, no. 10, pp. 4063-4070, 2010.

[182] F. Shekari, H. Sadeghpour, K. Javidnia et al., "Cytotoxic and multidrug resistance reversal activities of novel 1,4-dihydropyridines against human cancer cells," European Journal of Pharmacology, vol. 746, no. 1, pp. 233-244, 2015.

[183] X.-F. Zhou, Q. Shao, R. A. Coburn, and M. E. Morris, "Quantitative structure-activity relationship and quantitative structurepharmacokinetics relationship of 1,4-dihydropyridines and pyridines as multidrug resistance modulators," Pharmaceutical Research, vol. 22, no. 12, pp. 1989-1996, 2005.

[184] R. Berkels, T. Breitenbach, H. Bartels et al., "Different antioxidative potencies of dihydropyridine calcium channel modulators in various models," Vascular Pharmacology, vol. 42, no. 4, pp. 145-152, 2005.

[185] S. Borovic, G. Tirzitis, D. Tirzite et al., "Bioactive 1,4-dihydroisonicotinic acid derivatives prevent oxidative damage of liver cells," European Journal of Pharmacology, vol. 537, no. 1-3, pp. 12-19, 2006.

[186] D. Ya. Rubene, G. D. Tirzitis, and G. Ya. Duburs, "Interaction of some 1,4-dihydropyridine derivatives with Fenton's reagent," Latvijas PSR Zinatnu Akademijas Vestis, Kimijas Serija. Proceedings of the Latvian SSR Academy of Sciences, Chemistry Series, pp. 212-216, 1982 (Russian).

[187] K. Ondriaš, V. Mišík, D. Gergel, and A. Staško, "Lipid peroxidation of phosphatidylcholine liposomes depressed by the calcium channel blockers nifedipine and verapamil and by the antiarrhythmic-antihypoxic drug stobadine," Biochimica et Biophysica Acta-Lipids and Lipid Metabolism, vol. 1003, no. 3, pp. 238-245, 1989.

[188] I. T. Mak and W. B. Weglicki, "Comparative antioxidant activities of propranolol, nifedipine, verapamil, and diltiazem against sarcolemmal membrane lipid peroxidation," Circulation Research, vol. 66, no. 5, pp. 1449-1452, 1990.

[189] I. T. Mak, P. Boehme, and W. B. Weglicki, "Protective effects of calcium channel blockers against free radical-impaired endothelial cell proliferation," Biochemical Pharmacology, vol. 50, no. 9, pp. 1531-1534, 1995.

[190] S. Ray, S. Mondal, and N. Dana, "Evaluation of protective role of nifedipine on lipid peroxidation using reduced glutathione as model marker," Oxidants and Antioxidants in Medical Science, vol. 1, no. 2, pp. 97-100, 2012.

[191] M. Yamato, T. Shiba, T. Ide, Y. Honda, K.-I. Yamada, and H. Tsutsui, "Nifedipine treatment reduces brain damage after transient focal ischemia, possibly through its antioxidative effects," Hypertension Research, vol. 34, no. 7, pp. 840-845, 2011.

[192] V. Chander and K. Chopra, "Nifedipine attenuates changes in nitric oxide levels, renal oxidative stress, and nephrotoxicity induced by cyclosporine," Renal Failure, vol. 27, no. 4, pp. 441450, 2005.

[193] K. M. Gaafa, M. M. Badawy, and A. A. Hamza, “The protective effects of ascorbic acid, cimetidine, and nifedipine on diethyldithiocarbamate-induced hepatic toxicity in albino rats," Drug and Chemical Toxicology, vol. 34, no. 4, pp. 405-419, 2011.

[194] H. Sugawara, K. Tobise, and S. Onodera, "Absence of antioxidant effects of nifedipine and diltiazem on myocardial membrane lipid peroxidation in contrast with those of nisoldipine and propranolol," Biochemical Pharmacology, vol. 47, no. 5, pp. 887-892, 1994.

[195] I. E. Kirule, D. Y. Rubene, E. A. Bisenieks, G. D. Tirzit, and G. Y. Dubur, "4-Nitrophenyl-1,4-dihydropyridines-a new group of inhibitors of peroxide oxidation," Chemistry of Heterocyclic Compounds, vol. 18, no. 3, p. 316, 1982.

[196] G. D. Tirzit, I. E. Kirule, L. K. Baumane, R. A. Gavar, Y. P. Stradyn', and G. Y. Dubur, "Mechanism of the antioxidant action of 2,6-dimethyl-3,5-dimethoxy-carbonyl-4-(2-nitrophenyl)1,4dihydropyridine," Chemistry of Heterocyclic Compounds, vol. 20, no. 8, pp. 915-918, 1984.

[197] C. Yáñez, C. López-Alarcón, C. Camargo, V. Valenzuela, J. A. Squella, and L. J. Núñez-Vergara, "Structural effects on the reactivity 1,4-dihydropyridines with alkylperoxyl radicals and ABTS radical cation," Bioorganic and Medicinal Chemistry, vol. 12, no. 9, pp. 2459-2468, 2004.

[198] V. Misik, A. J. Stasko, D. Gergel, and K. Ondrias, "Spin-trapping and antioxidant properties of illuminated and nonilluminated nifedipine and nimodipine in heart homogenate and model system," Molecular Pharmacology, vol. 40, no. 3, pp. 435-439, 1991.

[199] K. Ondriaš, V. Mišík, A. Staško, D. Gergel', and M. Hromadová, "Comparison of antioxidant properties of nifedipine and illuminated nifedipine with nitroso spin traps in low density lipoproteins and phosphatidylcholine liposomes," Biochimica et Biophysica Acta-Lipids and Lipid Metabolism, vol. 1211, no. 1, pp. 114-119, 1994.

[200] A. Staško, V. Brezová, S. Biskupič, K. Ondriaš, and V. Mišík, "Reactive radical intermediates formed from illuminated nifedipine," Free Radical Biology and Medicine, vol. 17, no. 6, pp. 545556, 1994.

[201] K. Ishizawa, Y. Izawa-Ishizawa, N. Yamano et al., "Nitrosonifedipine ameliorates the progression of type 2 diabetic nephropathy by exerting antioxidative effects," PLOS ONE, vol. 9, no. 1, Article ID e86335, 2014.

[202] H. Fujii and L. J. Berliner, "In vivo EPR evidence for free radical adducts of nifedipine," Magnetic Resonance in Medicine, vol. 42, no. 4, pp. 691-694, 1999.

[203] S. Bollo, S. Finger, J. C. Sturm, L. J. Núñez-Vergara, and J. A. Squella, "Cyclic voltammetry and scanning electrochemical microscopy studies of the heterogeneous electron transfer reaction of some nitrosoaromatic compounds," Electrochimica Acta, vol. 52, no. 15, pp. 4892-4898, 2007. 
[204] F. Ursini, “Tissue protection by lacidipine: insight from redox behavior," Journal of Cardiovascular Pharmacology, vol. 30, supplement 2, pp. S28-S30, 1997.

[205] P. G. Cristofori, F. A. Crivellente, I. Faustinelli et al., "Involvement of the nitric oxide system in the anti-atherosclerotic potential of lacidipine in the apoE-deficient mouse: a morphological, functional, and electrochemical study," Toxicologic Pathology, vol. 32, no. 4, pp. 493-499, 2004.

[206] X.-P. Zhang, E. L. Kit, S. Mital, S. Chahwala, and T. H. Hintze, "Paradoxical release of nitric oxide by an L-type calcium channel antagonist, the R+ enantiomer of amlodipine," Journal of Cardiovascular Pharmacology, vol. 39, no. 2, pp. 208-214, 2002.

[207] F. Franzoni, G. Santoro, F. Regoli et al., "An in vitro study of the peroxyl and hydroxyl radical scavenging capacity of the calcium antagonist amlodipine," Biomedicine and Pharmacotherapy, vol. 58, no. 8, pp. 423-426, 2004.

[208] S. V. Gatsura, "Oxygen-dependent mechanisms underlying the antiischemic effect of verapamil and amlodipine," Bulletin of Experimental Biology and Medicine, vol. 137, no. 1, pp. 40-42, 2004.

[209] Y. Hirooka, Y. Kimura, M. Nozoe, Y. Sagara, K. Ito, and K. Sunagawa, "Amlodipine-induced reduction of oxidative stress in the brain is associated with sympatho-inhibitory effects in stroke-prone spontaneously hypertensive rats," Hypertension Research, vol. 29, no. 1, pp. 49-56, 2006.

[210] B. Tomlinson and I. F. F. Benzie, "Antioxidant effect of lercanidipine (note)," Hypertension, vol. 42, no. 4, pp. e10-ell, 2003.

[211] A. A. Faraqui, "Neurochemical aspects of 4-hydroxynonenal," in Lipid Mediators and Their Metabolism in the Brain, A. A. Faraqui, Ed., chapter 6, pp. 159-191, Springer, New York, NY, USA, 2011.

[212] V. S. Nascimento, M. S. D’Alva, A. A. Oliveira et al., "Antioxidant effect of nimodipine in young rats after pilocarpine-induced seizures," Pharmacology Biochemistry and Behavior, vol. 82, no. 1, pp. 11-16, 2005.

[213] O. Ismailoglu, P. Atilla, S. Palaoglu et al., "The therapeutic effects of melatonin and nimodipine in rats after cerebral cortical injury," Turkish Neurosurgery, vol. 22, no. 6, pp. 740-746, 2012.

[214] M. Matsubara and K. Hasegawa, "Benidipine, a dihydropyridine-calcium channel blocker, prevents lysophosphatidylcholine-induced injury and reactive oxygen species production in human aortic endothelial cells," Atherosclerosis, vol. 178, no. 1, pp. 57-66, 2005.

[215] M. Matsubara, K. Yao, and K. Hasegawa, "Benidipine, a dihydropyridine-calcium channel blocker, inhibits lysophosphatidylcholine-induced endothelial injury via stimulation of nitric oxide release," Pharmacological Research, vol. 53, no. 1, pp. 35-43, 2006.

[216] M. Matsubara and K. Hasegawa, "Effects of benidipine, a dihydropyridine- $\mathrm{Ca}^{2+}$ channel blocker, on expression of cytokineinduced adhesion molecules and chemoattractants in human aortic endothelial cells," European Journal of Pharmacology, vol. 498, no. 1-3, pp. 303-314, 2004.

[217] M. Matsubara, O. Akizuki, J.-I. Ikeda, K. Saeki, K. Yao, and K. Sasaki, "Benidipine, an anti-hypertensive drug, inhibits reactive oxygen species production in polymorphonuclear leukocytes and oxidative stress in salt-loaded stroke-prone spontaneously hypertensive rats," European Journal of Pharmacology, vol. 580, no. 1-2, pp. 201-213, 2008.

[218] A. C. Rosenkranz, H. Lob, T. Breitenbach, R. Berkels, and R. Roesen, "Endothelial antioxidant actions of dihydropyridines and angiotensin converting enzyme inhibitors," European Journal of Pharmacology, vol. 529, no. 1-3, pp. 55-62, 2006.

[219] V. Kain, S. Kumar, and S. L. Sitasawad, "Azelnidipine prevents cardiac dysfunction in streptozotocin-diabetic rats by reducing intracellular calcium accumulation, oxidative stress and apoptosis," Cardiovascular Diabetology, vol. 10, article 97, 2011.

[220] K. Nakamura, S. Yamagishi, and H. Inoue, "Unique atheroprotective property of azelnidipine, a dihydropyridine-based calcium antagonist," Medical Hypotheses, vol. 65, no. 1, pp. 155-157, 2005.

[221] T. Matsui, S. Yamagishi, K. Nakamura, S. Kikuchi, and H. Inoue, "Azelnidipine, a dihydropyridine-based calcium antagonist, inhibits angiotensin II-induced oxidative stress generation and downregulation of pigment epithelium-derived factor mRNA levels in microvascular endothelial cells," Drugs under Experimental and Clinical Research, vol. 31, no. 5-6, pp. 215-219, 2005.

[222] C. Ohmura, H. Watada, T. Shimizu et al., "Calcium channel blocker, azelnidipine, reduces lipid hydroperoxides in patients with type 2 diabetes independent of blood pressure," Endocrine Journal, vol. 54, no. 5, pp. 805-811, 2007.

[223] H. Daikuhara, F. Kikuchi, and T. Ishida, "The combination of OLmesartan and a CAlcium channel blocker (azelnidipine) or candesartan and a calcium channel blocker (amlodipine) in type 2 diabetic hypertensive patients: the OLCA study," Diabetes and Vascular Disease Research, vol. 9, no. 4, pp. 280-286, 2012.

[224] M. Abe, N. Maruyama, K. Okada, S. Matsumoto, K. Matsumoto, and M. Soma, "Additive antioxidative effects of azelnidipine on angiotensin receptor blocker olmesartan treatment for type 2 diabetic patients with albuminuria," Hypertension Research, vol. 34, no. 8, pp. 935-941, 2011.

[225] K. Mizushige, "Antioxidative activities of thiazolidinediones and dihydropyridine-type calcium antagonists," IRYO-Japanese Journal of National Medical Services, vol. 59, no. 11, pp. 581592, 2005.

[226] S. Manabe, T. Okura, T. Fukuoka, and J. Higaki, "Antioxidative effects of azelnidipine on mesangial cell proliferation induced by highly concentrated insulin," European Journal of Pharmacology, vol. 567, no. 3, pp. 252-257, 2007.

[227] Y. Koyama, Y. Takeishi, H. Takahashi et al., "Azelnidipine inhibits $\mathrm{H}_{2} \mathrm{O}_{2}$-induced cell death in neonatal rat cardiomyocytes," Cardiovascular Drugs and Therapy, vol. 21, no. 1, pp. 69-72, 2007.

[228] K. Shinomiya, K. Mizushige, M. Fukunaga et al., "Antioxidant effect of a new calcium antagonist, azelnipidine, in cultured human arterial endothelial cells," Journal of International Medical Research, vol. 32, no. 2, pp. 170-175, 2004.

[229] T. Ohyama, K. Sato, K. Kishimoto et al., "Azelnidipine is a calcium blocker that attenuates liver fibrosis and may increase antioxidant defence," British Journal of Pharmacology, vol. 165, no. 4, pp. 1173-1187, 2012.

[230] L. A. Calò, F. Zaghetto, E. Pagnin, P. A. Davis, A. Semplicini, and A. C. Pessina, "Effect of manidipine on gene expression and protein level of oxidative stress-related proteins: p22phox and HO-1. Relevance for antihypertensive and anti-remodeling effects," Journal of Cardiovascular Pharmacology, vol. 43, no. 4, pp. 531-538, 2004.

[231] R. Ghyasi, G. Sepehri, M. Mohammadi, R. Badalzadeh, and A. Ghyasi, "Effect of mebudipine on oxidative stress and lipid peroxidation in myocardial ischemic-reperfusion injury in male rat," Journal of Research in Medical Sciences, vol. 17, no. 12, pp. 1150-1155, 2012. 
[232] D. C. Andersson, J. Fauconnier, T. Yamada et al., "Mitochondrial production of reactive oxygen species contributes to the $\beta$ adrenergic stimulation of mouse cardiomycytes," The Journal of Physiology, vol. 589, no. 7, pp. 1791-1801, 2011.

[233] A. F. Ceylan-Isik, N. Ari, M. Stefek et al., "Effects of a longterm treatment with an antioxidant pyridoindole on vascular responsiveness in diabetes-induced aging rats," Current Aging Science, vol. 4, no. 2, pp. 150-157, 2011.

[234] S. Saponara, G. Sgaragli, and F. Fusi, "Quercetin antagonism of Bay K 8644 effects on rat tail artery L-type $\mathrm{Ca}^{2+}$ channels," European Journal of Pharmacology, vol. 598, no. 1-3, pp. 75-80, 2008.

[235] D. A. Sica, "Interaction of grapefruit juice and calcium channel blockers," American Journal of Hypertension, vol. 19, no. 7, pp. 768-773, 2006.

[236] P. Mulder, G. Litwinienko, S. Lin, P. D. MacLean, L. R. C. Barclay, and K. U. Ingold, "The L-type calcium channel blockers, Hantzsch 1,4-dihydropyridines, are not peroxyl radicaltrapping, chain-breaking antioxidants," Chemical Research in Toxicology, vol. 19, no. 1, pp. 79-85, 2006.

[237] L. J. Núñez-Vergara, R. Salazar, C. Camargo et al., "Oxidation of C4-hydroxyphenyl 1,4-dihydropyridines in dimethylsulfoxide and its reactivity towards alkylperoxyl radicals in aqueous medium," Bioorganic and Medicinal Chemistry, vol. 15, no. 12, pp. 4318-4326, 2007.

[238] M. E. Ortiz, L. J. Núñez-Vergara, and J. A. Squella, "Relative reactivity of dihydropyridine derivatives to electrogenerated superoxide ion in DMSO solutions: a voltammetric approach," Pharmaceutical Research, vol. 20, no. 2, pp. 292-296, 2003.

[239] M. E. Ortiz, L. J. Núñez-Vergara, C. Camargo, and J. A. Squella, "Oxidation of Hantzsch 1,4-dihydropyridines of pharmacological significance by electrogenerated superoxide," Pharmaceutical Research, vol. 21, no. 3, pp. 428-435, 2004.

[240] R. S. Raghuvanshi and K. N. Singh, "Superoxide induced oxidative aromatization of Hantzsch 1,4-dihydropyridines," Indian Journal of Chemistry, Section B: Organic and Medicinal Chemistry, vol. 47, no. 11, pp. 1735-1738, 2008.

[241] I. Kruk, A. Kladna, K. Lichszteld et al., "Antioxidant activity of 4-flavonil-1,4-dihydropyridine derivatives," Biopolymers, vol. 62 , no. 3, pp. 163-167, 2001.

[242] G. D. Tirzit, I. M. Byteva, K. I. Salokhiddinov, G. P. Gurinovich, and G. Y. Dubur, "1,4-Dihydropyridine derivatives as deactivators of singlet oxygen," Chemistry of Heterocyclic Compounds, vol. 17, no. 7, pp. 682-684, 1981.

[243] G. D. Tirzit, E. Y. Kazush, and G. Y. Dubur, "Influence of 1,4-dihydropyridine derivatives on the generation of hydroxyl radicals," Chemistry of Heterocyclic Compounds, vol. 28, no. 4, pp. 435-437, 1992.

[244] N. A. Pizarro-Urzúa and L. J. Núñez-Vergara, "Nifedipine and nitrendipine reactivity toward singlet oxygen," Journal of Photochemistry and Photobiology A: Chemistry, vol. 175, no. 2-3, pp. 129-137, 2005.

[245] L.-F. Wang, H.-Y. Zhang, L. Konga, Z.-W. Chena, and J.-G. Shi, "DFT calculations indicate that 1,4-dihydropyridine is a promising lead antioxidant," Helvetica Chimica Acta, vol. 87, no. 6, pp. 1515-1521, 2004.

[246] P. Mulder, H.-G. Korth, and K. U. Ingold, "Why quantumthermochemical calculations must be used with caution to indicate 'a promising lead antioxidant"' Helvetica Chimica Acta, vol. 88, no. 2, pp. 370-374, 2005.

[247] K. Yao, Y. Ina, K. Nagashima, K. Ohmori, and T. Ohno, "Antioxidant effects of calcium antagonists in rat brain homogenates,"
Biological and Pharmaceutical Bulletin, vol. 23, no. 6, pp. 766$769,2000$.

[248] T. Matsui, S.-I. Yamagishi, K. Nakamura, and H. Inoue, "Bay w 9798, a dihydropyridine structurally related to nifedipine with no calcium channel-blocking properties, inhibits tumour necrosis factor- $\alpha$-induced vascular cell adhesion molecule- 1 expression in endothelial cells by suppressing reactive oxygen species generation," Journal of International Medical Research, vol. 35 , no. 6, pp. 886-891, 2007.

[249] K. A. Mitrega, B. Varghese, M. Porc, and T. F. Krzemiński, "Antiarrhythmic and hemodynamic effects of oxy nifedipine, oxy nimodipine, oxy nitrendipine and oxy nisoldipine," Pharmacological Research, vol. 66, no. 4, pp. 300-308, 2012.

[250] V. Herbert, "Symposium: prooxidant effects of antioxidant vitamins. Introduction," The Journal of Nutrition, vol. 126, no. 4, supplement, pp. 1197S-1200S, 1996, http://jn.nutrition.org/ content/126/4_Suppl/1197S.full.pdf.

[251] B. Halliwell, "Are polyphenols antioxidants or pro-oxidants? What do we learn from cell culture and in vivo studies?" Archives of Biochemistry and Biophysics, vol. 476, no. 2, pp. 107$112,2008$.

[252] C. Winterbourn, Pro-Oxidants or Antioxidants, Christchurch School of Medicine, Depatment of Pathology, Free Radical School, SFRBM, University of Otago, San Francisco, Calif, USA, 2009, http://www.sfrbm.org/frs/Winterbourn.pdf.

[253] A. Morakinyo, B. Iranloye, and O. Adegoke, "Calcium antagonists modulate oxidative stress and acrosomal reaction in rat spermatozoa," Archives of Medical Science, vol. 7, no. 4, pp. 613618, 2011.

[254] The Alpha-Tocopherol Beta Carotene Cancer Prevention Study Group, "The effect of vitamin E and beta carotene on the incidence of lung cancer and other cancers in male smokers," The New England Journal of Medicine, vol. 330, no. 15, pp. 10291035, 1994.

[255] B. Poljsak, "Strategies for reducing or preventing the generation of oxidative stress," Oxidative Medicine and Cellular Longevity, vol. 2011, Article ID 194586, 15 pages, 2011.

[256] B. Poljsak and I. Milisav, "The neglected significance of 'antioxidative stress,' Oxidative Medicine and Cellular Longevity, vol. 2012, Article ID 480895, 12 pages, 2012.

[257] T. Godfraind and S. Salomone, "Ambiguities in dietary antioxidant supplementation compared to calcium channel blockers therapy," Frontiers in Pharmacology, vol. 6, article 10, 2015.

[258] H. Wagner, H. Norr, and H. Winterhoff, "Drugs with adaptogenic effects for strengthening the powers of resistance," Zeitschrift fur Phytotherapie, vol. 13, no. 2, pp. 42-54, 1992. 


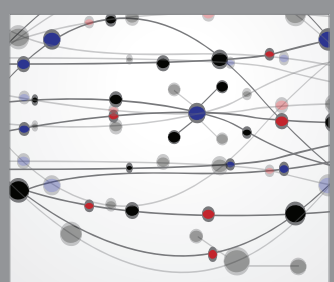

The Scientific World Journal
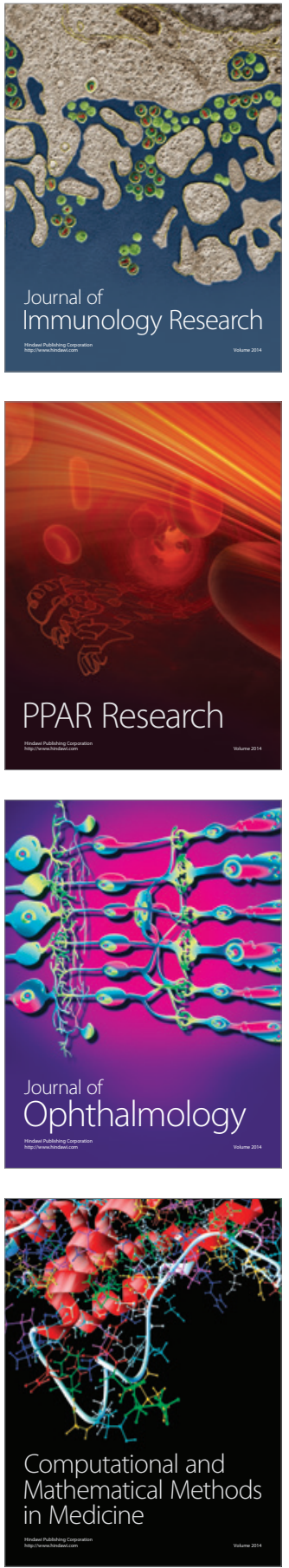

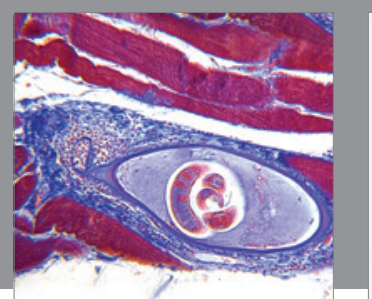

Gastroenterology Research and Practice

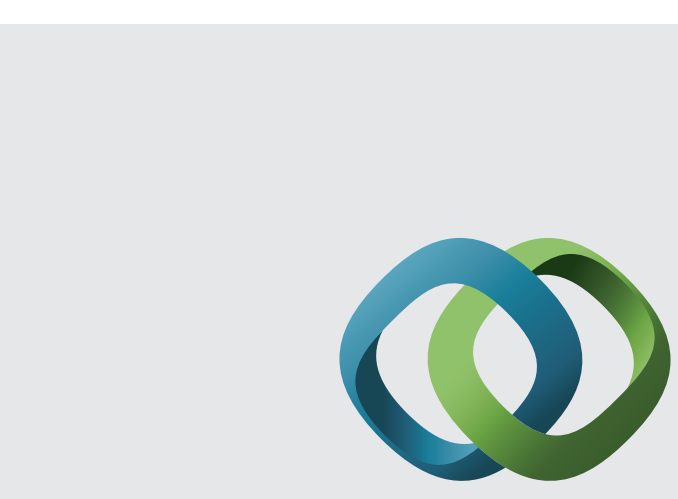

\section{Hindawi}

Submit your manuscripts at

http://www.hindawi.com
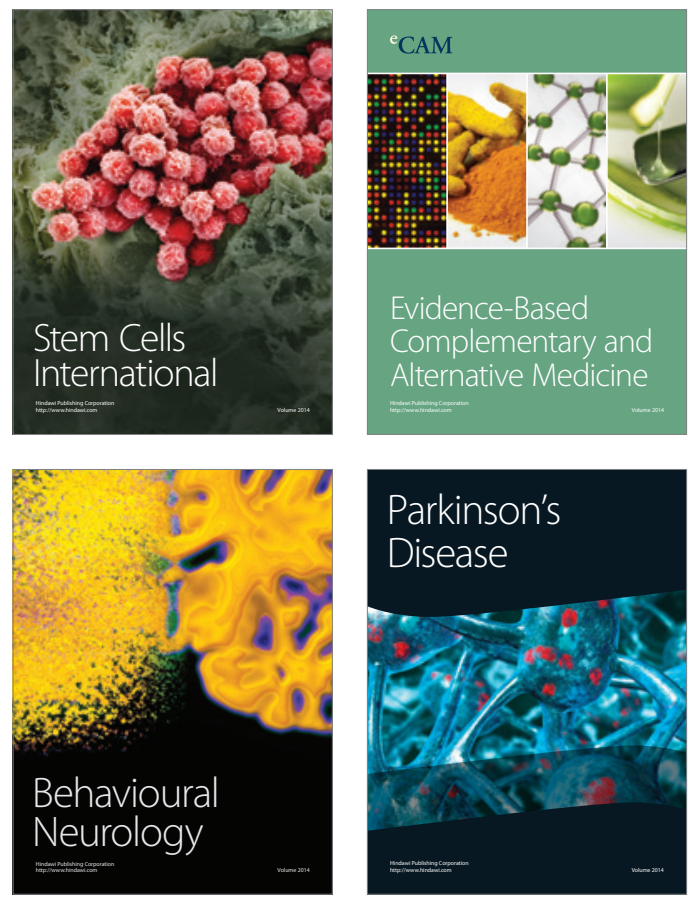
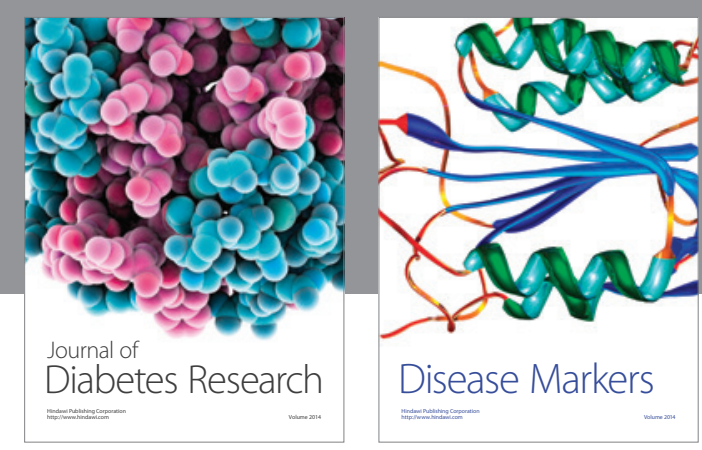

Disease Markers
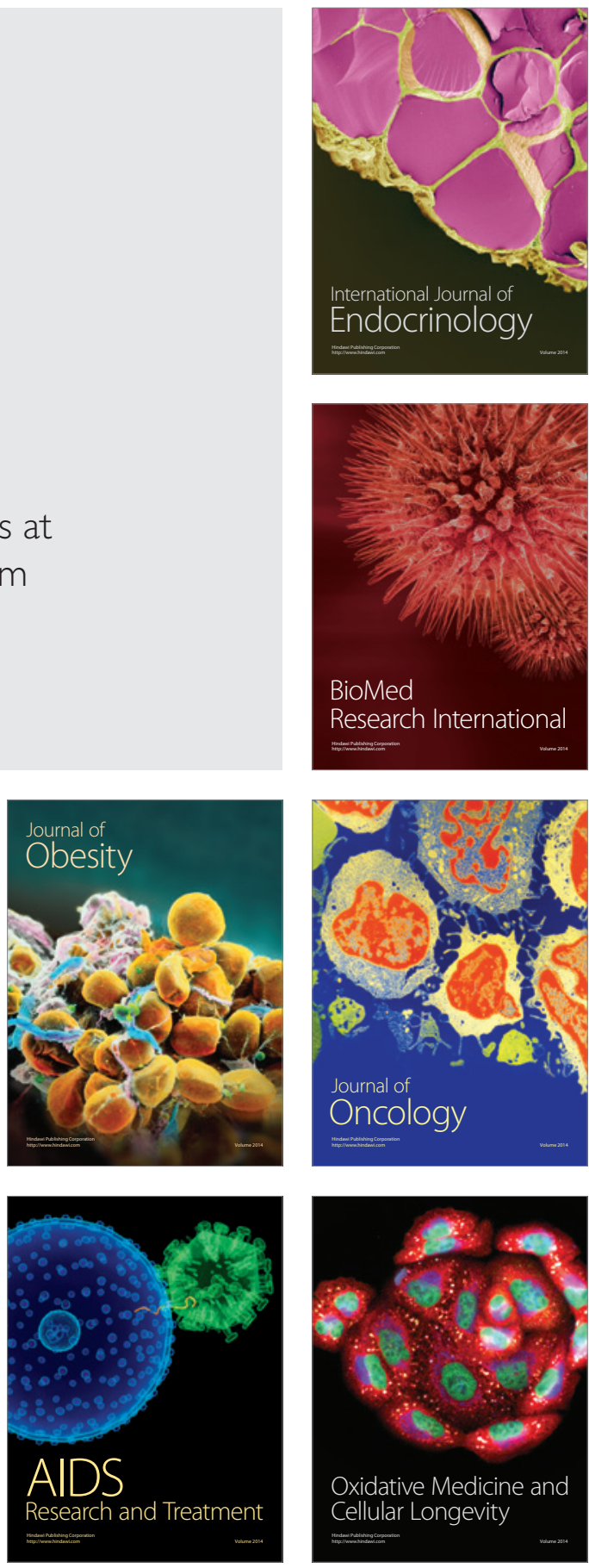